\title{
Neandertal-Modern Human Contact \\ in Western Eurasia: Issues of Dating, \\ Taxonomy, and Cultural Associations
}

\author{
João Zilhão
}

\begin{abstract}
Supporting Assimilation views of Neandertal/modern human interaction, chronostratigraphic reasoning indicates that the "transitional" industries of Europe predate modern human immigration, in agreement with their association with Neandertals in the Châtelperronian at the Grotte du Renne and St.-Césaire. Supporting the Neandertals' species separateness and less developed cognition, those industries are alternatively claimed to relate to pioneer groups of modern humans; the latter would have been the true makers of the precocious instances of symbolic material culture that, under Assimilation, are assigned to the Neandertals. However, the taxonomy of the Kent's Cavern and Grotta del Cavallo dental remains is uncertain, and their poor stratigraphic context precludes dating by association. The opposite happens at the Grotte du Renne, whose stratigraphic integrity is corroborated by both taphonomy and dating. Not questioning that the Early Ahmarian is a cultural proxy for modern humans and a source for the Protoaurignacian of Europe, its claimed emergence 46-49 ka ago at Kebara reflects the dating of Middle Paleolithic charcoal- to be expected, because the Early Ahmarian units at the back of the cave are made up of reworked Middle Paleolithic sediments derived from the entrance. The dating of inherited material also explains the old results for the Aurignacian of Willendorf II and Geissenklösterle. At the latter, the dates on anthropically modified samples of the hunted taxa (reindeer and horse) place its Aurignacian occupations in the same time range as elsewhere in Europe, after $\sim 40 \mathrm{ka}$ ago. The hypothesis that Neandertal/modern human contact in Europe resulted in a process of assimilation in connection with the spread of the Protoaurignacian $\sim 41.5 \mathrm{ka}$ ago remains unfalsified.
\end{abstract}

\section{Keywords}

Aurignacian • Bayesian modeling $\bullet$ Châtelperronian $\bullet$ Chronostratigraphy $\bullet$ Radiocarbon

J. Zilhão $(\bowtie)$

Departament de Prehistòria, Història Antiga i Arqueologia, University of Barcelona/ICREA, C/Montalegre 6, 08001 Barcelona, Spain

e-mail: joao.zilhao@ub.edu

\subsection{Introduction}

During the last two decades of the twentieth century, the debate concerning the emergence of European modern humans and the fate of the Neandertals revolved around the polar alternatives of "Multiregionalism" and "Recent African Origin." In their original formulations, where Multiregionalism saw modern humans as principally locally evolving from ancestral populations of "archaics," Recent 
African Origin defined them as a new species originating at least 150,000 years ago in Africa, from where the rest of the world was eventually colonized, with Eurasia's aboriginal humans, especially the Neandertals, becoming extinct without descent in the process.

A minority position, "Assimilation," accepted recent Outof-Africa migration and/or genetic diffusion but viewed Neandertals as a geographical variant of Homo sapiens, not as a different biological species. In this view, the disappearance of Eurasian archaics from the paleontological record after about 40,000 years ago would have been caused by loss of isolation and ensuing integration with the wider human gene pool, that is, by demographic and/or natural selection processes operating in a context of significant population admixture. Human Paleontology (Trinkaus 2007), Genetics (Hawks 2012) and Archeology (Zilhão 2006a, 2011, 2012) now concur in indicating that such Assimilation models best match the empirical data concerning the replacement of Neandertals by modern humans accumulated over the last 15 years of research developments, briefly summarized below.

Direct dating of the fossils that were once thought to represent Europe's earliest modern humans and, by their lack of archaic features, supported replacement-with-no-admixture of the Neandertals, showed they were all of a significantly younger age (recent Holocene for some), as the Vogelherd case (Conard et al. 2004) best illustrates. Conversely, all of the newly discovered or restudied fossils dated to the time of the Neandertal-to-modern human transition in Europe or shortly thereafter were shown to present archaic if not Neandertal-diagnostic features (e.g., the Lagar Velho and Oase fossils; Duarte et al. 1999; Trinkaus 2007; Trinkaus et al. 2013). These morphological mosaics indicated admixture at the time of contact, and the Neandertal genome project (Green et al. 2010) eventually produced corroborating evidence-namely, that 1-4\% of the genome of extant Eurasians is of Neandertal origin.

At the same time, archeological research provided evidence that, in the behavioral realm, late Neandertals had been as "modern" as their African contemporaries. While Recent African Origin views interpreted many innovations of the European Upper Paleolithic as a "Human Revolution" (Mellars and Stringer 1989) triggered by the immigration of modern humans, the new evidence credited many of those innovations to the Neandertals and showed that some had first appeared in the preceding Middle Paleolithic. Among the latter is the use in body ornamentation of painted/perforated marine shells, large raptor feathers, and mineral pigments modified as crayons or processed for the preparation of complex cosmetic recipes (Soressi and d'Errico 2007; Zilhão et al. 2010a; Peresani et al. 2011; Morin and Laroulandie 2012; Finlayson et al. 2012). It is also quite possible that Neandertals were the makers of the earliest known cave art, as suggested by the minimum age of $41.4 \pm 0.6 \mathrm{ka}(95.4 \%$ probability interval) provided by
U-series dating of calcite accretions covering geometric signs and hand stencils at the Spanish site of El Castillo (Cantabria; Pike et al. 2012).

The paleontological and genetics evidence vindicates Holliday's (2006) prediction that no biological barriers to productive interbreeding could have existed between Neandertals and their African contemporaries; as he pointed out, if human history is seen under the perspective of general mammalian evolutionary patterns, the amount of time elapsed since separation of the two lineages from their common ancestor becomes simply insufficient, and this by a factor of about ten, for intersterility to have arisen. The overall similarity in human culture between Eurasia and Africa implied by the symbolism-related features apparent in the archeological record of both continents after 100,000 years ago also carries admixture-related implications; namely, that the existence of cognitive or cultural barriers to interbreeding can be removed from the range of mechanisms putatively preventing its occurrence.

The corollary of these developments is that the Assimilation view of modern human/Neandertal interaction ought to be considered the null hypothesis of modern human origins in Eurasia (and, therefore, that the burden of proof lies on those who think otherwise). A strand of scientific opinion maintains, however, that the evidence for Assimilation is equivocal. Namely, there are two major and closely inter-related tenets of this view that critics have directly or indirectly challenged: the association of Neandertals with the Châtelperronian and coeval, "transitional" cultures of the Early Upper Paleolithic; and the view that the Protoaurignacian represents the earliest archeological manifestation that conceivably can be related to modern humans in Europe.

Although based on different aspects of the empirical record and following different lines of reasoning, such challenges to Assimilation share the contention that problems with dating have so far obscured the fact that the instances of precocious symbolism seen in the archeological record of Europe, those that apparently pre-date modern human immigration, are in deed modern human-, not Neandertal-related. In some instances, the case is made that the direct dates on Neandertal fossils placing them in the time range of the first appearance of symbolic artifacts in the European record are too young (or that the association of the fossils with stratigraphic contexts of such age is spurious). In other instances, the case is made for modern humans, as represented by their fossils or putative archeological proxies, to have arrived in western Eurasia significantly earlier than hitherto thought, which would imply that Europe's oldest symbolic material culture is theirs, not the Neandertals'.

In the following, I will examine and discuss such claims. I have no intention of being exhaustive, and will therefore focus on those cases that have attracted more attention or whose implications are of more far-reaching consequence. The discussion will proceed on a case by case basis, examining 
the arguments and assessing their strength in terms of the empirical observations that support them. I will then wrap up with a conclusion that sets the debate on western Eurasia's Middle-to-Upper and Neandertal-to-modern human transitions in the broader perspective of patterns of cultural change during the last 150,000 years.

Throughout, the following conventions will be followed: solar calendar dates as well as those derived from TL (Thermoluminescence), OSL (Optically Stimulated Luminescence) and U-series techniques will be expressed in years or thousands of years (ka) ago; dates derived from Radiocarbon will be expressed in years or thousands of years (ka) " ${ }^{14} \mathrm{C}$ BP," and, when calibrated, denoted as "cal BP," in which case they will be given either as approximate ages (e.g., $40 \mathrm{ka} \mathrm{cal} \mathrm{BP}$ ) or as $95.4 \%$ probability intervals. When dates are compared to assess whether they are statistically distinct or the same, the tool used is the sample significance test (Case 1) of Ward and Wilson (1978), carried out with Calib 6.1. (Stuiver and Reimer 1993).

\subsection{Axiomatic Principles and Chronological Framework}

My null chronological hypothesis is a model of the Middleto-Upper and Neandertal-to-modern human transitions in western Eurasia first proposed by d'Errico et al. (1998) and Zilhão and d'Errico (1999), and further elaborated in Zilhão and d'Errico (2003), Zilhão (2006a, 2007, 2011) and Banks et al. (2013). This model can be summarized as follows:

(a) The Châtelperronian, Uluzzian, Altmühlian, Bohunician, Szeletian and Bachokirian underlie the earliest Aurignacian across the whole of their shared geographic range, and, therefore, they must predate the Aurignacian in each of their particular areas of occurrence.

(b) The recognized subdivisions of the Aurignacian have chronological value and are not functional or cultural variants that could have been in coexistence at given points of the technocomplex's time range or even throughout its entire duration.

(c) A Protoaurignacian phase preceded the classic Aurignacian I with split-based points.

(d) This framework is replicated by dating provided that one rejects radiometric results that fail to pass a number of specified quality criteria.

(e) When only reliable radiocarbon results are considered, the boundary between the Protoaurignacian and the preceding "transitional" industries falls in the millennium centered around $36.5 \mathrm{ka}{ }^{14} \mathrm{C}$ BP (i.e., $~ 41.5 \mathrm{ka}$ cal BP), with Bayesian modeling constraining the Protoaurignacian time range to the $39.9-41.5 \mathrm{ka}$ cal BP interval.

(f) In Europe, all directly dated, or reliably associated diagnostic fossil remains of modern humans, are, at the earliest, of Protoaurignacian age, implying Neandertal authorship of the archeological record formed with anteriority, as otherwise corroborated by the Neandertaldiagnostic remains found in stratigraphic association with the Châtelperronian or directly dated to the corresponding chronostratigraphic slot.

This model is based on two key axioms. The first axiom is that the technocomplexes of the Upper Paleolithic are valid culture-stratigraphic units. The low resolution of stratigraphic sequences and the standard deviations of individual dating results (compounded, where the radiocarbon method is concerned, with the uncertainty added by calibration) mean that the smallest units of time we can work with in the interval of concern here (between 30,000 and 50,000 years ago) are in the range of five centuries to a millennium, at the very best. However, in the absence of major barriers to diffusion, advantageous innovations spread among huntergatherers much faster than that because of the open, exogamic nature of their social networks. Therefore, even though, obviously, a given innovation will have arisen first in a given place, it is almost inevitable that, in this period, its emergence and spread will become observationally conflated in a single process, one that will appear to us as an "event" taking place in "simultaneous" fashion over extensive areas. As, due to such inherent properties of the data it works with, Paleolithic Archeology is not about the short-term processes that occur in human lifetime scales (the study of which requires written or oral history records) but about the "steady state" of cultural/adaptive systems and their long-term change through time, this apparent "limitation" is, in fact, an "advantage" (Binford 1983).

When the comparison between two geographically connected regional sequences shows that the change from a given, shared steady state led to a new, different steady state that is also common to them, it is therefore axiomatic to Paleolithic Archeology that such a change must have occurred "simultaneously" in both regions. Such culturestratigraphic reasoning has provided the backbone of Paleolithic chronologies for more than a century. The advent of radiometric dating made it possible to refine such chronologies to a certain extent, especially where the Upper Paleolithic is concerned. It also generated a number of apparent contradictions with traditional schemes, but such contradictions resulted from ambiguity in definitions and/or errors in the dating process (cf. Zilhão and d'Errico 1999); as the last 15 years of research have demonstrated, the chronological predictions derived from culture-stratigraphic arguments were indeed the correct ones, with advancements in dating technique and methodology (cf. Higham 2011) eventually producing results that agreed with culture-stratigraphic expectations.

The second axiom is that, regardless of which taxonomic status best describes their separateness (e.g., species or subspecies), 
Neandertals and modern humans are populations whose differentiation from a common ancestor was caused by geographic isolation. The possibility of long-term sympatry between the two phyla was envisaged by some in the past (e.g., Vallois 1949), but it has since become clear that no Neandertal fossils exist in the late Middle and early Upper Pleistocene record of northern Africa and, conversely, that no modern human fossils exist in the coeval European record. Even though, for particular space/time slots, the lack of fossil finds means that no direct association with the corresponding cultural record exists, an allopatric understanding of Neandertals and modern humans carries a straightforward implication - that, prior to the time when the replacement of the former by the latter is documented in the paleontological record of Europe, the continent was inhabited by Neandertals only, with the attendant corollary for issues of authorship.

\subsection{Late Neandertals: How Late, and What Associations?}

In Iberian regions situated to the south of the Ebro River drainage, Neandertals and the Mousterian arguably persisted for several millennia beyond their documented time range elsewhere in Europe (Zilhão et al. 2010a, b; Hoffmann et al. 2013). It is also possible that a similar but shorter persistence pattern, albeit in an Upper Paleolithic context (the Lincombian/ Ranisian/Jerzmanowician), not a Middle Paleolithic one, underpins the direct dating to the $\sim 41.0-41.5 \mathrm{ka}$ cal BP interval of the two adult individuals from Spy (Semal et al. 2009; Flas 2011). In both cases, such late Neandertal occurrences concern areas located outside the geographic range of the Protoaurignacian, while the directly dated Oase fossils, although lacking an immediate archeological context, come from a region where a coeval Protoaurignacian is well documented (Hahn 1977; Zilhão 2006a; Teyssandier 2008).

Still, as no human remains have so far been found in direct association with the Protoaurignacian, it would be legitimate to infer from the Spy dates that no one-to-one correspondence exists between this culture and human paleontological taxa-i.e., that Neandertals and modern humans could both have been involved in the making of the Protoaurignacian. Two other conceivable implications of that evidence would, however, be clearly fallacious:

(a) The first would be that, if Neandertals made the Châtelperronian, we can then infer from their persistence in regions both to the south and to the north that the French Châtelperronian could have been as late as the Lincombian of Belgium or the Late Mousterian of Iberia. However, the Châtelperronian stratigraphically precedes the Protoaurignacian, and the geographic range of the Châtelperronian is totally encompassed within that of the Protoaurignacian. Therefore, envisaging a persistence of the Chatelperronian alongside the Protoaurignacian, with both falling in the same time interval but occupying different regions, amounts to positing an archeological impossibility, a point whose full significance will become apparent below.

(b) The second would be that the late dates for the last of the Belgian and Iberian Neandertals could simply be a byproduct of incomplete sample decontamination, leading to results that are too young (Pinhasi et al. 2011; Wood et al. 2013); therefore, such could well be also the case with the dates for Neandertal remains that place them, either directly or by stratigraphic association, in the time range of the Châtelperronian and coeval technocomplexes. However, the dates supporting the Neandertal/Châtelperronian link are, firstly, much older than those supporting late Neandertal persistence in Belgium and Iberia, and, secondly, fall in a period when Europe is entirely lacking in diagnostic modern human fossils; consequently, it is clear that no logical connection exists between the two propositions. If the last of the Neandertals are going to be made significantly older than indicated by the current dating record, it can only be on the basis of a robust case built on the chemistry of the dated samples and/or on issues of inconsistency with the stratigraphic context.

The above explains why, for the purposes of this paper, it is sufficient to restrict the discussion of late Neandertal dating and cultural associations to the key French occurrences. Such key occurrences are the Grotte du Renne, at Arcy-surCure (Yonne), and the rock-shelter of La Roche-à-Pierrot, at St.-Césaire (Charente-Maritime). The first site is where Leroi-Gourhan (1958) originally proposed (on the basis of archaic features perceived in the dental remains from the corresponding levels of the site) that the Châtelperronian could have been made by the Neandertals. Fifteen years later, this notion would be boosted by the discovery at the second site, in a Châtelperronian context, of a diagnostic partial skeleton (Lévêque and Vandermeersch 1980). If current age estimates for these two occurrences are indeed too young, then the speculation explicitly or implicitly entertained by recent critics of Assimilation-that, in the period between 40,000 and 45,000 years ago, modern humans were the true makers of the archeology of most if not all of Europe-becomes an empirically viable hypothesis.

\subsubsection{St.-Césaire}

La Roche-à-Pierrot features a stratigraphic sequence spanning the Middle-to-Upper Paleolithic transition, one where, as originally described, Châtelperronian levels EJOPsup and EJOPinf are sandwiched between two ensembles of Aurignacian (levels EJJ to EJOsup) and Mousterian (levels 

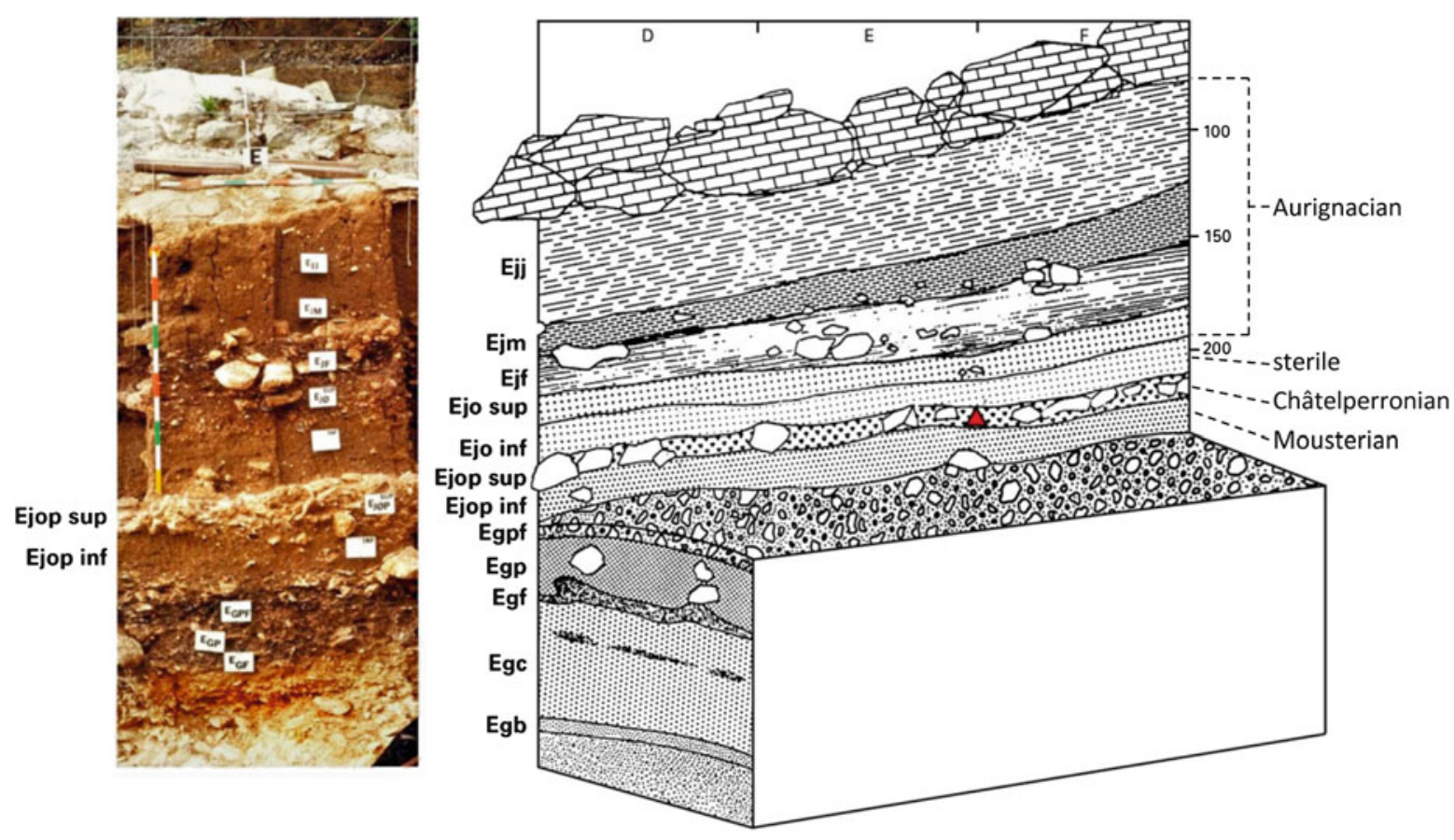

Fig. 3.1 Saint-Césaire. Left: Photograph of the stratification with indication of layers Ejop sup and Ejop inf; the scale bar is $1 \mathrm{~m}$. Right: Schematic stratigraphy of the site with indication of the main units and

EGBinf to EGPF) deposits (Morin et al. 2005) (Fig. 3.1). The partial skeleton, interpreted as a secondary burial, was found exposed, and partly eroded, at the surface of EJOPsup; removed from the site as a block, it was subsequently excavated in the laboratory.

Recent re-analyses (Bar-Yosef and Bordes 2010; Bordes and Teyssandier 2011; Soressi 2011), however, raise a number of questions concerning the association between the skeleton and the Châtelperronian. Namely, they show that the lithic assemblage of EJOPinf is in fact Mousterian, while EJOPsup contains both Châtelperronian and Middle Paleolithic components, the latter displaying a distinct preservation condition and representing more than two thirds of the level's retouched tools. In addition, it is argued that no detailed description of the stratigraphy observed during the laboratory excavation of the block has been published, making it difficult to assess whether an intentional burial pit truly existed.

In this situation, alternative interpretations of the skeleton's associations are legitimate. For instance, the Mousterian component of EJOPsup could stand for the occurrence of an episode of debris flow or solifluction through which the level would have been originally laid down; the Châtelperronian component would have accumulated at a later time on the surface of this redeposited context, the palimpsest in existence at the time of excavation resulting from the action of penecontemporaneous natural and anthropogenic factors. In such a scenario, the Neandertal remains could represent a Mousterian burial displaced by (and partly destroyed in) the process. of the position of the partial Neandertal skeleton (represented by the red triangle); elevations are in cm. From Hublin et al. (2012a: Fig. S2), modified

Based on the reported lack of stones in the immediate context of the skeleton, in contrast with their abundance elsewhere in EJOPsup, one might interpose, however, that a burial pit indeed existed (Vandermeersch 1993). In that case, the site formation scenario above would imply that the pit post-dated the redeposition event responsible for the level's Middle Paleolithic artifact component and, therefore, that the Neandertal skeleton could only be of a Châtelperronian or later (i.e., in this case, given stratigraphy, Aurignacian) age.

The direct radiocarbon dating of the skeleton to $36,200 \pm 750{ }^{14} \mathrm{C}$ BP (OxA-18099; Hublin et al. 2012a, that is, to $39.6-42.5 \mathrm{ka}$ cal BP, has clarified the picture in at least one way: under the assumption that the result is accurate, the dating unambiguously rejects the hypothesis that the St.Césaire Neandertal is associated with the Mousterian component of EJOPsup. However, since the age range obtained overlaps the boundary between the chronostratigraphic time slots of the Châtelperronian and the Protoaurignacian in France, the dating does not reject that the skeleton relates to the latter instead of the former.

Based on the stratigraphic configurations observed at the time of excavation, and bearing in mind that the relevant levels (EJOPsup and EJOsup) are separated by the $>10 \mathrm{~cm}$-thick sterile level EJOinf, a Protoaurignacian connection is, however, unlikely, and this for two reasons. Firstly, if a pit had been excavated from EJOsup deep into EJOP, then it should have left a readily apparent scar in EJOinf, but none was observed. Secondly, such a pit would 
in that case post-date the formation of both EJOinf and EJOPsup and, therefore, the partial exposure of the skeleton at the surface of EJOPsup could no longer be related to the latter's clearly erosional upper boundary.

Thirty-five years after the discovery, attribution of the St.-Césaire skeleton to the Châtelperronian remains, therefore, the parsimonious reading of the evidence.

\subsubsection{Grotte du Renne}

The Grotte du Renne features a Châtelperronian sequence (levels VIII, IX and X) sandwiched between Mousterian (levels XI-XIV) and Protoaurignacian (level VII) deposits, the latter in turn overlain by Aurignacian and Gravettian levels. The Châtelperronian yielded a juvenile temporal bone and 29 teeth of undisputed Neandertal affinities (Hublin et al. 1996, 2012a; Bailey and Hublin 2006), as well as 39 objects of personal ornamentation, 1,615 pigment chunks (weighing a total of $17 \mathrm{~kg}$, and mostly red ochre), and 139 worked bone items of a diverse typology (mostly awls) (Caron et al. 2011; Fig. 3.2). In the framework of Recent African Origin, this association posed an obvious problem. It is therefore unsurprising that supporters have insistently tried to explain it away, with the principal suggestions to that effect having been the following:

(a) The association is genuine, but the presence of symbolic artifacts in these levels is incidental, resulting from curiosity-driven collection by Neandertals of items discarded by modern humans living nearby, from Neandertal "imitation without understanding" of such modern human crafts, or from trade or exchange.

(b) The association is an artifact of post-depositional disturbance, with the Châtelperronian having been made by Neandertals and the apparently associated symbolic artifacts having been downwardly displaced from the overlying Aurignacian.

(c) The association is an artifact of post-depositional disturbance, with the Châtelperronian having been made by modern humans and the apparently associated Neandertal remains having been upwardly displaced from the underlying Mousterian.

The first hypothesis, otherwise known as the "Acculturation" model of the Châtelperronian (Mellars 1999; Hublin 2000; Gravina et al. 2005; Mellars et al. 2007; Mellars and Gravina 2008), is overtly inconsistent with the empirical evidence, as highlighted by d'Errico et al. (1998), Zilhão and d'Errico (1999), and Zilhão et al. (2006, 2008a, b). Namely, the byproducts of bone tool and personal ornament production recovered alongside the finished objects refute notions of acquisition via trading or scavenging of abandoned modern human sites, while the differences in blank choice, technology and typology counter imitation. In addition, chronostratigrapy shows that the Châtelperronian precedes the Aurignacian, the putative interstratification of Châtelperronian and Aurignacian levels at the sites of Le Piage, Roc-de-Combe and Grotte des Fées representing in fact excavation error and post-depositional disturbance or mixing. In short, since, at the time, there were no modern humans around to trade with or imitate, Acculturation is an empirically invalid explanation of the Grotte du Renne record.

Moreover, as discussed at greater length elsewhere (Zilhão 2007), at the time the Châtelperronian emerged in France, Southwest Asia was, overland, the closest place where a modern human presence is conceivable; therefore, if the Grotte du Renne's Châtelperronian resulted from long distance acculturation, the same sort of process should be apparent in the intervening geography, which is not the case. In addition, the ornamental material in use at that time in the Levant consists entirely of marine shells, mostly Nassarius and similar small-sized species recovered in some of the region's Initial Upper Paleolithic (IUP) or Emiran contexts (Kuhn et al. 2001). Even under the assumption that these technocomplexes are associated with modern humans, one can hardly see how their use of such beadwork material would have prompted Neandertals living thousands of kilometers away to start piercing the teeth of fox and other animals to use as neck pendants. Over such large distances, the only "influence" that could have been exerted is that concerning the notion of "personal ornamentation" itself. However, in western Europe, Neandertal body painting and personal ornamentation have Middle Paleolithic beginnings and predate both the IUP/Emiran and the Châtelperronian by thousands of years (Soressi and d'Errico 2007; Zilhão et al. 2010a; Peresani et al. 2011; Morin and Laroulandie 2012; Finlayson et al. 2012).

The second hypothesis, originally proposed by Taborin $(1998,2002)$ and White $(2001,2002)$, not only is equally unable to explain the techno-typological distinction between the Grotte du Renne's Châtelperronian productions and those from the Aurignacian, it is also inconsistent with the vertical distribution of the finds across the stratigraphic sequence of the site. In fact, contra what one would expect under such a hypothesis, Protoaurignacian level VII yielded only 8 ornaments, while 39 were found in the Châtelperronian sequence and, of these, three quarters came not from the level immediately underlying the Protoaurignacian, level VIII, but from the deepest one, level X (Zilhão 2006a, 2007, 2011). A similar objection applies to the third hypothesis, originally proposed by Bar-Yosef (2006) and Bar-Yosef and Bordes (2010), as, conversely, of the 34 Neandertal teeth found at the Grotte du Renne, three came from basal Mousterian level XIV, 29 from the Chatelperronian, and only two from the immediately underlying Mousterian levels XI and XII.

Until the late 1990s, attempts at radiocarbon dating the Grotte du Renne sequence yielded results for the Châtelperronian falling for the most part in the 32-34 ka 


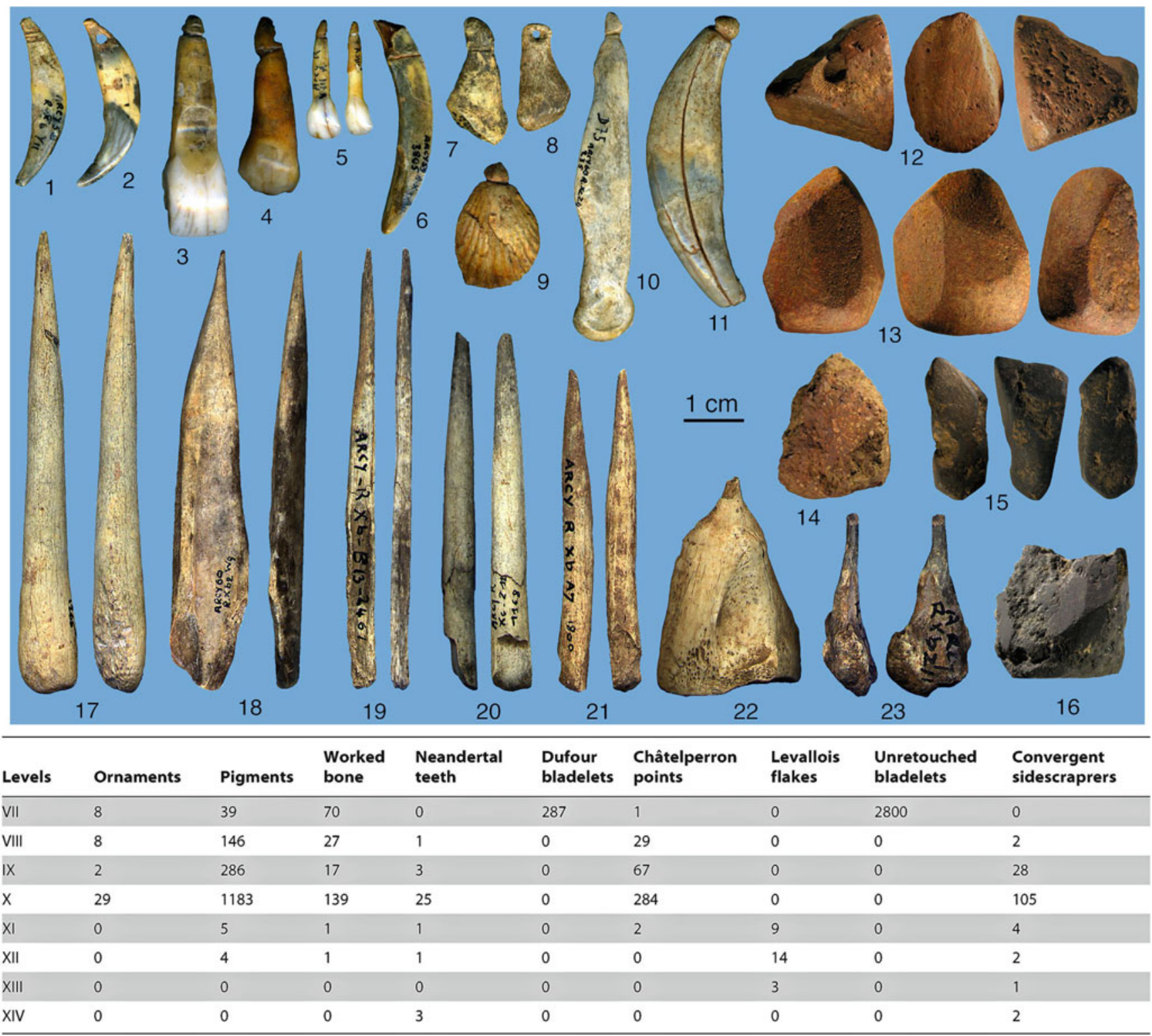

Fig. 3.2 The symbolic material culture of the Grotte du Renne Châtelperronian. Above: Personal ornaments made of perforated and grooved teeth $(1-6,11)$, bones $(7-8,10)$, and a fossil (9); red (12-14) and black (15-16) colorants bearing facets produced by grinding; bone awls (17-23). Below: Stratigraphic distribution of the key finds made in the site's Mousterian (levels XI-XIV), Châtelperronian (levels VIII-X) and Protoaurignacian (level VII) deposits. From Caron et al. (2011), modified
${ }^{14} \mathrm{C}$ BP age range (David et al. 2001), supporting the interstratificaton arguments for long-term contemporaneity with the Aurignacian and thereby strengthening Acculturation views of the evidence. The numerous inconsistencies in the dating corpus, however, indicated that those results, obtained on associated animal bone samples, were likely to be minimum ages only, while detailed analysis of the stone tool assemblage in level VII eventually allowed its assignation to the Protoaurignacian (Bon 2002; Bon and Bodu 2002). The recognition that this facies was of chronological rather than geographic or cultural significance implied in turn that levels VIII-X of the Grotte du Renne had to predate $\sim 36.5 \mathrm{ka}{ }^{14} \mathrm{C} \mathrm{BP}$ and, therefore, that most if not all of the radiocarbon dates for the site had to be rejected (Zilhão and d'Errico 2003).

Recent redating of the sequence at the Oxford Radiocarbon Accelerator Unit (ORAU) using samples treated with the more robust ultrafiltration protocol ameliorated the situation considerably, but some problems of stratigraphic inconsistency remained nonetheless (Higham et al. 2010, 2011a, b). These anomalies prompted a revival of the notion that the site had undergone major post-depositional disturbance, thereby providing ammunition to the view that the presence of symbolic artifacts in the Châtelperronian was spurious (e.g., Mellars 2010). 
In a response to such claims, Caron et al. (2011) and Zilhão et al. (2011) countered that the new results could at best signify limited post-depositional displacement across the boundaries of adjacent levels. That such limited displacement existed was already known for levels VII and VIII, on the basis of the distribution of small fragments of ivory beads (d'Errico et al. 1998; Zilhão 2007), and for levels IX and X, on the basis of stone tool refits (Bodu 1990). This evidence in no way questions the site's overall stratigraphic integrity, and this for a number of reasons, namely:

(a) Mathematical simulation of the post-depositional movement of individual items across stratigraphic boundaries shows that the level of disturbance implied by Higham et al.'s and Mellars' interpretation of the new ORAU results is inconsistent with the vertical distributions of diagnostic stone tools, personal ornaments, bone artifacts and mineral pigments.

(b) In level X, where the Grotte du Renne's symbolic finds are concentrated, their distribution is fully congruent with that of the hearths and other habitation features.

(c) The stratigraphic outliers among the new dates reflect inaccurate results rather than displaced samples, the cause of the errors lying in the poor preservation of collagen, aggravated, in the case of bone tools, by contamination arising from their curation with glues and consolidants.

(d) The Bayesian model of dates and stratigraphy underpinning Higham et al.'s interpretation is flawed in their choice of priors and testable propositions; when testing the significance of outliers under phasing premises that are appropriate to the research issue at stake (which is whether the personal ornaments and Neandertal remains in level X could have been displaced from, respectively, levels VII and XI-XII), the new ORAU results fail to reject the association between Neandertals and symbolic artifacts in the Châtelperronian even in Higham et al.'s own terms, i.e., even under the assumption that their results are all accurate.

These arguments have since been vindicated by a larger set of dates, obtained by a different laboratory, on samples selected for their good collagen preservation and using the same pre-treatment, calibration and modeling tools as Higham et al. (Hublin et al. 2012a). The 26 radiocarbon results obtained for the Châtelperronian of the Grotte du Renne by Hublin et al.'s study place it in the $\sim 41-45 \mathrm{ka}$ cal $\mathrm{BP}$ interval, and the four obtained for underlying level XI place its last Mousterian occupation in the $\sim 45-46$ ka cal BP interval (Fig. 3.3). In turn, the five dates obtained for Protoaurignacian level VII all post-date $\sim 41 \mathrm{ka}$ cal BP, even though some corroborate that later Aurignacian components also exist therein, as otherwise indicated by a few Aurignacian I diagnostics found among the level's bone and stone tool assemblages (including a split-based bone point fragment; Julien et al. 2002).
In short: stratigraphic integrity is not an issue at the Grotte du Renne, and no reason exists to question the association of Neandertal fossils with personal ornaments in its Châtelperronian levels.

\subsection{Early European Modern Humans: How Early?}

Hopefully, Hublin et al.'s (2012a) results will have settled the Grotte du Renne controversy. From their dates, however, Hublin et al. also concluded that Neandertals "produced body ornaments in the northernmost part of [the Châtelperronian] geographical distribution only after modern humans arrived in western Europe and Protoaurignacian or Early Aurignacian populations occupied neighboring regions" and that "this new behavior could therefore have been the result of cultural diffusion from modern to Neandertal groups." On the logical side of things, this resurrection of the Acculturation model of the Châtelperronian championed by Hublin (e.g., Hublin 2000) is rather puzzling, as it ignores the evidence accumulated in the meanwhile for personal ornamentation in the Middle Paleolithic of Europe, $\geq 50,000$ years ago (Zilhão et al. 2010a). On the empirical side of things, it is based on the premise that the Aurignacian and modern humans were present farther south and farther east at the time, $45 \mathrm{ka}$ cal BP, of Châtelperronian emergence. That such is the case has indeed been argued, but is the argument valid? This is the issue to which I now turn.

\subsubsection{Grotta del Cavallo}

The Uluzzian deposits excavated in the early 1960s at Grotta del Cavallo, in southern Italy, yielded two deciduous left upper molars: Cavallo-B, a dM $\mathrm{dM}^{1}$ from spit EIII of level E, at the base of the Uluzzian sequence, and Cavallo- $\mathrm{C}$, a $\mathrm{dM}^{2}$ from immediately overlying spit EI-II. Churchill and Smith (2000), as others before them, had considered these teeth to be of Neandertal affinities, but Benazzi et al. (2011) assigned them to modern humans on the basis of a morphometric comparison employing a combination of two methods: the analysis of two-dimensional enamel thickness and of dental tissue proportions; and the analysis of the outlines of dental crown (for the Cavallo-B $\mathrm{dM}^{1}$ ) and cervix (for the Cavallo-C $\mathrm{dM}^{2}$ ). On both counts, the two teeth fell clearly outside the range of the comparative Neandertal sample and fully within that of the comparative modern human sample. However, before taking for granted that these results warrant Benazzi et al.'s conclusion that the people of the Uluzzian were modern humans, we need to discuss two issues that they failed to address: whether the comparative samples used are sufficient to assess the taxonomic issue at stake; and whether the two 


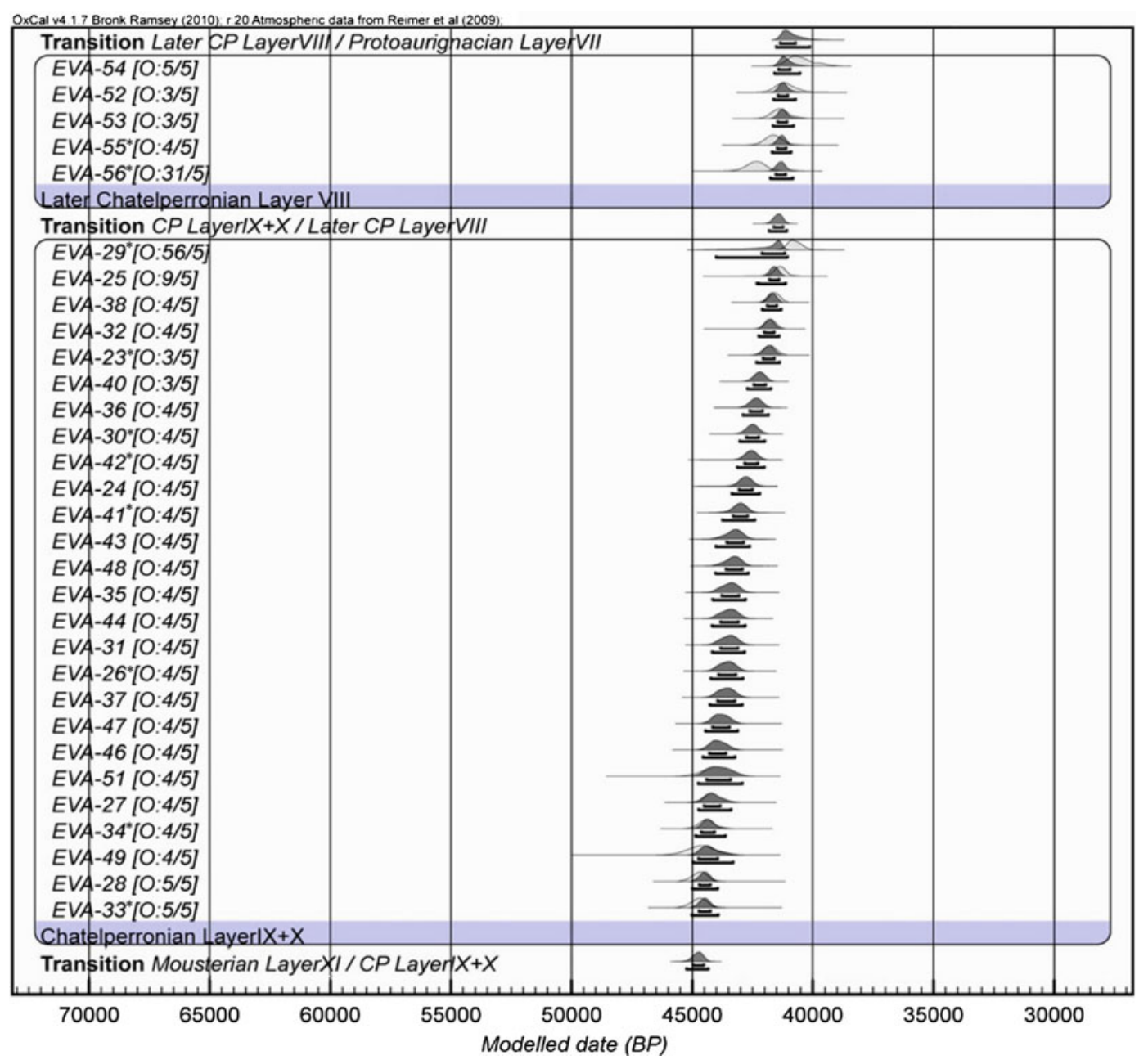

Fig. 3.3 Calibrated ages and boundaries, modeled with OxCal 4.1 (Bronk Ramsey 2009) and IntCal09 (Reimer et al. 2009), for the two blocks into which Hublin et al. (2012a) divided the Châtelperronian

teeth are in situ finds and truly represent the makers of the associated stone tools.

\subsubsection{Tooth Morphology}

Where the morphometric analysis is concerned, the main problem is representativeness: of the 11 Neanderthal teeth in the comparisons, one (from Subalyuk) is of unknown chronology, eight (from Krapina and Roc-de-Marsal) are of Marine Isotope Stage (MIS-) 5 age, and only two (those from Pech de l'Azé I) are not much earlier than the Cavallo fossils. In their graphs, Benazzi et al. (2011) do not individually identify the fossils, presumably because they assume that Neandertal anatomy remained static, there being no need, therefore, to consider the issues raised by the change through time toward more modern-like patterns seen among later Neandertals in post-crania (Trinkaus et al. 1999) as much as in skull and dentition (Wolpoff et al. 1981; Wolpoff 2002). Of particular relevance in this context is the fact that such directional change is most apparent in the contrasts between sequence of the Grotte du Renne (upper, level VIII; lower, levels IX-X); the samples marked with an asterisk bear anthropogenic modification. From Hublin et al. (2012a: Fig. 1), modified

the Krapina (MIS-5) and Vindija (mid-MIS-3) fossil assemblages, i.e., in the evolution of Neandertals from south central Europe, the broader geographic region concerned by the Cavallo study. Therefore, all that can be concluded from Benazzi et al.'s study is that the Cavallo teeth are distinct from those of last interglacial Neandertals. Whether they are also distinct from those of the Neandertals from 50,000 years later remains an open issue, and all the more so since, as Churchill and Smith (2000) pointed out, the Cavallo teeth are taurodont, as is often the case with Neandertal deciduous molars but has never been observed among early modern human juveniles.

In addition, Benazzi et al. ignore the fact that a deciduous incisor, on which Gambassini et al. (2005) identified Neandertal apomorphies and a wear pattern similar to that seen in other Neandertal incisors, was also recovered in spit EIII of Cavallo (Riel-Salvatore 2009). On the face of the combined evidence, one would therefore have to conclude that Neandertals and moderns coexisted in southern Italy at 
the time of the Uluzzian and that the issue of who made it cannot be answered simply because both groups were implicated. Alternatively, and perhaps more sensibly, one might instead conclude: firstly, that our understanding of the variation in the dental morphology of Neandertals and modern humans from around the time of contact in western Eurasia is incomplete; and, secondly, that it is therefore unwarranted to assume that a clear-cut distinction existed at that time solely on the basis of the contrasts observed when comparing present-day humans with the Neandertals of 100,000 years ago.

The pertinence of this point is further highlighted by the misidentifications produced when Bailey et al. (2009) applied to the Romanian early moderns from Oase a set of diagnostic dental criteria designed to discriminate Neandertals from modern humans when dealing with isolated finds. Despite the large size of the comparative sample, it turned out that, if found loose, the Oase 1 mandibular teeth would have been classified as modern and the Oase 2 maxillary ones as Neandertal. Bailey et al. fell short of deriving the conclusion, but this outcome highlights the inappropriateness, with respect to the fossils of the contact period, of a framework where classical Neandertals are dichotomically contrasted with extant people or late Upper Paleolithic modern humans.

Bailey et al. used discrete crown traits, but using endostructural tissue properties instead does not necessarily clarify the picture, as shown by Bayle et al.'s (2010) study of the dentition of the Lagar Velho child, dated to $\sim 30 \mathrm{ka}$ cal BP. Five of the child's teeth were analyzed for their linear, surface and volumetric tissue proportions, of which the deciduous right upper central incisor came out as Neandertal-like, the permanent lower right first molar as modern human-like, and the other three (a deciduous lower right lateral incisor, a deciduous lower right canine and a deciduous lower right second molar) as intermediate on some parameters and modern human- or Neandertal-like in others.

In a subsequent paper dealing with the crown and cervical outlines of deciduous lower second molars, Benazzi et al. (2012) acknowledged this problem. Where the corresponding Lagar Velho tooth is concerned, they found it to be intermediate between Neandertals and modern humans in crown outline, and described this finding as corroborating the similar conclusion derived by Bayle et al. (2010) from tissue proportions. Benazzi et al. (2012) also found that the crown outlines of three other fossils, two Neandertals and one Upper Paleolithic modern, were misclassified by the predictive tool derived from the observed patterns. It is also noteworthy that the Neandertal sample in this study is composed of 14 specimens, of which 11 (those from Abri Suard, Krapina, Roc-de-Marsal and Scladina) are of MIS-5 age, two are of MIS-3 age (those from Couvin and Engis), and another, Cavallo-A, is, presumably, from a Mousterian level of unknown age underlying the site's Uluzzian deposit.
Subsequent to Benazzi et al.'s (2012) study, Le Cabec et al.'s (2013) analysis of anterior tooth root morphology and size also found a significant overlap between Neandertals and early modern humans. In light of these findings, of the problems encountered by Bailey et al. (2009) with the Oase fossils, and of the contradictions in expert opinion about the affinities of the teeth found in the Uluzzian levels of Cavallo, the conclusion is inescapable: for teeth from around the time of contact, secure classification in terms of the taxonomic categories of Human Paleontology may be possible for large sets (e.g., the Grotte du Renne's) but not for isolated finds. In short, the evidence upon which Benazzi et al. (2011) assign the Uluzzian to modern humans is inconclusive and insufficient to reject the hypothesis that the Cavallo teeth are Neandertal.

\subsubsection{Dating}

Benazzi et al.'s argument is further weakened by the fact that the new radiocarbon dates they obtained for the site suggest a more complex stratigraphic situation than they describe: "The Uluzzian deposits, about 80-85 cm thick, (...) are divided into Archaic Uluzzian (E III), Evolved Uluzzian (E II-I) and Final Uluzzian (D II-D Ib). They are separated from the upper part of the sequence by a stalagmitic crust (D Ia) and two sterile layers of volcanic ash (C II and C Ia-b). (...) Directly superimposed are Epigravettian horizons B II-B I (Romanellian and Epiromanellian facies), of much younger age ( $\approx 11,000$ years BP)" (Supplementary Information, p. 2).

Contradicting this straightforward scenario of Late Epigravettian over Uluzzian with an intervening level of sterile volcanic ash of presumed Campanian Ignimbrite age (i.e., $39.3 \pm 0.11 \mathrm{ka}$; de Vivo et al. 2001), four of the six dates for level D fall in the time range of the Early Epigravettian or the Protoaurignacian, which supposedly do not exist at the site (Fig. 3.4). The three dates in the Protoaurignacian age range are consistent with the presence in the stone tool assemblage of level D of a component with clear Aurignacian affinities, as pointed out by Gioia (1990). Based on this lithic evidence, I had previously suggested (Zilhão 2007) that the perforated Columbella rustica and Cyclope neritea shells from the "Evolved" and "Final" Uluzzian of Cavallo were likely to be intrusive items and, indeed, the Early Epigravettian date ( $22.7 \mathrm{ka}$ cal BP, confirmed by a repeat) was obtained on a specimen of the latter species. This Early Epigravettian date raises the question of whether the ash lenses capping level D really are Campanian Ignimbrite, but significant disturbance at this stratigraphic interface and affecting deeper levels in the sequence is additionally shown by the OxA19257 result for level D; at $\sim 45.3 \mathrm{ka}$ cal BP, this date is some two millennia older than the single result obtained for underlying level E (OxA-19242, 43.6 ka cal BP), and, given the relatively small standard deviations, the difference is statistically significant. 


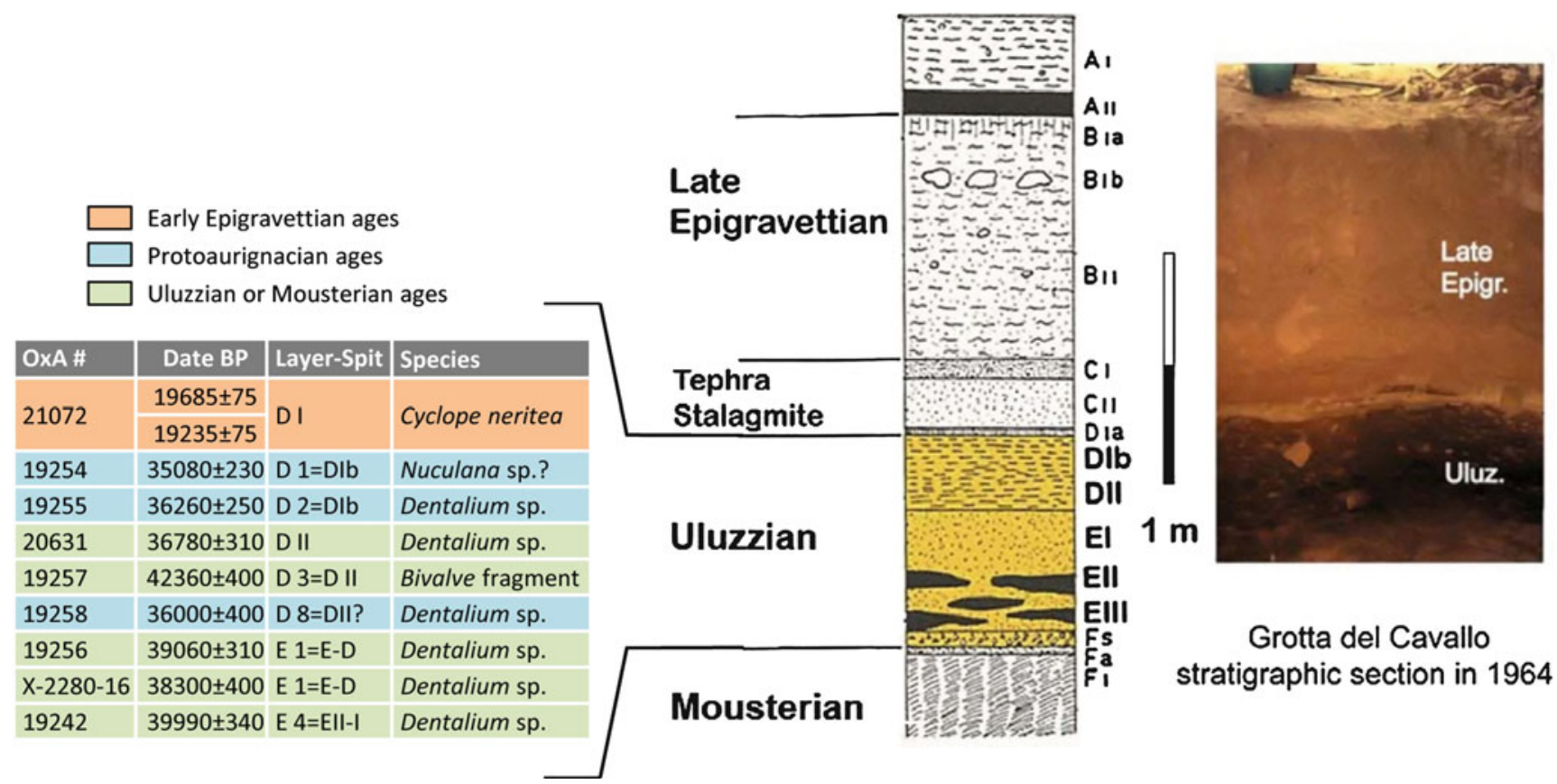

Fig. 3.4 Stratigraphy and dating at Grotta del Cavallo. Left: the uncalibrated radiocarbon results obtained on samples of marine shell ornaments from the Uluzzian levels. Right: detail of the succession at the

In their analyses of, respectively, the stone and bone tool assemblages from the Cavallo Uluzzian, neither RielSalvatore (2009) nor d'Errico et al. (2012) spotted the presence of intrusive material in level $\mathrm{E}$, and the ornament shell date of $\sim 43.6 \mathrm{ka}$ cal BP is consistent both with those published in d'Errico et al. (2012) for basal spit EIII of the site (on charcoal samples) and with age estimates for the Uluzzian elsewhere in Italy and Greece (Koumouzelis et al. 2001a, b; Higham et al. 2009). These observations warrant the overall stratigraphic integrity of level $\mathrm{E}$, but do not exclude localized movement of individual, small-sized items across its boundary with the significantly disturbed level $\mathrm{D}$, as suggested by the OxA-19257 result discussed above, in all likelihood an upwardly displaced sample.

\subsubsection{An Open Issue}

From the above, it is clear that even if the two teeth described by Benazzi et al. (2011), Cavallo-B and -C, are eventually shown to be of modern humans, their true association with the Uluzzian has yet to be securely established, and that can only come from the direct dating of the fossils themselves. This is because they come from spit EIII, which remains undated, and because the presence of intrusive items in overlying spits of the Uluzzian deposits is indicated by both dating results and stone tool typology. This precludes the use of the dates obtained for level D and for spit EI-II of level $\mathrm{E}$ as an absolute terminus ante quem for the material recovered in spit EIII. interface between the Middle and the Upper Paleolithic (modified from Benazzi et al. 2011: Fig. S1, reproduced with permission from Macmillan Publishers Ltd/Nature)

The reasoning above assumes that the dates are chronologically related to the human activity recorded in the deposits from where they come. However, all of Benazzi et al.'s (2011) dates are on beach-collected marine shell beads; therefore, the interval between the death of the organism (the radiocarbon-dated event) and the time of collection (the archeological event of interest) is unknown and can be of several hundred or even thousands of years. In this regard, a relevant cautionary tale is provided by Douka's (2011) dating of a Glycymeris shell tool from Ksar' Akil (Lebanon) whose age turned out to be seven millennia older than that of the Evolved Aurignacian context where it was found. Conceivably, the dating anomalies pointed out in the preceding section could relate to this problem instead of reflecting episodes of human occupation that went unrecognized at the time of excavation. The dated Cyclope shell, for instance, could represent an object of Early Epigravettian age humancollected from an exposed beach in Late Epigravettian times, while the $\sim 42.4 \mathrm{ka}{ }^{14} \mathrm{C}$ BP bivalve fragment from level D could represent an object of Mousterian age likewise humancollected in later, Uluzzian times. In order to avoid circularity and maintain logical consistency, introducing this possibility into the discussion implies that all of the results be treated as maximum ages. Doing so, however, also automatically means not using Benazzi et al.'s (2011) dates to support a minimum age, no matter which, for the fossils recovered in level EIII.

In these circumstances, hanging upon the Cavallo evidence the notion that modern humans made the Uluzzian is, 
at present, unwarranted. And even more so are, therefore, the speculations concerning the migration route followed by such putative pioneer moderns in order to travel from Africa to southern Italy (e.g., Moroni et al. 2012).

\subsubsection{Kent's Cavern}

The other European site where modern humans have recently been claimed to predate the $\sim 41.5 \mathrm{ka}$ cal BP time horizon is Kent's Cavern, in the southern United Kingdom. By their reanalysis of the three teeth in the KC4 maxillary fragment and the dating of associated faunal samples, Higham et al. (2011c) assigned the fossil to a modern human that would have lived in the region of 41.5-44.2 ka cal BP.

Bearing in mind the issues discussed above concerning the representativeness of comparative samples and the fuzziness of the contrasts between late Neandertal and early European moderns in many aspects of dental morphology, the first problem with this conclusion is that the taxonomic classification was proposed as a probabilistic statement, not a certainty. More importantly, even if the fossil is indeed one of a modern human, the age suggested for it by Higham et al. derives from a Bayesian model that makes three key assumptions: that the provenience information associated with the fossil is reliable; that the deposits in the Vestibule area of the site, from where KC4 was recovered in 1927, are characterized by a high degree of stratigraphic integrity; and that, in such a context, depth-below-datum is a good proxy for the time ordering of the dated samples. Zilhão et al. (2011) and White and Pettitt (2012), however, have since demonstrated these assumptions to be unwarranted. It is therefore sufficient here to briefly summarize the reasons why this is so:

(a) $\mathrm{KC} 4$ was recovered in the context of the excavations undertaken at the site by Arthur Ogilvie between 1926 and 1942. The coeval documentation published by White and Pettitt (2012) leaves no doubt that the bad reputation of this work, notorious for its lack of quality in both method and recording, is entirely deserved. From the photographic evidence (Fig. 3.5) we can see how the excavations were carried out: by untrained workmen using picks and shovels in quarry-like fashion and under poor lighting conditions, with finds being sorted by Ogilvie, with volunteer help, from sediment transported away in wheelbarrows.

(b) The maxillary fragment and the teeth, although anatomically associated, were recovered as scattered finds, the teeth dislodged from their sockets, spread over a distance of at least $60 \mathrm{~cm}$ and in an unrecorded part of Trench $\mathrm{C}$, which, at around the time of discovery, was being excavated over an area of at least $15 \mathrm{~m}^{2}$. The finds were reportedly made at a depth of $3.2 \mathrm{~m}$ below datum, but the precision of this information is illusory, as the
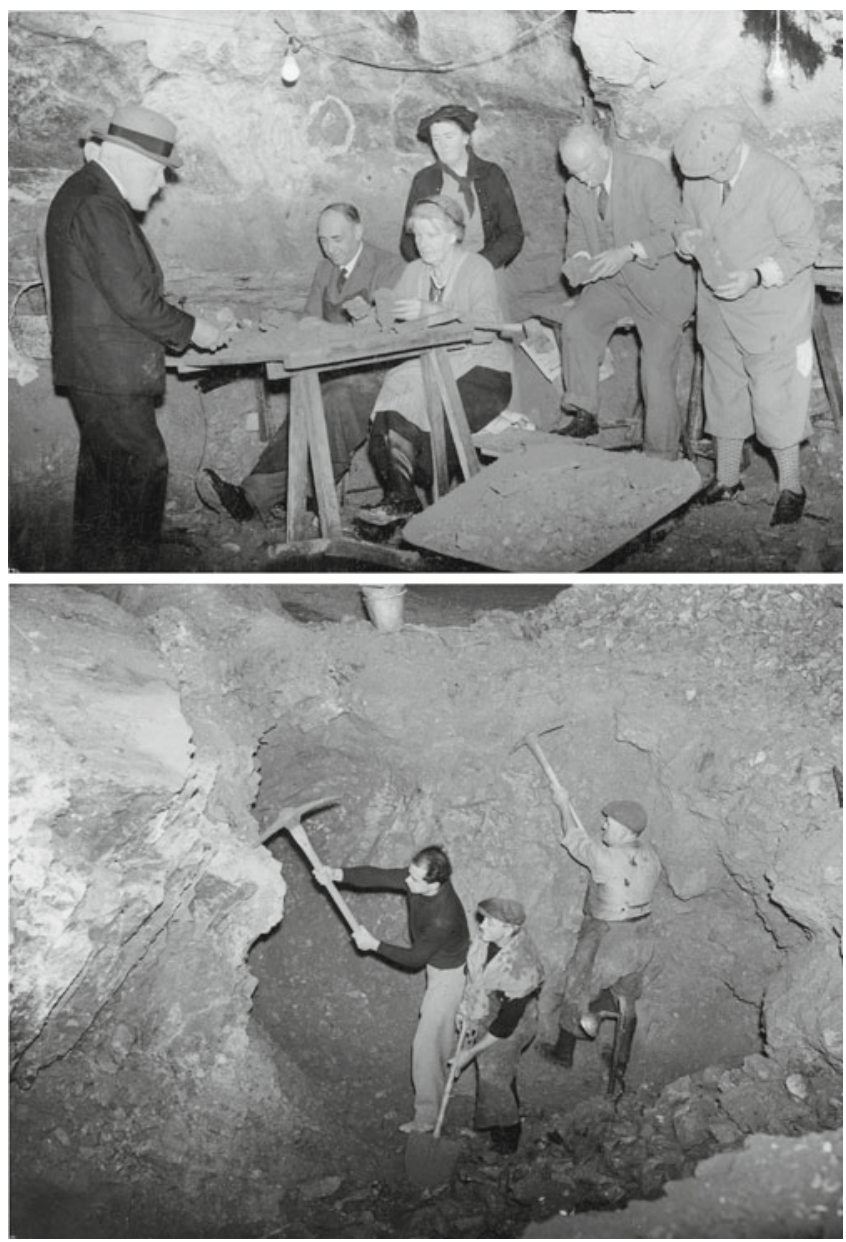

Fig.3.5 Ogilvie's 1927 excavations at Kent's Cavern. Below: a view of the work in the Vestibule. Above: the spoil, transported by wheelbarrow, is sorted by Ogilvie and volunteers. From White and Pettitt (2012: Figs. 4-5), courtesy of the authors, reproduced with permission from Torbay Libraries

datum used was the non-horizontal base of a granular stalagmite above the trench and the diaries acknowledge discrepancies of up to $30 \mathrm{~cm}$ between measurements made in different years.

(c) The uncertainty in the position of the datum implies that the finds' depth information, even if deriving from actual on-the-spot measurements, cannot be used as a proxy for their relative age. Additionally, such a use would be legitimate only if the bedding were horizontal or nearly so, which is hardly the case.

(d) Above a stalagmitic floor encountered at a depth of $\sim 2.4 \mathrm{~m}$, the Trench $\mathrm{C}$ deposits were accumulated by torrential flooding, which implies that material of rather disparate ages could be included therein, and in no internal stratigraphic order. This jumbling effect would have been aggravated by post-depositional displacement (through solifluction, cryoturbation and animal burrowing). The pertinence of these points is highlighted by 
Fig.3.6 Right: Schematic stratigraphy of Kent's Cavern Trench C (modified from Higham et al. 2011c: Fig. 2, reproduced with permission from Macmillan Publishers Ltd/Nature), and radiocarbon results obtained on faunal samples associated with the KC4 maxillary fragment; given the deposit's formation process, the only age constraint for the fossil is the terminus post quem provided by the ages obtained for samples reported to come from a lower elevation. Left: The different fragments of a single refitted blade from Trench $\mathrm{C}$ (reproduced from Jacobi and Higham 2011: Fig. 11.7, with permission from Elsevier Ltd) are reported to come from both above and below the LS stalagmite

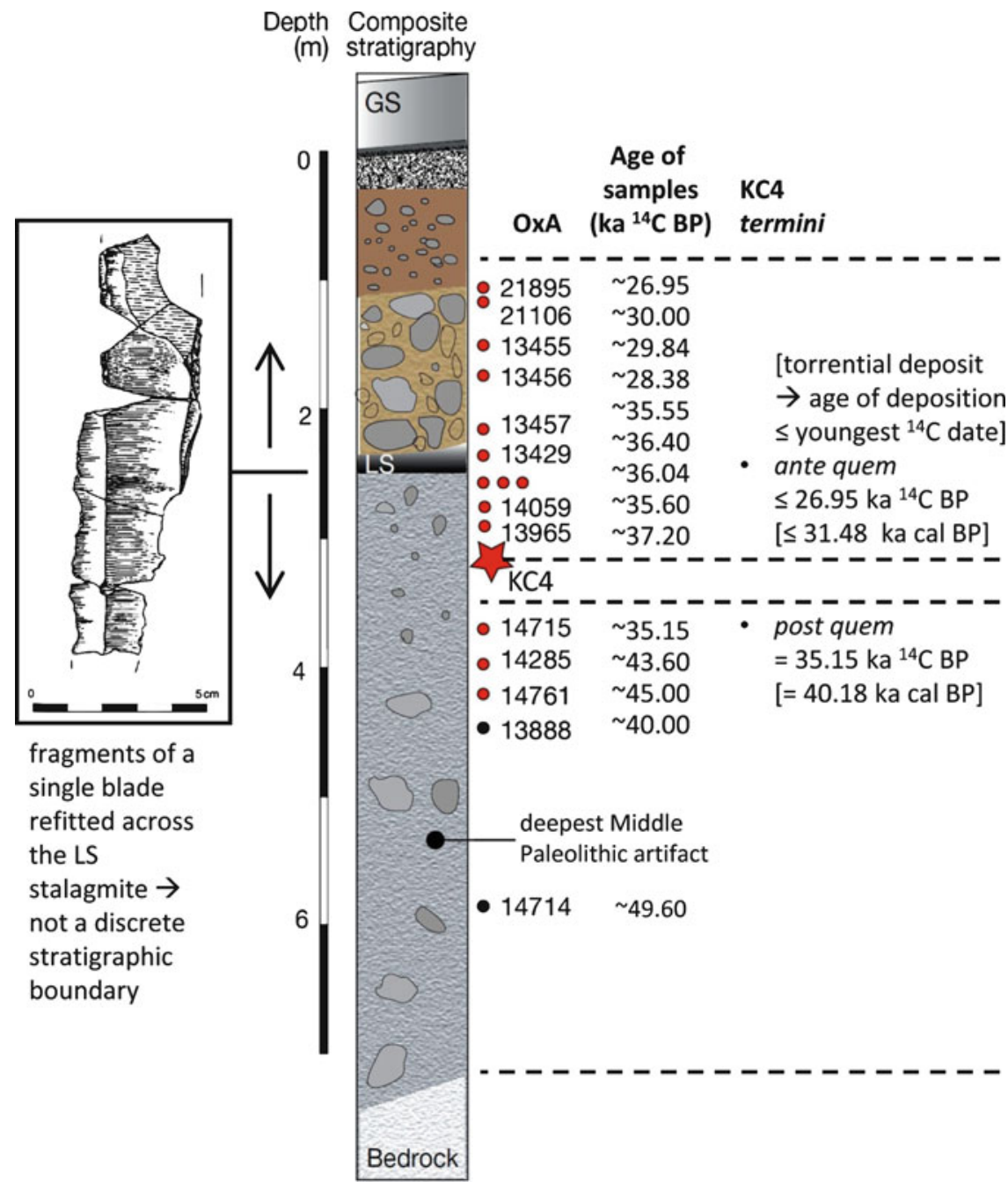

(f) The $2.4 \mathrm{~m}$ stalagmitic floor provides evidence that the Trench $\mathrm{C}$ sequence formed over at least two periods of accumulation, but the post-depositional disturbance observed across this boundary means that finds made at about its depth or somewhat lower down are not necessarily older. Therefore, the age of $\mathrm{KC} 4$ can at best be constrained by the results obtained for the samples collected well below it, at the base of the sequence. The terminus post quem so provided is one of $35.2 \mathrm{ka}{ }^{14} \mathrm{C} \mathrm{BP}$, the age of a rhino tibia sample (OxA-14715) reportedly found $45-75 \mathrm{~cm}$ deeper than the human fossil.

Under the assumption that these stratigraphic constraints are valid, it becomes apparent that the date obtained in 1989 for a sample from KC4 itself $\left(30,900 \pm 900{ }^{14} \mathrm{C}\right.$ BP; OxA-1621) may well be not much off the mark, despite all the potential problems with its chemistry. Alternatively, we can treat the entire sequence as jumbled or potentially so, in which case little else can be said about the age of the fossil beyond that it must lie somewhere between the youngest and oldest of all the dates obtained for Trench $\mathrm{C}$, i.e., in the $27-50 \mathrm{ka}{ }^{14} \mathrm{C}$ BP interval. therein-i.e., that terminus is $\sim 27 \mathrm{ka}{ }^{14} \mathrm{C} \mathrm{BP}$ (Fig. 3.6). 
In short: contra the claims made by Higham et al. (2011c), $\mathrm{KC} 4$ provides no support for modern human presence in Europe prior to $\sim 41.5 \mathrm{ka}$ cal BP.

\subsection{The Chronology of Modern Humans' Archeological Proxies}

Neither the two Cavallo deciduous teeth nor the Kent's Cavern maxillary fragment support the presence of modern humans in pre-Aurignacian times, but the directly dated Oase fossils place them in at least Eastern Europe during the Protoaurignacian. As I have extensively discussed elsewhere (Zilhão 2007, 2011), relating the latter with modern humans therefore makes sense, and all the more so since a significant transformation of Europe's cultural geography occurred at the time: where, before, regionally diverse early Upper Paleolithic, so-called "transitional" industries existed, the pattern then became one of cultural homogeneity across vast regions of southern Europe and of mid-latitude central and western Europe.

In fact, the pattern extends to southwest Asia, given the technological and typological similarity between the Protoaurignacian and the Early Ahmarian (Belfer-Cohen and Goring-Morris 2003), and the latter's association with modern humans (the now lost child "Egbert" from Ksar' Akil; Bergman and Stringer 1989). As discussed above and in more detail elsewhere (Zilhão 2006b; Trinkaus and Zilhão 2013), the Protoaurignacian/modern human relation needs not be exclusive and Neandertal involvement in the spread of the technocomplex cannot be ruled out at present. Even so, these patterns imply that it does make sense to construe the Protoaurignacian as the spilling off of Near Eastern cultural developments into adjacent Europe as part of the process of modern human dispersal into the continent.

In the following, I will therefore discuss some recent work on the chronology of the Early Ahmarian and the Protoaurignacian, as well as related claims that both could have emerged well before $\sim 41.5 \mathrm{ka}$ cal BP. As some scholars have suggested that these technocomplexes are representative of Mediterranean areas only and that a separate spread of modern humans following the Danube corridor took place alongside or even at an earlier time (Conard and Bolus 2003; Mellars 2004; Higham et al. 2012), I will also discuss whether claims for the precocious occurrence of other forms of the Aurignacian in southern Germany and Austria are supported by dating and stratigraphy.

\subsubsection{Early Ahmarian: Kebara}

The cave of Kebara, Israel (Bar-Yosef and Meignen 2007), has been the key site for the radiocarbon dating of the
Middle-to-Upper Paleolithic transition in Southwest Asia, but the results on charcoal reported by Bar-Yosef et al. (1996) (Table 3.1) for the corresponding levels show many inconsistencies. Two open air sites in the Negev (Boker Tachtit and Boker A; Marks 1983; Jones et al. 1983; Monigal 2003) also feature radiocarbon-dated occurrences of the Early Ahmarian, but the associated uncertainty intervals are too large.

Given this situation, I have suggested (Zilhão 2007) that the chronology of this technocomplex be anchored to the terminus post quem provided by the sequence of IUP (or Emiran) levels of the southern Turkish site of Üçağizli (Kuhn 2002, 2003; Kuhn et al. 2001, 2009), where the Early Ahmarian overlies the IUP (as is always the case in the region when both are present, namely at Ksar' Akil). This approach implies a time of emergence for the Early Ahmarian no earlier than $\sim 40.0-41.5 \mathrm{ka}$ cal BP, in the range of the European Protoaurignacian. Based on a new series of charcoal results (Table 3.2), Rebollo et al. (2011), however, have since claimed that, at Kebara, the Early Ahmarian emerged no earlier than $\sim 49$ and no later than $\sim 46 \mathrm{ka} \mathrm{cal} \mathrm{BP.}$

This claim creates a contradiction with the chronostratigraphic framework based on the correlation of the three long sequences that span the Middle-to-Upper Paleolithic transition in the region: if Rebollo et al. (2011) are correct for Kebara, the Early Ahmarian would have begun there five to ten millennia earlier than at Ksar' Akil (only $150 \mathrm{~km}$ to the north) or Üçağizli (another $240 \mathrm{~km}$ further north), and would have been even earlier than the Mousterian of the former and the IUP of the latter. So, either the dates for the pre-Early Ahmarian deposits of Ksar' Akil and Üçağizli are greatly rejuvenated, something that Rebollo et al. (2011) do not suggest, or their interpretation of the Kebara results is flawed.

\subsubsection{The Discrepancy Between ABA and ABOx}

The charcoal samples collected in the field by Rebollo et al. (2011) come from Early Ahmarian units III and IV, and from Mousterian unit V. A first set of results was obtained on subsamples pre-treated at the Weizmann Institute with the standard ABA (Acid-Base-Acid) protocol and then measured at the ORAU; the second set was obtained on untreated subsamples processed with the ABOx-SC (Acid-BaseOxidation-Stepped Combustion) protocol at the ORAU and measured there.

Contrary to what is usually the case (Brock and Higham 2009), the ABOx results came out systematically younger than those obtained with ABA, in some cases by more than five millennia. Rebollo et al.'s (2011) explanation for this anomaly is that the dating was carried out in the initial phase of setting-up ABOx at the ORAU and that, nowadays, the anomalous ABOx results would have been failed because of their low $\% \mathrm{C}$ on combustion. They argue that, by rejecting results where this parameter is below $50 \%$, ABOx and $\mathrm{ABA}$ 
Table 3.1 The radiocarbon dates on charcoal samples reported by Bar-Yosef et al. (1996) for Kebara

\begin{tabular}{lll}
\hline Provenience & Lab \# & Date BP \\
\hline Unit VII square Q19 & OxA-3981 & $>44,800$ \\
\hline Unit VI square P24 & Gif-TAN-90029 & $>48,000$ \\
\hline Unit Vw square Q15d & Gif-TAN-90030 & $>46,900$ \\
\hline Unit Vw square Q16, near burrow & OxA-1568 & $38,000 \pm 2,100$ \\
\hline Unit V square Q15d & OxA-3980 & $>44,800$ \\
\hline Unit V square Q14d & OxA-3979 & $>44,000$ \\
\hline Limit Unit IV-V, in Q16b/Q15d & Pta-5141 & $43,700 \pm 1,800$ \\
\hline IVB & Pta-5002 & $42,500 \pm 1,800$ \\
\hline IVB & Pta-4987 & $42,100 \pm 2,100$ \\
\hline IVB, adjacent to burrow & OxA-3978 & $28,890 \pm 400$ \\
\hline IIIB & OxA-3976 & $43,500 \pm 2,200$ \\
\hline IIIBf & OxA-3977 & $>43,800$ \\
\hline IIIBf & Gif-TAN-90037 & $>42,500$ \\
\hline IIIBf & OxA-1567 & $35,600 \pm 1,600$ \\
\hline IIIBf & Gif-TAN-90168 & $>41,700$ \\
\hline IIIB & Pta-4267 & $36,100 \pm 1,100$ \\
\hline IIf hearth & Gif-TAN-90028 & $34,300 \pm 1,100$ \\
\hline IIf hearth & Gx-17276 & $42,800 \pm 4,800$ \\
\hline IIf & OxA-1230 & $36,000 \pm 1,600$ \\
\hline IIf above hearth & Gif-TAN-90151 & $32,670 \pm 800$ \\
\hline II, in burrow & Pta-4263 & $31,400 \pm 480$ \\
\hline II, in burrow & Pta-4269 & $28,700 \pm 450$ \\
\hline II top & OxA-3975 & $33,920 \pm 690$ \\
\hline I base & OxA-3974 & $34,510 \pm 740$ \\
\hline I & Pta-4268 & $32,200 \pm 630$ \\
\hline I subsurface & Pta-4247 & $22,900 \pm 250$ \\
\hline & & \\
\hline & & \\
\hline
\end{tabular}

do agree; for the Kebara samples, the latter would be generally more reliable because the rejuvenation would be caused by carbon dioxide adsorbed from the atmosphere by "siliceous aggregates that are not eliminated during the ABA and $\mathrm{ABOx}$ pre-treatments and are present in relative higher concentration in the ABOx fractions" (p. 2429).

However, for a radiocarbon measurement in this age range to be rejuvenated to the extent seen in, for instance, the pair of subsamples from unit $\mathrm{V}$ sample R19V2 (OxA$\mathrm{V}-2253-46,45,200 \pm 700{ }^{14} \mathrm{C}$ BP, by ABA; OxA-X-2252-7, $36,300 \pm 650{ }^{14} \mathrm{C} \mathrm{BP}$, by $\left.\mathrm{ABOx}\right)$, the proportion of modern (e.g., 20 year-old), atmospheric-induced contamination remaining in the ABOx-ed subsample would have to be $0.73 \%$ (Fig. 3.7). This is under the assumption that the ABA result is accurate, but Rebollo et al.'s (2011) explanation implies that their ABA results are also affected by modern contamination, even if less so. As ABA dates in the range of $51.5 \mathrm{ka}{ }^{14} \mathrm{C}$ BP were obtained for unit $\mathrm{V}$, we can place at $\sim 0.15 \%$ the maximum level of modern contamination admissible for such dates because, even if a sample's true age is infinite, 52,250 is the oldest radiocarbon age measurement possible at that level (Fig. 3.8); or, put another way, because higher levels of modern contamination will result in dates younger than 52,250 even for samples of infinite age.
Given these constraints, let us postulate a general level of $0.10 \%$ modern contamination for the ABA subsamples and recalculate the contamination of the $\mathrm{ABOx}$ subsamples implied by the discrepancy seen in the pair of results obtained for unit V sample R19V2. The true age of this sample would then be 47,800 instead of the measured 45,200 , i.e., the $\mathrm{ABOx}$ result of 36,300 would be rejuvenated by 11,500 years instead of 8,900 , and the level of modern contamination implied would therefore be of $0.83 \%$ instead of $0.73 \%$. At these levels, the oldest radiocarbon age measurements possible are 38,510 and 39,541, respectively (Fig. 3.8), so postulating such general levels of contamination for the ABOx results is inconsistent with the ABOx date of 50,600 \pm 1600 ${ }^{14} \mathrm{C}$ BP (OxA-18803) obtained for unit V sample R19aV_4 (Table 3.2) even if the ABA dates are deemed exempt of any form of contamination.

If, instead, we take this 50,600 result as an indicator of the maximum extent to which the $\mathrm{ABOx}$ dates could have been affected by modern contamination, then the corresponding level is 0.18 \% (Fig. 3.8). Averaging Rebollo et al.'s (2011) validated ABA results for units III and IV would place them at $\sim 42,000$ and $\sim 42,625$, respectively. Therefore, if these $\mathrm{ABA}$ results are accurate and the ABOx-ed subsamples retained $0.18 \%$ of modern contaminating carbon, then the 
Table 3.2 The AMS radiocarbon dates on charcoal samples from Kebara published by Rebollo et al. (2011). The age measurements were carried out at the ORAU. The ABA results are on subsamples pretreated at the Weizmann Institute, the ABOx results are from a different set of untreated subsamples separately processed at the ORAU
${ }^{a}$ AMS measurement repeated for this sample as a standard procedure at ORAU

bSample pre-treated twice, and each fraction subjected to AMS measurement, as a standard quality control procedure at ORAU

\begin{tabular}{|c|c|c|c|c|c|c|c|c|}
\hline Sample number & Sample name & Square & Unit & Pre-treatment & $\begin{array}{l}\text { Weight loss \% } \\
\text { after } \\
\text { pre-treatment }\end{array}$ & $\% \mathrm{C}$ (combustion) & OxA & Date BP \\
\hline \multirow[t]{3}{*}{1} & \multirow[t]{3}{*}{ R16cIIIb_2 } & \multirow[t]{3}{*}{$\mathrm{R} 16 \mathrm{c}$} & \multirow[t]{3}{*}{$\mathrm{IIIb}$} & $\mathrm{ABA}$ & \multirow[t]{2}{*}{74.9} & 58.0 & V-2253-42 & $40,500 \pm 400$ \\
\hline & & & & & & 60.9 & $V-2253-43^{a}$ & $40,600 \pm 400$ \\
\hline & & & & $\mathrm{ABOx}-\mathrm{SC}$ & 95.4 & 72.1 & 18,458 & $41,050 \pm 450$ \\
\hline \multirow[t]{2}{*}{2} & \multirow[t]{2}{*}{ R17aIIIb,f } & \multirow[t]{2}{*}{$\mathrm{R} 17 \mathrm{a}$} & \multirow[t]{2}{*}{ IIIbf } & $\mathrm{ABA}$ & 53.9 & 57.0 & V-2220-42 & $42,600 \pm 500$ \\
\hline & & & & $\mathrm{ABOx}-\mathrm{SC}$ & 98.4 & 64.3 & 18,791 & $42,800 \pm 650$ \\
\hline \multirow[t]{2}{*}{3} & \multirow[t]{2}{*}{ R16cIIIb_1 } & \multirow[t]{2}{*}{$\mathrm{R} 16 \mathrm{c}$} & \multirow[t]{2}{*}{ IIIb } & ABA & 56.4 & 59.7 & $\mathrm{~V}-2220-41$ & $42,850 \pm 550$ \\
\hline & & & & $\mathrm{ABOx}-\mathrm{SC}$ & 94.3 & 49.3 & $\mathrm{X}-2222-32$ & $41,400 \pm 1,200$ \\
\hline 4 & R19aIV_1 & R19a & UP Channel & $\mathrm{ABA}$ & 68.0 & 55.7 & V-2220-43 & $34,540 \pm 250$ \\
\hline \multirow[t]{2}{*}{5} & \multirow[t]{2}{*}{ R17aIV } & \multirow[t]{2}{*}{$\mathrm{R} 17 \mathrm{a}$} & \multirow[t]{2}{*}{ IV } & $\mathrm{ABA}$ & 48.0 & 69.8 & V-2253-44 & $41,650 \pm 450$ \\
\hline & & & & $\mathrm{ABOx}-\mathrm{SC}$ & 84.7 & 67.7 & 18,459 & $40,400 \pm 400$ \\
\hline \multirow[t]{3}{*}{6} & \multirow[t]{3}{*}{ R19aIV_2 } & \multirow[t]{3}{*}{ R19a } & \multirow[t]{3}{*}{ IV } & $\mathrm{ABA}$ & 79.6 & 55.9 & V-2253-45 & $43,600 \pm 600$ \\
\hline & & & & $\mathrm{ABOx}-\mathrm{SC}$ & 95.7 & 29.5 & 18,402 & $40,300 \pm 550$ \\
\hline & & & & $\mathrm{ABOx}-\mathrm{SC}$ & 96.5 & 27.7 & $18,801^{\mathrm{b}}$ & $35,160 \pm 310$ \\
\hline \multirow[t]{2}{*}{7} & \multirow[t]{2}{*}{ R19aIV_4 } & \multirow[t]{2}{*}{ R19a } & \multirow[t]{2}{*}{ IV } & $\mathrm{ABA}$ & 77.0 & 46.7 & V-2269-35 & $36,110 \pm 330$ \\
\hline & & & & ABOx-SC & 97.4 & 10.6 & X-2264-29 & $40,500 \pm 1,200$ \\
\hline \multirow[t]{2}{*}{8} & \multirow[t]{2}{*}{$\mathrm{R} 19 \mathrm{aV} \_2$} & \multirow[t]{2}{*}{ R19a } & \multirow[t]{2}{*}{ V } & $\mathrm{ABA}$ & 77.9 & 53.8 & V-2253-46 & $45,200 \pm 700$ \\
\hline & & & & ABOx-SC & 94.9 & 13.3 & $X-2252-7$ & $36,300 \pm 650$ \\
\hline \multirow[t]{2}{*}{9} & \multirow[t]{2}{*}{$\mathrm{R} 15 \mathrm{cV}$} & \multirow[t]{2}{*}{$\mathrm{R} 15 \mathrm{c}$} & \multirow[t]{2}{*}{ V } & $\mathrm{ABA}$ & 70.3 & 62.3 & V-2267-43 & $46,250 \pm 650$ \\
\hline & & & & ABOx-SC & 89.3 & 51.7 & 18,792 & $44,800 \pm 650$ \\
\hline 10 & R19aV_4 & R19a & V & $\mathrm{ABA}$ & 77.0 & 55.6 & V-2267-45 & $49,600 \pm 1,000$ \\
\hline & & & & $\mathrm{ABOx}-\mathrm{SC}$ & 93.8 & 33.1 & 18,803 & $50,600 \pm 1,600$ \\
\hline 11 & $\mathrm{R} 19 \mathrm{cV}$ & $\mathrm{R} 19 \mathrm{c}$ & V & $\mathrm{ABA}$ & 88.6 & 56.6 & V-2267-46 & $51,500 \pm 1,200$ \\
\hline & & & & $\mathrm{ABOx}-\mathrm{SC}$ & 91.0 & 21.8 & 18,804 & $44,300 \pm 1,000$ \\
\hline
\end{tabular}

ABOx measurements for these units should have been $\sim 40,000$ (Fig. 3.8; specifically, 39,690 for unit III and $\sim 40,150$ for unit IV). This is in the range of what was actually measured, except for OxA-18801, an ABOx result of $35,160 \pm 310^{14} \mathrm{C}$ BP obtained for unit IV. For this particular result, $0.77 \%$ is the level of modern contamination implied if the real age of the sample was $\sim 42,000$ (Fig. 3.8) - about the same as that implied under comparable assumptions for the statistically identical ABOx result of $36,300 \pm 650{ }^{14} \mathrm{C} \mathrm{BP}$ (OxA-X-2252-7) for unit V (Fig. 3.7). Conversely, postulating a $0.18 \%$ level for OxA-18801 produces an age shift from 35,160 to only 36,380 , which keeps it fully within the Early Ahmarian age range implied by regional chronostratigraphy and clearly outside the range of the other $\mathrm{ABOx}$ resultsexactly as discussed above for OxA-X-2252-7.

From this exercise we can draw two conclusions. The first is that the discrepancy between the ABA and $\mathrm{ABOx}$ results cannot be explained by a lab-specific or protocol-specific contaminating factor acting upon the samples in a regular, consistent manner; clearly, the contamination problems are sample- or subsample-specific and, consequently, calculating a parameter that would enable us to estimate the extent to which each individual result deviates from the sample's real age is not possible. In these circumstances, the validity and archeological significance of the results can only be assessed against external criteria, namely those of stratigraphic consistency, not against the intrinsic chemical properties of the samples themselves, even when these meet pre-specified quality controls. The alternative approach is to sort out the "good" from the "bad" dates on the basis of inferred levels of modern contamination that would explain the anomalies. Such post-hoc assigning of the level of contamination that would bring the "bad young" result obtained for a given sample in line with the "good old" result expected would constitute, however, an evidently circular, and therefore invalid, argument.

The second conclusion is that many if not all of Rebollo et al.'s (2011) results are likely to correspond to minimum ages only. In fact, under their "atmospheric adsorption by siliceous aggregates" explanation and consequent admission that the ABA dates are also affected by the problem, a residual modern contamination level of $0.10 \%$ suffices to shift the 51,500 result for unit $\mathrm{V}$ to 59,000 (Fig. 3.7)-i.e., to beyond the ten half-lives accepted by the radiocarbon dating 


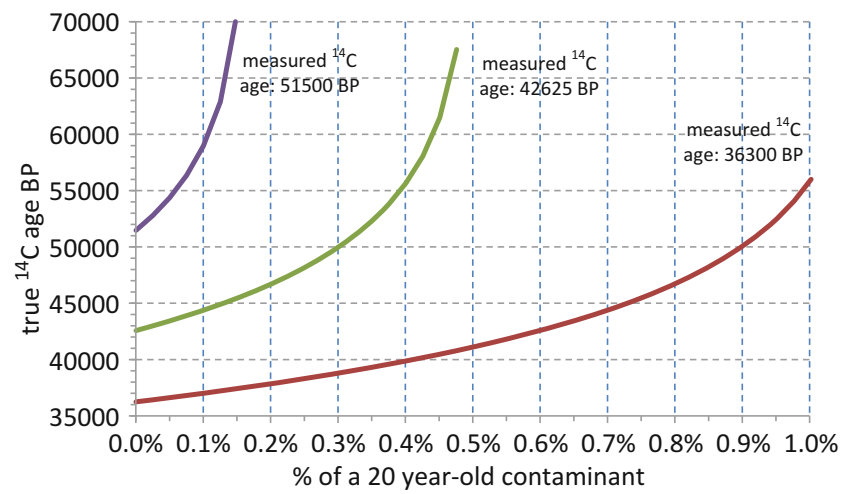

Fig. 3.7 The true age that samples radiocarbon-dated to 51,500, 42,625 and 36,300 BP would have if a low-level, atmospheric-induced (here modeled as 20-year old) contamination remained after pretreatment. For such dates to be returned with modern contamination levels above, respectively, $0.15 \%, 0.48 \%$ and $1.10 \%$, the samples would have to be of infinite radiocarbon age

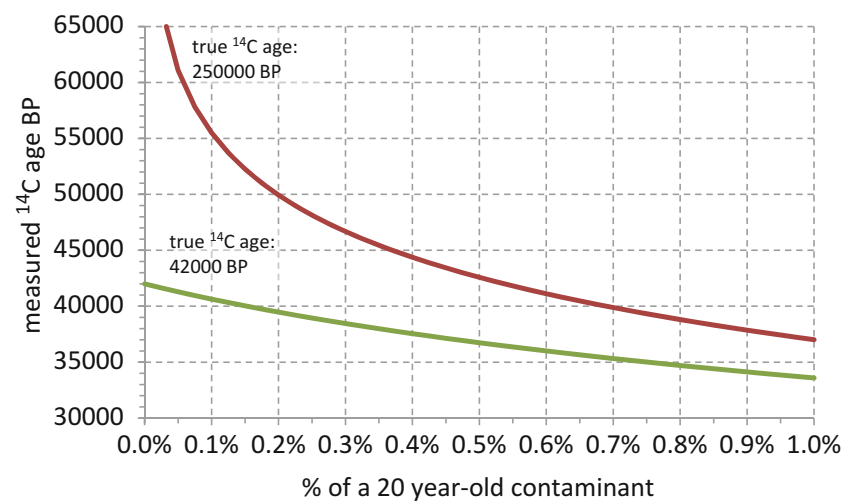

Fig. 3.8 The age measurements that would be obtained for a sample with a true radiocarbon age of $42,000 \mathrm{BP}$ and for a sample of infinite age (here modeled as 250,000 BP) if a low-level, atmospheric-induced contamination (here modeled as 20 -year old) remained after pre-treatment. The infinite age curve can also be read as returning the maximum age measurement possible for the given level of a sample's contamination by modern carbon

community as the practical limits of the method. This threshold is also crossed for the other ABA results of Rebollo et al. (2011) given a somewhat higher value of $0.40 \%$; but even the $0.10 \%$ level suffices to bring their ABA dates for units III, IV and $\mathrm{V}$ to an age range $\left(\geq 45,000{ }^{14} \mathrm{C} \mathrm{BP}\right.$, i.e., $\geq 48,000$ cal BP) that fully overlaps that determined by TL for underlying units VI and VII-48.3 $\pm 3.5 \mathrm{ka}$ and $51.9 \pm 3.5$ ka years ago, respectively (Valladas et al. 1987).

Given the contamination issues, it is thus entirely plausible that all of Rebollo et al.'s (2011) samples, including those collected in the Early Ahmarian levels, are in fact of Middle Paleolithic age. Indeed, the possibility that these levels contain inherited or intrusive charcoal was already implicit in the set of ABA dates published by Bar-Yosef et al. for unit III. Besides three infinite results, this set included three finite ones-43,500 $\pm 2,200 \mathrm{BP}(\mathrm{OxA}-3976)$,
$36,100 \pm 1,100 \mathrm{BP}(\mathrm{Pta}-4267)$, and 35,600 1 1,600 BP (OxA1567) (Table 3.1). Rebollo et al. (2011, Fig. 4A) accept their accuracy and combine them in a single phase to produce a Bayesian model putatively supporting the notion derived from their own results that the start date for this Early Ahmarian unit falls in the 46-49 ka cal BP range. However, despite the large standard deviations involved, the oldest of Bar-Yosef et al.'s finite results for unit III, which does fall in the same time range as those obtained by Rebollo et al. (2011), is clearly statistically distinct from the others; and, if two different populations of age measurements exist in a given stratigraphic unit, then, by definition, this unit cannot be modelled as a single occupation phase.

Modelling modern contamination as above and under assumptions that do not shift to radiocarbon infinity the older of Bar-Yosef et al.'s finite results for unit III, we see that, because of exponential decay, the corresponding impact is insufficient to change the younger ones. The averaged result of these younger results is $35.8 \mathrm{ka}{ }^{14} \mathrm{C} \mathrm{BP}$ and, for modern contamination values up to $0.65 \%$, the corresponding contamination curve runs broadly parallel to the 36,300 curve in Fig. 3.7; using this graph, it is therefore easy to obtain the true ages - 37,100 and 36,500, respectively - into which a 35,800 result would translate with contamination levels of 0.18 and $0.10 \%$. However, considering the associated uncertainty intervals, 35,800, 37,100 and 36,500 are in this case statistically the same radiocarbon age. Therefore, modelling such low levels of modern contamination is insufficient to impact the chronological significance of the Pta-4267 and OxA-1567 measurements, which is that they place the Early Ahmarian of Kebara in full contemporaneity with the Protoaurignacian of Europe; as can also be easily verified in Fig. 3.7, the level we have to model in order to bring these two results to the range of Rebollo et al.'s (2011), i.e., to $\sim 42$ $\mathrm{ka}^{14} \mathrm{C} \mathrm{BP}$, is $0.63 \%$. As a last resort, one could hypothesize that such a level pertained in the specific case of the samples from unit III; the hypothesis, however, would be inconsistent with the fact that seven out of the nine ABA dates obtained for it by both Bar-Yosef et al. and Rebollo et al. (2011; Tables 3.1 and 3.2) are older than the limit $-40.7 \mathrm{ka}{ }^{14} \mathrm{C}$ $\mathrm{BP}-$ beyond which finite age measurements become impossible with that level of contamination (Fig. 3.8).

To sum up, the impact of atmospheric-induced, modern contamination cannot provide an overarching explanation for the discrepancy between Rebollo et al.'s (2011) ABA and $\mathrm{ABOx}$ results. Depending on model assumptions, the levels of such contamination implied by the discrepancy would either bring all of their Early Ahmarian results into the range of those obtained by TL for the underlying Middle Paleolithic, or be insufficient to age in any significant manner those obtained by $\mathrm{ABOx}$ that fall in the $35-36 \mathrm{ka}{ }^{14} \mathrm{C} \mathrm{BP}$ range. Either way, another conclusion is inescapable: even though the artefacts in Kebara units III and IV are of Early Ahmarian 
affinities, a significant proportion of the charcoal therein is of an earlier, Middle Paleolithic age. This may seem counterintuitive at first glance, but is in fact supported by the site's geological study, to the implications of which I now turn.

\subsubsection{Implications of Site Formation Process for the Age of the Dated Carbon}

Under the premise that the valid ABA results for unit III are Bar-Yosef et al.'s Pta-4267 and OxA-1567 (35.6-36.1 ka ${ }^{14} \mathrm{C}$ BP, $\sim 40.0-41.5 \mathrm{ka}$ cal BP), two explanations are conceivable for the older results: they are accurate but reflect the true age of charcoal that, although recovered in units III and IV, is reworked from the Mousterian; or they are inaccurate and reflect some form of ancient (instead of modern) contamination, one resulting from the physical presence in the Early Ahmarian samples of charcoal (or burnt organic particles) of an earlier, Mousterian age, or from the chemical interaction between such components and the Early Ahmarian charcoal.

The site formation process described by the excavators for the accumulation of Kebara's Upper Paleolithic deposits supports the presence of Mousterian charcoal in units III and IV of the profile sampled by Rebollo et al. (2011): “... the onset of the collapse and subsequent filling of the cave (...) into the Upper Paleolithic took place during relatively wetter conditions" as demonstrated "not only by the constant finely laminated nature of these deposits, which were placed by low energy sheetflow, but also by the presence of diatoms, which indicate a wet substrate in the cave in the Upper Paleolithic layers" (Goldberg et al. 2007, p. 86). These layers were laid down over a slope formed as a result of erosion and subsidence processes that, in this part of the cave, deformed the surface of the Middle Paleolithic deposit prior to (and continuing throughout) the accumulation of the Upper Paleolithic layers. For water-saturated material, such a configuration implies instability; until an equilibrium is reached, the sediments will flow like a fluid, entailing the redeposition along the slope of material derived from higher up, i.e., in this case, from Middle Paleolithic units located toward the entrance of the cave (Figs. 3.9 and 3.10). As these Middle Paleolithic units are made up of ashy and organic-rich burned material, the formation process of the Early Ahmarian units from the area of the cave that was sampled for radiocarbon dating implies that abundant amounts of inherited charcoal and carbon-rich soil particles of Middle Paleolithic age must exist therein.

The implications of this inference are obvious, but it must be borne in mind that in and of itself the inference I am making here is nothing new; it is a restatement of Goldberg et al.'s (2007) unambiguous description of the Upper Paleolithic deposits of Kebara: "Inside the cave they grade laterally to thinly bedded silt- and sand-sized aggregates composed of reworked Middle Paleolithic hearths, ashes,
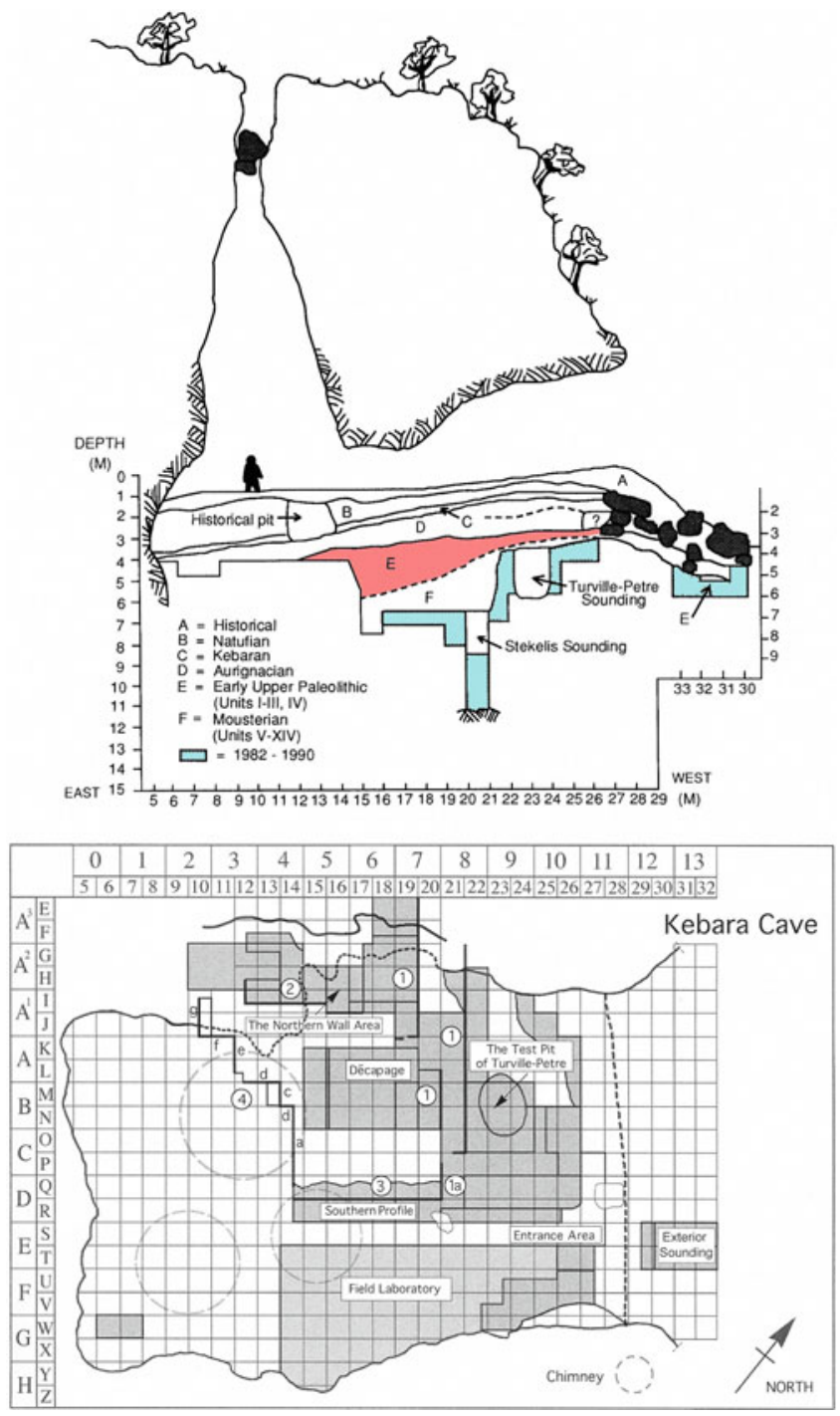

Fig. 3.9 Kebara. Bottom: Site plan with indication of the grid (the $2 \times 2 \mathrm{~m}$ units are from Stekelis' $1951-1965$ excavations, the $1 \times 1 \mathrm{~m}$ units are from the 1980s work; courtesy Kebara Archive, modified) and of the excavated areas and their designation ( 1 western sector; $1 a$ west profile composite; 2 northern sector and kitchen area; 3 south sector and composite profile; 4 eastern sector and composite profile). Top: Schematic cross-section of the site, with indication of the main stratigraphic blocks (courtesy Kebara Archive, modified); when viewed in two dimensions, the Early Ahmarian deposit has a wedge shape reflecting a formation process primarily involving the accumulation against the back wall of reworked Middle Paleolithic sediments derived from the entrance; however, interspersed within the deposit, there are several in situ partial hearths (black charcoal and white ashy layers; cf. Fig. 3.10), often cut by erosion processes (mostly sheet flow spreading the ashy components)

and other Mousterian sediments that were eroded after the major phase of subsidence" (p. 50); "the composition of these deposits indicates that they are largely a mixture of reworked burned materials and some terra rossa, much of which was derived from upslope to the west" (p. 73).

Some of Rebollo et al.'s (2011) samples are reported to come from the in situ hearth features found interspersed 
Fig. 3.10 Kebara. Columns 14-18 of the south profile along mid-row R of the 1990s grid, after the 2006 sample collection season (courtesy Kebara Archive, modified), with indication of the position of samples 1-3, 5 and 9 of Rebollo et al. (2011) and of the major stratigraphic units (the letter "C" indicates a channel cut into units III-V and filled with Upper Paleolithic materials); note that, according to Goldberg et al. (2007), the sedimentary matrix of units III and IV includes reworked burnt and phosphatized material, derived from Middle Paleolithic levels located at higher elevation elsewhere in the cave

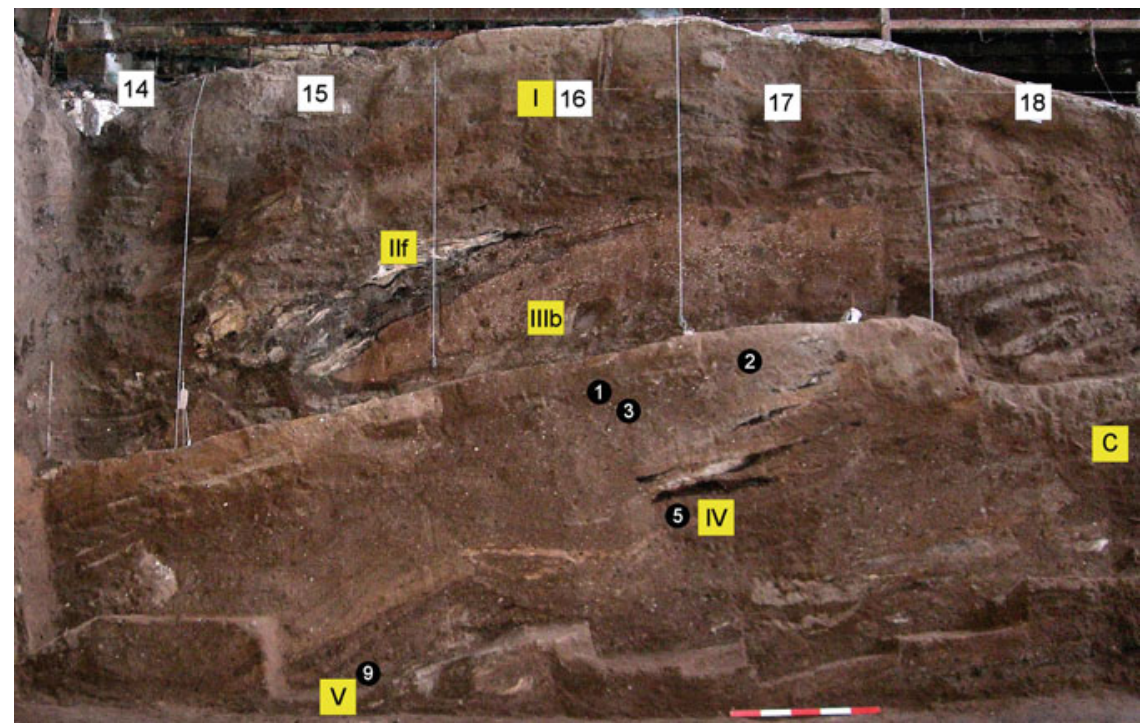

within units III and IV. This is not the case, however, with all of them: "Collection of charcoal samples for this study was conducted during the 2006 excavation season, and was primarily limited to hearth areas which we considered to be well-defined intact contexts" (p. 2426, my emphasis). Also, of the 23 samples obtained, only 11 were eventually found to be suitable for dating, and only three of them (two from unit III and one from unit IV) are piece-plotted. Since the specific information is missing from Rebollo et al.'s (2011) provenience table, it is unclear whether the samples from units III and IV that ended up being dated are among those collected in the hearths. The projection over the south profile of the two that were both dated and piece-plotted (samples 1 and 3; cf. Fig. 3.10, where the information is taken from Rebollo et al. 2011, Fig. 2) suggests not. And, of those that were not piece-plotted, only sample 2 can be assumed to be among those collected in a hearth feature, given its "IIIbf" labeling (where "f" stands for the French word foyer, or hearth).

The important point, however, is that, in the case of Kebara units III and IV, the likelihood that a sample is of Mousterian age (or contaminated by carbon of that age) is not necessarily smaller simply because it was collected in a hearth context. The hearths in those units are not constructed, namely, they do not correspond to basins with a fill entirely made up of material combusted after the excavation of the basin itself. Instead, they correspond to areas where the fuel was burnt directly on the ground surface and, therefore, ones where the sediments bearing the distinctive characteristics of in situ fire activity include material present in the preexisting, surface-exposed deposits. Additionally, it must be borne in mind that not all of the dated samples were individual charcoal pieces: "when several pieces had to be pooled in order to obtain the minimal necessary weight (around $100 \mathrm{mg}$ ) it was known from field observations that the charcoal fragments were all derived from one depositional unit" (Rebollo et al. 2011, p. 2426).

Given the presence of reworked charcoal in the sediments upon which the in situ hearths were fired and the composite nature of at least some of the dated samples, it is clear that their physical contamination with charcoal or charred organic material of Middle Paleolithic age is more than a distinct possibility. The discrepancies in the results obtained by Rebollo et al. (2011) for subsamples of the same sample when using ABOx instead of ABA (and, in the case of R19aIV_2, even for two separately processed ABOx dates; Table 3.2) suggest, however, that the problems go beyond the physical displacement of charcoal fragments, especially in the light of the micromorphological observations reported by Goldberg et al. (2007, p. 86): "Ensembles A and B [in the south profile, units Ia to V-upper, including Early Ahmarian units III and IV] in the interior commonly contain crudely bedded aggregates and masses of reddish silty clay. In addition, however, they commonly contain charcoal and, more importantly, finely comminuted pieces of charred organic matter that are incorporated into the matrix." Because of their small size, these particles cannot be removed by mechanical methods prior to chemical pre-treatment. At Kebara, what is returned as a date is therefore the percent ${ }^{14} \mathrm{C}$ content of the carbon extracted from samples that contain inherited organic matter particles; consequently, whether such carbon is entirely endogenous to the wood burnt in the firing event whose age one intends to measure is clearly an open issue. This is implicit in Rebollo et al.'s (2011) rejection of 12 of the 23 samples originally collected on the grounds that the weight loss undergone at the end of the ABA pre-treatment-a quality indicator for charcoal samples-was too high. However, weight loss was still quite significant even for those 11 samples that were considered 


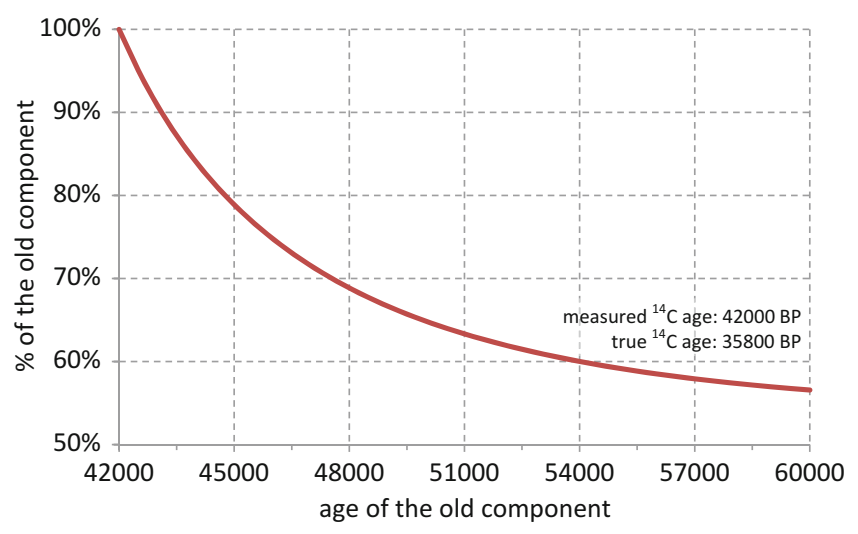

Fig. 3.11 The impact of ancient contamination in the dating of the Kebara charcoal samples. A sample with a radiocarbon age of 35,800 years will return a 42,000 result if $62.7 \%$ of the carbon in it derives from a source with a radiocarbon age of 51,500 . Higher

reliable-between 48.0 and $79.6 \%(65.0 \pm 12.5 \%)$ for the six samples from units III and IV (Table 3.2).

In this respect, note that, as illustrated in Fig. 3.11, a sample with a true radiocarbon age of 35,800 years (the average of Pta4267 and OxA-1567) can indeed yield an age measurement of 42,000 (the average of Rebollo et al.'s (2011) three ABA measurements for unit III) if $62.7 \%$ of the carbon in it has a radiocarbon age of 51,500 years (Rebollo et al.'s (2011) ABA date for Middle Paleolithic unit V). Because of exponential decay and the half-life of radiocarbon, increasing the age of the contaminant does not much change the amount required for the shift, which has to be at least $53.8 \%$ even if the contaminant is of infinite radiocarbon age. In theory, these values could explain Rebollo et al.'s (2011) results if we reversed their argument concerning the reliability of $\mathrm{ABOx}$ versus $\mathrm{ABA}$.

For instance, in the case of samples R19aIV_2 (unit IV) and R19aV_2 (unit V), ABOx-dated to $\sim 35-36 \mathrm{ka}{ }^{14} \mathrm{C} \mathrm{BP}$ (Table 3.2), let us assume that only ABOx was capable of removing all contaminants, including old ones; the $\mathrm{ABA}$ results for those samples $\left(\sim 43-45 \mathrm{ka}{ }^{14} \mathrm{C} \mathrm{BP}\right.$; Table 3.2) would then be explained by 77.2-81.8\% of 50,000 year-old carbon remaining in the corresponding subsamples after pretreatment. This reasoning implies that unit V sample R19aV_2 is of Upper Paleolithic age, but that Upper Paleolithic charcoal could be present in unit V is implicit in Rebollo et al.'s (2011, p. 2431) acknowledgment that it "contains mostly a Late Mousterian assemblage with less than $10 \%$ of small tool types (including a few bladelets) traditionally attributed to UP. This intrusion is possibly due to trampling and vertical penetration through minicracks observed in the fine clay terra rossa, sediments that originated from the entrance of the cave." Where the Middle Paleolithic deposits of the south profile, from where Rebollo et al.'s (2011) samples come, are specifically concerned, such intrusions are explicitly mentioned by Goldberg et al. (2007, p. 55): "some layers in uppermost part contain Upper Paleolithic material." percentages will be required for $<50,000$ year-old contaminants, while a 42,000 result for a 35,800 sample requires at least $53.8 \%$ of exogenous carbon even if the contaminants are of infinite radiocarbon age

The proportions of older carbon required by this "chemical" contamination scenario are, however, unrealistic. They are also so high that, for all practical purposes, such a scenario cannot be distinguished from that of "physical" contamination-of the deposits or, in the case of the composite samples, of the samples themselves. In any case, whichever the cause, the problems with the Kebara samples clearly preclude the use of Bayesian modeling, which requires certainty about the accuracy of both the results and their time ordering. That cannot be the case at Kebara, where (a) introducing the possibility that the ABA results are modern-contaminated, even if only quite moderately, implies that the entire set could be made up of infinite ages, and (b) introducing the possibility that only $\mathrm{ABOx}$ managed to remove all contaminants, both modern and ancient (and, even so, not always), implies that only two of Rebollo et al.'s (2011) results are consistent with site stratigraphy and regional chronostratigraphy (and, for one, only if the sample is interpreted as displaced).

\subsubsection{An Alternative Interpretation of the Kebara Dates}

The only other conceivable approach is to follow the argument that the ABOx results are somehow unreliable, perhaps for reasons related to the experimental phase during which they were produced, and remove contamination from the discussion by accepting that ABA worked well with the Kebara samples - as suggested by the fact that all of Rebollo et al.'s (2011) such samples have \% C on combustion values between 46.7 and 69.8 (Table 3.2). In doing so, however, we also need to consider the ABA results of Bar-Yosef et al., and there is then no escaping the conclusion that two populations of radiocarbon dates exist in the Upper Paleolithic levels of Kebara (Fig. 3.12): one at $\sim 35.8 \mathrm{ka}{ }^{14} \mathrm{C} \mathrm{BP}$ $(\sim 41.0 \mathrm{ka}$ cal BP$)$, and another at $\sim 42.0 \mathrm{ka}{ }^{14} \mathrm{C} \mathrm{BP}(\sim 45.4 \mathrm{cal}$ $\mathrm{BP})$. Which of these two sets relates to the Early Ahmarian is something that, against the site's dating background, can 


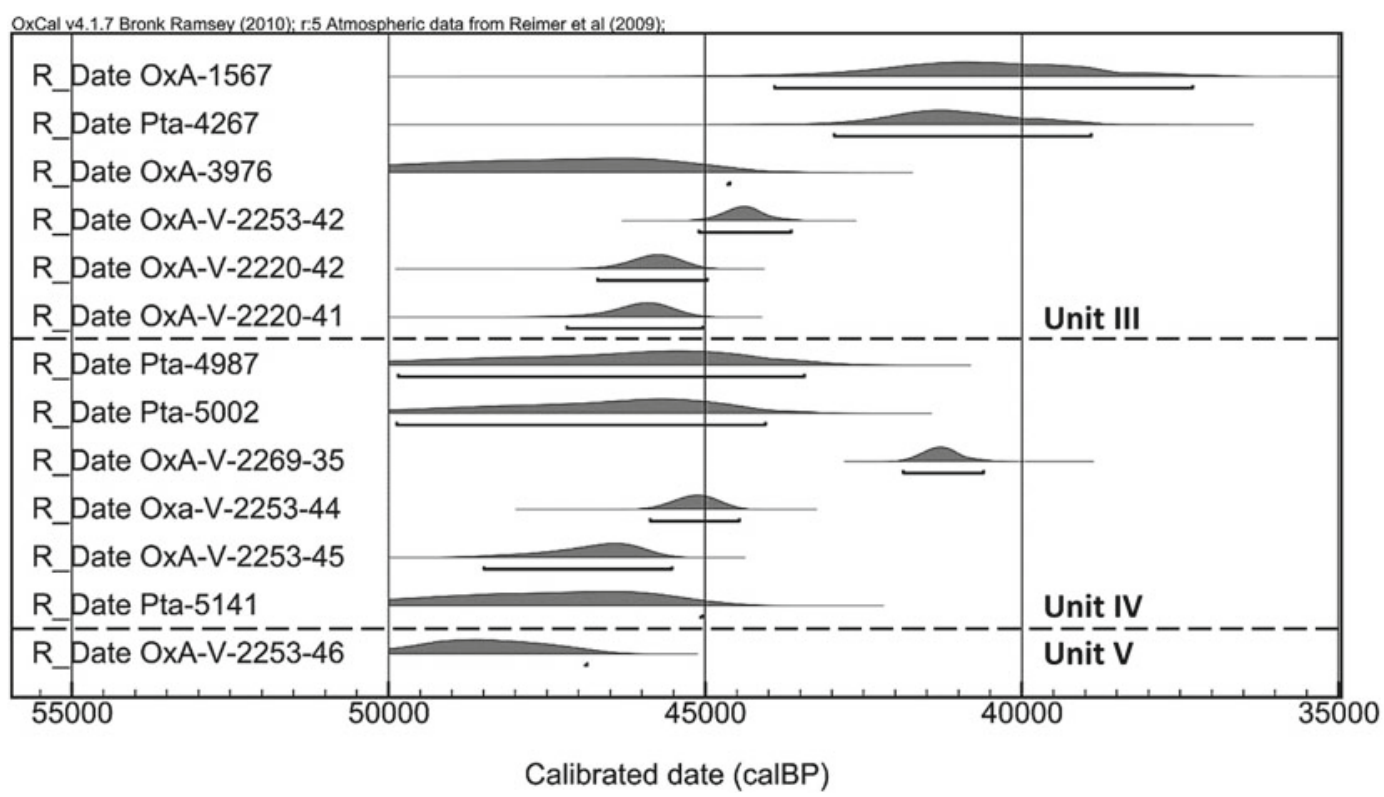

Fig. 3.12 Calibrated ages, calculated with OxCal 4.1 (Bronk Ramsey 2009) and IntCal09 (Reimer et al. 2009), of the finite ABA charcoal dates reported by Bar-Yosef et al. (1996) and Rebollo et al. (2011) for units III, IV and V of Kebara. At least two populations of dates are apparent. Based on regional chronostratigraphy, the Early Ahmarian in Units III-IV must be of the age indicated by the younger set of results; the older must reflect either the impact of contamination by ancient carbon or, most likely, the presence of an inherited charcoal component only be decided on the basis of external consistency with regional patterns; and the set satisfying this criterion is the younger, not the older one.

Therefore, the corollary of validating all the ABA results for units III and IV is that, under Goldberg et al.'s (2007) rendition of the site's stratigraphy, the set of older dates must be a reflection of the presence in those units of inherited or intrusive Middle Paleolithic charcoal. Additionally, it remains conceivable that unit IV is a palimpsest where a hitherto unrecognized IUP/Emiran component is present alongside the Early Ahmarian, a possibility raised by BarYosef et al.'s (1996, p. 304) remark that "the presence of a few Emireh points in Kebara (...) may indicate that this tool type, despite being considered the marker of the Transitional Industry (...), occurred in late Mousterian assemblages, derived from a disturbed Emiran layer to be found elsewhere in the chamber of Kebara, or that it lasted longer than the earliest Upper Paleolithic phase."

\subsubsection{Protoaurignacian}

Validating all of the ABA dates for Kebara and interpreting them in the framework of regional chronostratigraphy implies an age for the site's Early Ahmarian falling in the same time interval as that of the Protoaurignacian, thereby removing any rationale for making the emergence of the latter significantly earlier in the eastern part of its range. Where the western part is concerned, however, Hublin et al. (2012a) argue that the age recently obtained for the Protoaurignacian of Isturitz supports their claim that the
Châtelperronian of the Grotte du Renne, St.-Césaire and Les Cottés overlaps in time with the earliest evidence for modern humans in central and southern France.

This claim is unsupported, as shown by Banks et al.'s (2013) Bayesian modeling of the chronology of the Protoaurignacian. The oldest of the lower limits of these authors' $95.4 \%$ confidence intervals for Isturitz's modeled cal $\mathrm{BP}$ results is 41,840 , and the corresponding youngest upper limit is 40,078; both are fully consistent with the 39.9$41.5 \mathrm{ka}$ cal BP range modeled for the entire technocomplex. The same applies to Les Cottés, dates for which have since been published (Talamo et al. 2012). At this site, not only does the Protoaurignacian overlie the Châtelperronian, it is also separated from it by a $12 \mathrm{~cm}$-thick sterile layer. This stratigraphic pattern should suffice to refute the notion that the two technocomplexes overlapped in time in this region of central France, but the dating results leave no doubt that no such overlap exists. In radiocarbon years BP, the six results obtained for the Protoaurignacian place it after $35,250 \pm 280$, while the six obtained for the Châtelperronian place it between $37,400 \pm 500$ and 42,410 \pm 400 . In calendar years, these Les Cottés results place the site's Protoaurignacian in the younger part of Banks et al.'s (2013) 39.9-41.5 ka cal BP interval for this culture as a whole, and the site's Châtelperronian in full contemporaneity with the $\sim 41-45 \mathrm{ka}$ cal BP interval obtained for the Grotte du Renne by Hublin et al. (2012a).

Additional Protoaurignacian results have now also been published for two Mediterranean sites, the Abric Romaní in Catalonia (Camps and Higham 2012; Vaquero and Carbonell 2012) and the Riparo Mocchi, in northern Italy (Douka et al. 2012). In both cases, the results fall well within the expected 
39.9-41.5 ka cal BP interval and, where the Catalonian site is concerned, confirm Zilhão and d'Errico's (1999) interpretation of the previously available dates for level A, namely concerning the presence of a later, Gravettian component alongside that related to the Protoaurignacian.

\subsubsection{Early Aurignacian}

\subsubsection{Geissenklösterle}

Based on a large series of AMS radiocarbon dates for the stratigraphic sequence of the Geissenklösterle cave site, Conard and Bolus (2003) placed at $\sim 40,000$ radiocarbon years ago, significantly earlier than everywhere else in Europe, the beginnings of the Aurignacian in the Swabian Jura region of southwest Germany. Zilhão and d'Errico (2003) questioned this conclusion, arguing that:

(a) The site's Aurignacian sequence was a palimpsest of a number of occupations by both humans and cave bears, the latter being the most abundant taxon in the fauna from the corresponding levels (30.7 \% by weight) (Münzel and Conard 2004, Table 1).

(b) Hahn's (1988) grouping of the Aurignacian deposits into only two "Archeological Horizons" (AH) was a useful data presentation tool but should not be misconstrued as real, observed stratigraphic units or as representing human occupation in only two moments of time.

(c) Given the slow sedimentation rate $(\sim 7.5 \mathrm{~cm} /$ millennium but, considering the volumetric weight of the artifactual and faunal components, much less in fact), coupled with cave bear activity and deformation of the deposits by periglacial phenomena (e.g., cryoturbation), significant post-depositional disturbance was probable and indeed confirmed by stone tool refitting.

(d) The numerous stratigraphic anomalies and the scatter apparent in the large set of radiocarbon dates then available primarily reflected this formation process.

(e) Such anomalies implied that not all dates obtained for a given level could be taken as accurately reflecting the age of the artifact assemblages therein, which themselves did not necessarily correspond to chronologically homogeneous assemblages.

(f) When only the dates on anthropically modified bones were considered, it was clear that the earliest Aurignacian occupation of this site did not predate $\sim 36.5 \mathrm{ka}{ }^{14} \mathrm{C} \mathrm{BP}$ and probably had taken place between 35 and $33 \mathrm{ka}{ }^{14} \mathrm{C}$ BP.

Based on a new set of 24 results obtained on ultrafiltered bone samples (Table 3.3), which show that many of the anomalies in the previously available corpus of dates derive from incomplete decontamination, Higham et al. (2012) concluded, however, that Conard and Bolus' (2003) original contention was supported: in the Swabian Jura, the Early Aurignacian would indeed have appeared very early, around
42,500 cal BP in fact. If correct, the implications of this conclusion are threefold:

(a) The Early Aurignacian or Aurignacian I and the Protoaurignacian would not be chronological phases of the Aurignacian technocomplex, with the former evolving out of the latter, but different cultures altogether.

(b) As the beginnings of the Early Aurignacian in different regions would seemingly extend over a considerable timespan, the lags would have to represent the difference between its time of emergence at a point of origin in Central Europe and the time of subsequent dispersals to other parts of the continent.

(c) The notion that the Protoaurignacian is a continent-wide stratigraphic marker and the earliest archeological culture of Europe with which modern humans can be associated would become untenable; not only would modern humans have spread into Europe much earlier than hitherto thought but they would also have done so via a number of different routes and under a diverse range of cultural guises.

Assessing the validity of these implications requires assessing the validity of the Bayesian model of the radiocarbon results upon which hangs the chronology proposed by Higham et al. for the Early Aurignacian of the Geissenklösterle. That model is based upon acceptance of Hahn's archeological horizons as a valid analytical framework for the discussion of the site's dating. As pointed out by Zilhão and d'Errico (2003, p. 75), this is erroneous and a fundamental flaw of Higham et al.'s study.

\section{Are the "Archeological Horizons" Valid Bayesian Phases?}

When items have the analytical significance of singular manifestations of a certain category of finds whose occurrence is common (e.g., when assessing the stratigraphic distribution of thick scrapers/cores), the archeological horizons framework applies regardless of moderate post-depositional disturbance and/or potential mixing. Hahn (1988) had estimated that about $7 \%$ of the items in each horizon were displaced. In such a context, recovering five thick scrapers/cores in AH-II means that this artifact type was being discarded at the site during the time interval represented in that horizon, even though a certain probability exists that any of them, individually considered, could be an item displaced from AH-III, where 44 were recovered (data from Teyssandier 2003).

However, when items have meaning in and of themselves, as in the case of single bone fragments sampled for AMS radiocarbon dating, site formation processes such as those in operation at the Geissenklösterle imply that the archeological horizons framework is inappropriate. This is because dates on such samples represent the time of death of a single animal whose association with the artifacts found alongside has to be 
Table 3.3 AMS radiocarbon dates on ultrafiltered bone samples from the Geissenklösterle published by Higham et al. (2012)

\begin{tabular}{|c|c|c|c|c|c|}
\hline Sample name & Level & $\mathrm{AH}$ & OxA & Date BP & Species and material dated \\
\hline GK 99 Ir 185 & $\mathrm{I}-\mathrm{r}$ & I & 21,740 & $26,420 \pm 230$ & Ursus spelaeus parietal cranium with cutmarks? \\
\hline GK 130 It 328 & $\mathrm{I}-\mathrm{t}$ & I & 21,660 & $27,960 \pm 290$ & Mammuthus primigenius rib, impact marks \\
\hline GK 26 Ia 18 & $\mathrm{I}-\mathrm{a}$ & I & 21,739 & $28,600 \pm 290$ & Mammuthus primigenius rib (?) cutmarked \\
\hline GK 86 Ic 122 & $\mathrm{I}-\mathrm{c}$ & I & 21,661 & $32,900 \pm 450$ & Rangifer tarandus, metacarpal, impact mark \\
\hline GK 33 IIa 80 & II-a & II & 21,737 & $35,700 \pm 650$ & cf. Rangifer tarandus \\
\hline GK IIa 131 & II-a & II & 21,656 & $33,000 \pm 500$ & Equus ferus, scapula \\
\hline GK 58 IIb 246 & II-b & II & 21,724 & $33,950 \pm 550$ & Mammuthus primigenius rib fragment with impact point \\
\hline GK 57 IIb 706 & II-b & II & 21,727 & $34,100 \pm 550$ & Ursus spelaeus, rib fragment, with a cutmark \\
\hline GK 67 IIb 931 & II-b & II & 21,742 & $34,800 \pm 600$ & Equus ferus, humerus \\
\hline GK IIb 143 & II-b & II & 21,738 & $34,900 \pm 600$ & Equus ferus, humerus (retoucher marks inferred) \\
\hline GK 55 IId 319 & II-d & III & 21,726 & $34,200 \pm 550$ & Equus ferus, humerus (retoucher) \\
\hline GK 77 III 627 & III & III & 21,659 & $35,050 \pm 600$ & Rangifer tarandus, tibia, impact mark \\
\hline GK 77 III 641 & III & III & 21,744 & $36,850 \pm 750$ & Coelodonta antiquitatus humerus no cutmarks \\
\hline GK 86 III 294 & III & III & 21,725 & $37,400 \pm 800$ & $\begin{array}{l}\text { Large unidentified mammal rib fragment (cf Coelodonta } \\
\text { antiquitatus/Mammuthus primigenius) }\end{array}$ \\
\hline GK 66 III 1144 & III & III & 21,722 & $38,900 \pm 1,000$ & Equus ferus, distal femur \\
\hline GK 66 IIIa 1073 & III-a & III & 21,745 & $36,650 \pm 750$ & Rangifer tarandus, tibia, impact marks \\
\hline GK 67 IIIa 1453 & III-a & III & 21,746 & $36,850 \pm 800$ & Rangifer tarandus, tibia with cutmarks \\
\hline GK 67 IIIb 1655 & III-b & III & 21,743 & $36,100 \pm 700$ & Rangifer tarandus, tibia with impact and cutmarks \\
\hline GK 69 IIIb 958 & III-b & III & 21,723 & $37,800 \pm 900$ & Artiodactyl limb bone fragment \\
\hline GK 57 IIIb 1238 & III-b & III & 21,721 & $37,300 \pm 800$ & $\begin{array}{l}\text { cf. Coelodonta antiquitatus/Mammuthus primigenius bone } \\
\text { fragment with scrape marks, i.e., humanly modified bone. }\end{array}$ \\
\hline GK 57 IIIc 2389 & III-c & III & 21,658 & $38,300 \pm 900$ & Capra ibex, left tibia, no human modification \\
\hline GK 57 IIIc 2430 & III-c & III & 21,657 & $39,400 \pm 1,100$ & Cervus elaphus, tibia, no human modification \\
\hline GK 78 IV 1495 & IV & IV & 21,720 & $35,500 \pm 650$ & cf. Ursus spelaeus juvenile shaft fragment. Possible impact. \\
\hline GK 48 VII 456 & VII & VII & 21,741 & $48,600 \pm 3,200$ & $\begin{array}{l}\text { Capra ibex, phalanx I, which articulates with metataurus. No clear } \\
\text { cutmarks although two are inferred. }\end{array}$ \\
\hline
\end{tabular}

AH denotes "Archeological Horizon"

treated, if post-depositional disturbance is significant, as an open issue. In that case, the correct approach is to assess the samples independently of their context and as representing a separate category of stratigraphic information, one where time ordering comes from their intrinsic properties (their radiocarbon ages), not from their extrinsic ones (their strata of provenience or their putative archeological associations).

Higham et al. disagree with Zilhão and d'Errico's (2003) position on the grounds that subsequent excavation and stone tool refitting work suggested that Hahn's (1988) estimates of stratigraphic disturbance were exaggerated. They argue that this new work, coupled with micromorphological analysis (Conard et al. 2006), showed that the apparent disturbance pattern diagnosed by Hahn is caused by the fuzziness of level boundaries, and consequent "excavation error," rather than by the vertical displacement of objects.

To suggest that post-depositional disturbance is not a significant issue in the case of a $\sim 50 \mathrm{~cm}$-thick sequence accumulated in a periglacial environment, over some ten millennia, and under the impact of continued human or cave bear activity, is unrealistic to begin with. In fact, it is also contradicted by refitting, which documents numerous interlevel links, often scattered across the entire sequence-not just across the boundaries of adjacent levels, as the excavation error model implies. Hahn's (1988) data already showed that more refits existed between the levels grouped to form his upper Aurignacian horizon AH-II (II-n, II-a and II-b) and those forming his lower Aurignacian horizon AH-III (II-d, III, III-a and III-b) than within AH-II itself. Teyssandier's (2003) re-analysis of the primary data, while illustrating a number of cases where post-depositional displacement is limited, also provided several instances of the opposite case, namely the detailed, telltale example of the A1 refitting unit (a block of high-quality, easily recognizable red radiolarite), whose 44 elements are spread over $14 \mathrm{~m}^{2}$ and all the way from II-a at the top of the sequence to III-a at its base (Table 3.4). The only conclusion that can be drawn from this refitting work is, therefore, that the interface between levels II-b and II-d cannot be used as a discrete boundary separating an "upper" from a "lower" Aurignacian. In order to understand what has gone on at the site, the distributions of significant items have to be seen relative to each other and across the entire sequence taken as a single, continuous analytical framework (Fig. 3.13).

More importantly, Higham et al.'s excavation error argument is an obvious non-sequitur. Regardless of whether 
Table 3.4 Horizontal and vertical distribution of the individual items in Geissenklösterle refitting unit A1 (Teyssandier 2003: Table 11)

\begin{tabular}{|c|c|c|c|c|c|c|c|c|}
\hline \multirow[b]{2}{*}{ Square } & \multicolumn{7}{|c|}{ Archeological level } & \multirow[b]{2}{*}{ Total } \\
\hline & IIIa & III & IId & IIb & IIa & II? & ind. & \\
\hline 15 & - & 1 & - & - & - & - & - & 1 \\
\hline 25 & - & - & - & 1 & - & - & - & 1 \\
\hline 26 & - & - & - & 1 & 1 & - & - & 2 \\
\hline 37 & - & 2 & - & 1 & - & 4 & - & 7 \\
\hline 38 & - & 4 & 2 & 2 & - & - & - & 8 \\
\hline 45 & - & - & - & 1 & 1 & - & - & 2 \\
\hline 47 & - & 1 & 1 & 1 & - & - & - & 3 \\
\hline 48 & - & 3 & 2 & 1 & - & - & - & 6 \\
\hline 49 & - & 1 & - & - & - & 1 & - & 2 \\
\hline 56 & 2 & - & 2 & 1 & - & - & - & 5 \\
\hline 57 & 1 & - & - & - & - & - & - & 1 \\
\hline 58 & - & - & 1 & - & - & - & - & 1 \\
\hline 59 & - & 1 & - & - & - & - & - & 1 \\
\hline 66 & 1 & 1 & - & - & - & - & - & 2 \\
\hline ind. & - & - & 1 & - & & - & 1 & 2 \\
\hline Total & 4 & 14 & 9 & 9 & 2 & 5 & 1 & 44 \\
\hline
\end{tabular}

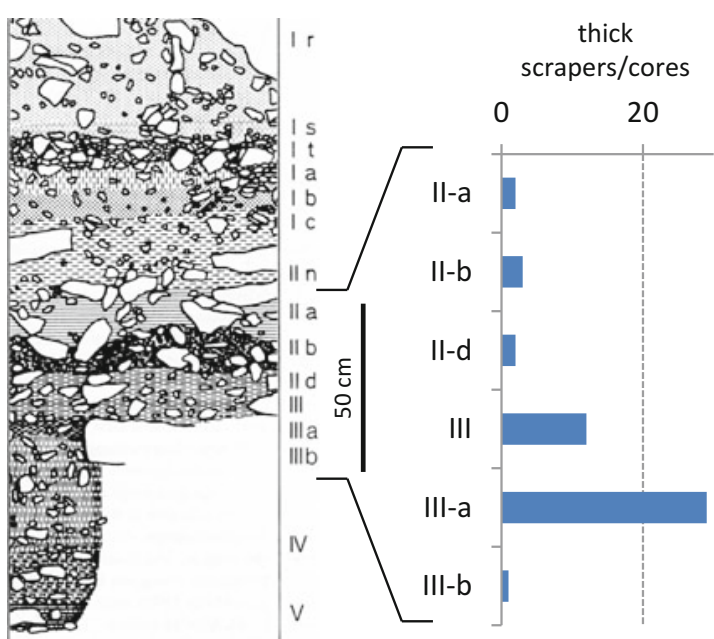

Fig. 3.13 Geissenklösterle. Vertical distribution of finds diagnostic of the Aurignacian I, of mobiliary art items, and of musical instruments across the levels assigned to the Aurignacian by Hahn (1988; data from Teyssandier 2003 and Teyssandier and Liolios 2003). Note that Higham

assignment of a given item to a level other than that where it originally lay results from natural (disturbance) or human (error) agency, the implication is the same-if the agent is observed to have had a significant impact, reasoning by association is of limited value and, in the best of cases, needs to be qualified. Additionally, while correctly pointing out that excavation error implies that the finds assigned to each of Hahn's fine stratigraphic subdivisions cannot be taken as closed assemblages, Higham et al. fail to consider that boundary fuzziness must also imply that Hahn's two archeological horizons, or even the Aurignacian package as a whole, cannot be taken as closed assemblages either: whether beads,

bands and

bracelets figurines flutes

$0 \quad 200 \quad 100 \quad 10$

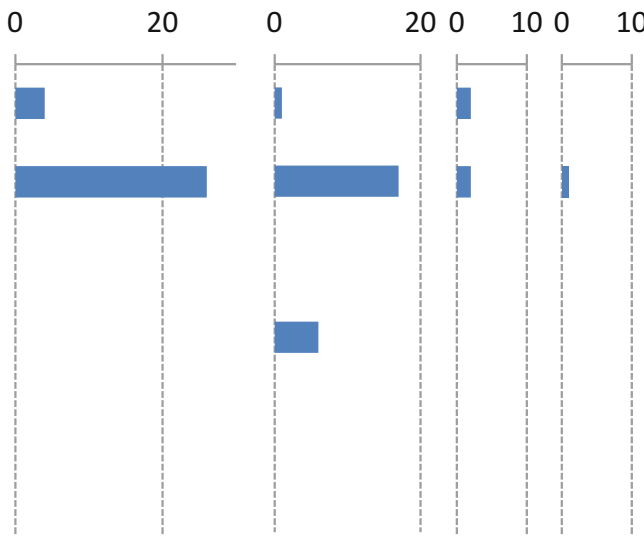

et al. (2012) claim a very early age for the site's Aurignacian I based on samples from Archeological Horizon III but that split-based bone points, the index fossil of the Aurignacian I, were only present in levels (II-a and II-b) assigned to the site's Archeological Horizon II above

by disturbance or error, stratigraphic misplacement of finds is a problem that must then concern not only the subdivisions within the Aurignacian but also the divisions between the Aurignacian and adjacent units, on one hand, and Hahn's Aurignacian horizons I and II, on the other.

In such a context, for instance, there is no reason to assume that an item recovered in III-b, at the base of AH-III, is more likely to be contemporaneous with an item from II-d, at the top of AH-III but separated from III-b by the $\sim 15 \mathrm{~cm}$ of deposits forming levels III and III-a, than with an item from immediately underlying level III-c. In short, for dating, excavation error has the same implication as post-depositional 
Table 3.5 Results of a sample significance test (Ward and Wilson 1978, Case 1) carried out with Calib 6.1 (Stuiver and Reimer 1993) on the samples grouped under the AH-II and AH-III phases of Higham et al.'s (2012) Bayesian model

\begin{tabular}{lllcl}
\hline Phase & Test statistic $t$ & $\chi^{2}(0.05)$ & Degrees of freedom & $\begin{array}{l}\text { Significantly distinct at the } 95.4 \% \\
\text { level }\end{array}$ \\
\hline AH-II & 13.60796 & 11.1 & 5 & Yes \\
\hline AH-III & 45.16257 & 19.7 & 11 & Yes \\
\hline
\end{tabular}

disturbance: it precludes the discretization of the deposits into phases, making Higham et al.'s Bayesian model logically invalid, and implies that the distribution of the dated samples must be treated as a stratigraphic continuum, in much the same way as that of the bone and stone tool index fossils.

\section{Vertical Distribution of Index Fossils and Dating Samples}

The material cultural categories found at the site that are representative of the Aurignacian I as known from a large number of well-stratified localities from southwestern France (namely, the rock-shelters of Pataud and Castanet; Higham et al. 2011d; White et al. 2012) are: split-based bone/antler points; ivory beads, bands and bracelets; and thick scrapers/ cores. The distributions of such items by level (Fig. 3.13) show that they were recovered between II-b and III-a, with a trickle of finds spilling over to II-a above and III-b below; elements of clustering also exist, ones whose explanation likely relates to spatial patterning in both human activity and postdepositional disturbance. These distributions also indicate that the four sculpted figurines and the flute from levels II-a and II-b belong to a post-Aurignacian I occupation of the site, as one might suspect on the basis of the radiocarbon dates associated with similar material at the neighboring sites of Hohle Fels, Vogelherd and Hohlenstein-Stadel (Zilhão 2007).

It is only against this background that meaning can be assigned to Higham et al.'s new radiocarbon dates, as otherwise indicated by the observation that the results included in each of the Aurignacian phases (AH-III and AH-II) of their Bayesian model are statistically distinct ones (Table 3.5). Given the evidence for a number of different human and animal occupation episodes to be represented within each of those phases, this is hardly surprising; if the archeology indicates that the assemblages are chronologically heterogeneous, it is to be expected that their sampling for dating will eventually return heterogeneous results. The really important point to bear in mind, however, is that seven out of the twelve results obtained for the levels that yielded the diagnostic finds (II-b to III-b) fall fully in, or significantly overlap with, the time range of the Aurignacian I-the 39.8-37.9 ka cal BP interval, based on the European-wide database of radiocarbon results analyzed by Banks et al. (2013) (Fig. 3.14).

Of the 24 samples dated by Higham et al., only 15 are of anthropically modified bone. Of these, four are qualified as possible, inferred or questionable, and only eight are on taxa that we can safely assume to have been hunted (horse, reindeer and ibex). This point is important because the anthropically modified samples of wooly rhino and mammoth may reflect subfossil (i.e., radiometrically older) rawmaterial collected as site furniture or for the manufacture of bone/ivory tools, an activity that, as Higham et al. emphasize, was very important in AH-III. The same conceivably applies to the modified cave bear samples, although these could also reflect episodic interaction with the carnivores owning the site at times when humans were infrequent in the landscape; even in that case, however, they would by definition be indicative of intervals during which no artifacts related to human residence were discarded in the cave.

Bearing this in mind, let us take the bone samples that are secure indicators of contemporaneous human activity as proxies for the time of occupation, regardless of stratigraphic provenience and putative artifact associations but assuming the accuracy of the results obtained for them. When this is done (Fig. 3.15), we obtain a very clear pattern, one that, although somewhat blurred by the potential sources of noise, is already apparent in the overall plot: at the time of the Middle-to-Upper Paleolithic transition, human activity at the Geissenklösterle occurred in three distinct time intervals, first $\sim 41.5 \mathrm{ka}$, then $\sim 40.0 \mathrm{ka}$, and finally $\sim 37.5 \mathrm{ka}$ cal BP (an earlier Mousterian occupation of level VII is documented by a possibly cut-marked ibex bone dated to beyond the reach of current calibration tools and, consequently, not represented in Fig. 3.14).

Interestingly, this restricted set of results is in full stratigraphic order: the three samples documenting the intermediate episode come from levels II-d, II-b and III, the sample documenting the younger episode comes from level I-c above, and the three samples documenting the older episode come from levels III-a and III-b below. This pattern shows that, despite the disturbance, the Geissenklösterle sequence preserves the original stratigraphic structure to a considerable extent. Within limits, it can thus be used to assess issues of dating and diachronic change, but only in terms of the relative stratigraphy of individual find categories or type fossils (e.g., their order of appearance, or their frequency change through time). Assigning an absolute age to the points in the sequence where one can see phenomena of emergence or change, however, requires an external referent, which, in this case, can only be the European-wide chronostratigraphy of the Aurignacian. 


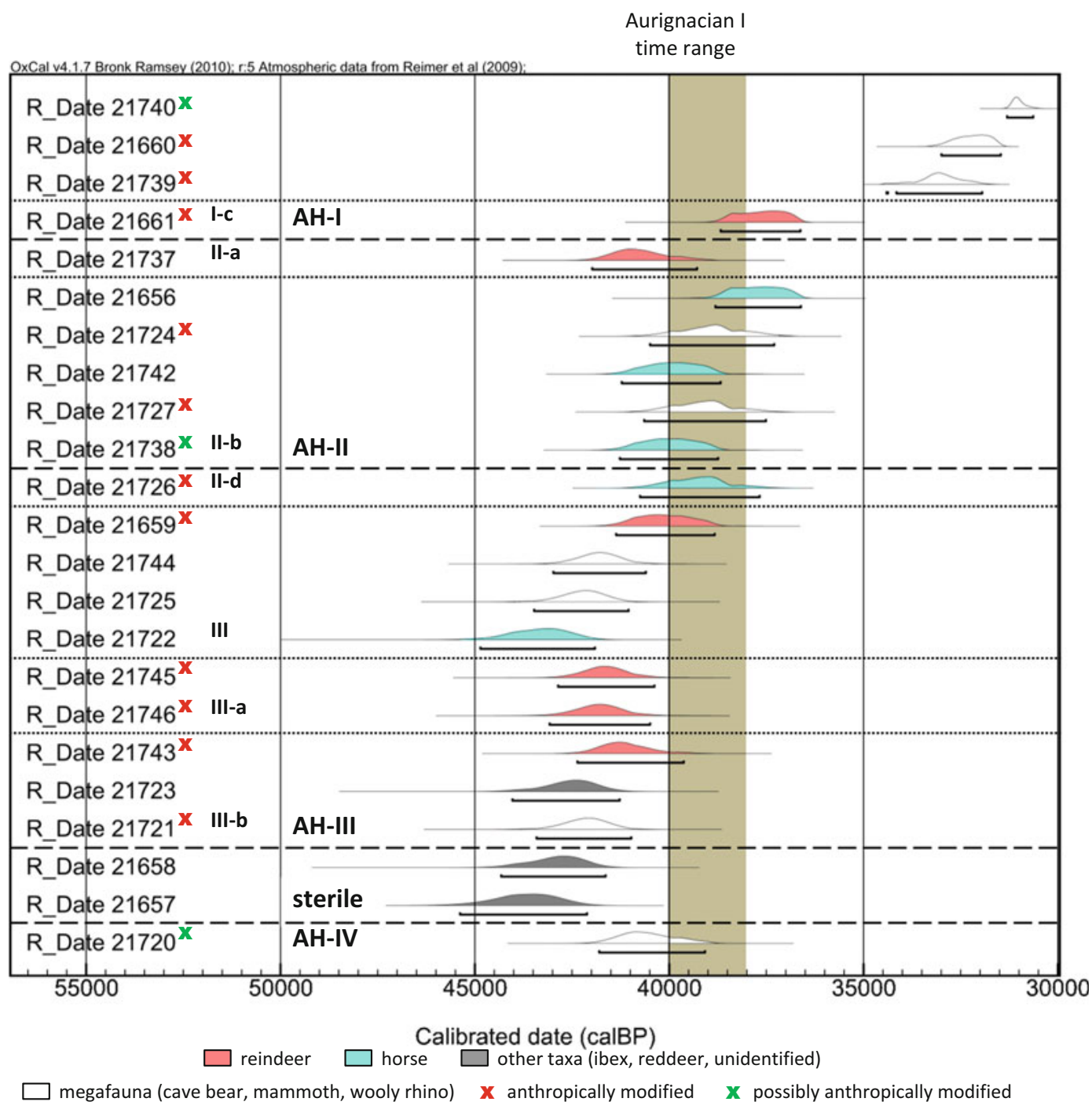

Fig. 3.14 Calibrated ages, calculated with OxCal 4.1 (Bronk Ramsey 2009) and IntCal09 (Reimer et al. 2009), for the ultrafiltered bone dates reported by Higham et al. 2012 for the Geissenklösterle. The result for

\section{An Alternative Interpretation of the Geissenklösterle Stratigraphy}

In this framework, there can be little question that the intermediate and younger of the three episodes indicated by the set of anthropically modified horse and reindeer bone samples are local manifestations of the Aurignacian I and Aurignacian II, respectively. Where the younger episode is concerned, this conclusion is further strengthened by the recent identification of diagnostic Roc-de-Combe bladelets among the small finds from sieving (Moreau 2009, 2012). The remaining issue is how to interpret the older episode.

On the basis of the presence of a significant number of thick scrapers/cores in one of the levels (III-a) where the corresponding samples come from, we could conclude, alongside Higham et al., that the older, $41.5 \mathrm{ka}$ cal BP episode is also related to the Aurignacian I. If so, one would have to an ibex bone with inferred cutmarks from level VII falls outside the calibration curve and is not plotted

concur with them that the Aurignacian I emerged in the Swabian Jura earlier than elsewhere in Europe (even if only by one and a half instead of two and a half millennia), and, hence, that it should be assigned the status of a distinct culture instead of a chronological phase. However, such a culturally separate manifestation of modern human immigration would still be no earlier than that represented by the Protoaurignacian. Therefore, even such an interpretative scenario would represent no challenge to the time horizon $\left(\sim 36.5 \mathrm{ka}{ }^{14} \mathrm{C} \mathrm{BP}\right.$, $\sim 41.5$ ka cal BP) postulated by Zilhão and d'Errico (1999) for the dispersal of modern humans into Europe.

However, another explanation can be proposed that is consistent with both the evidence from the site and continentwide chronostratigraphic patterns and, therefore, ought to be considered the parsimonious alternative. Considering excavation error and post-depositional displacement, it is quite 


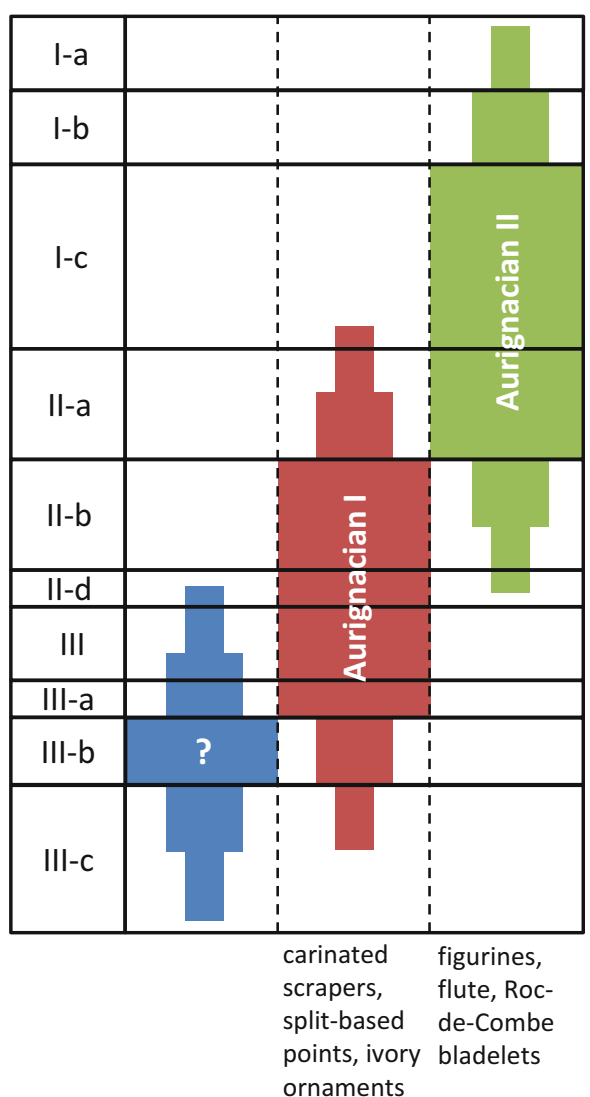

Fig. 3.15 Geissenklösterle. An alternative reading of the stratigraphy: instead of Higham et al.'s two well delimited phases, based on Hahn's (1988) less rigid concept of two horizons, at least three periods of occupation with fuzzy boundaries are proposed; level II-b is considered to belong in the Aurignacian I and, following Moreau $(2009,2010)$, level I-c subsumes level II-n and is considered to be part of the Aurignacian sequence. A three-period pattern is also apparent when considering only the samples from game taxa (horse

possible that, of the three anthropically modified reindeer samples that were dated to $\sim 41.5 \mathrm{ka}$ cal BP, the two labeled III-a were originally laid down with the material recovered in III-b, from where comes the other sample. That this is entirely conceivable is supported by two lines of evidence: firstly, statistically identical results were obtained for another two samples from III-b (Fig. 3.14); secondly, III-a is a very thin, $\sim 5 \mathrm{~cm}$-thick lens of material, where, given the general issue of boundary fuzziness, incorrect assignment and vertical displacement (even of very limited scope) would be even more of a problem than at other points in the sequence.

If the $\sim 41.5 \mathrm{ka}$ cal BP human occupation of the Geissenklösterle does not relate to the Aurignacian I, where do its cultural affinities lie? Based on the then available results, Zilhão and d'Errico (2003) had proposed the same three-phase model revealed by proper interpretation of the new ones, and suggested two possibilities for the earlier

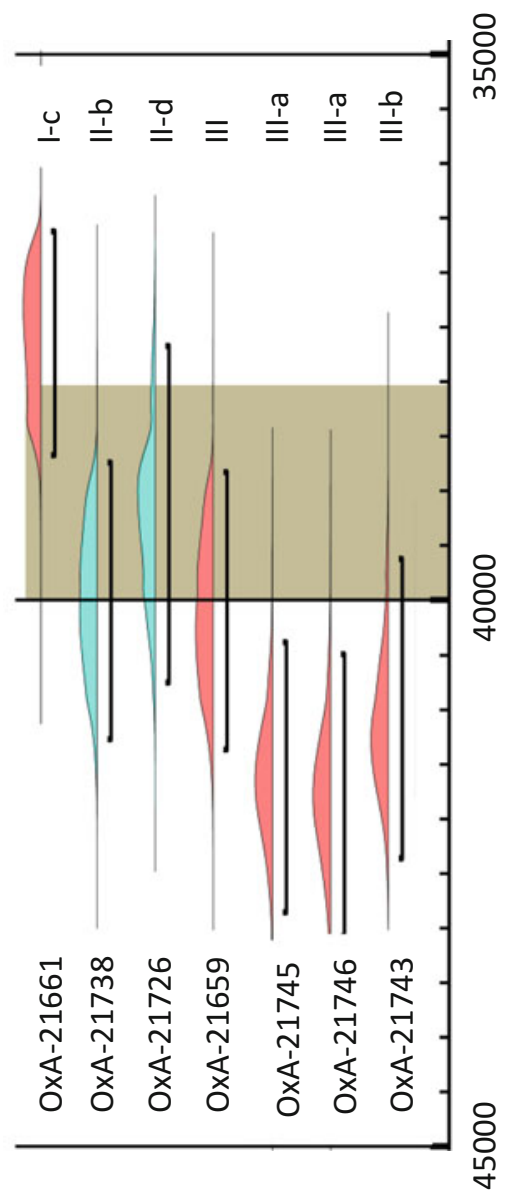

and reindeer) with possible or secure anthropic modification. The relative thickness of the stratigraphic subdivisions in the model is derived from the published profiles. The dating evidence, given in cal BP years, consists of the results obtained on samples of anthropically modified game taxa, extracted from Fig. 3.14 (with the same sample color codes, and with the same time band to indicate the chronostratigraphic slot of the Aurignacian I)

phase. The first was that of a short-lived, logistical expedition by Protoaurignacian people leaving behind no diagnostic tools (or ones that remain to be identified among the excavation's unsorted water-sieved sediments; cf. Moreau 2009, 2010, 2012) - a possibility suggested by the contemporaneous presence of such people further downstream, in the middle and lower Danube basin (e.g., at KremsHundsteig, in Austria, or Tincova, in Romania). The second possibility was that of an expedition of a similar kind but related to the Altmühlian and reflecting the activity of the latest Neandertal inhabitants of the region. The alternative remained undecided for Zilhão and d'Errico (2003), and recent work has not changed our understanding of level III-b, which only yielded four retouched tools: a carinated scraper/ core related to the overlying Aurignacian I, and three that are undiagnostic (two blades with use wear and a truncated blade; Teyssandier and Liolios 2003). Therefore, the prudent 
approach continues to be that of treating the cultural affinities of the $\sim 41.5 \mathrm{ka}$ cal $\mathrm{BP}$ human occupation of the Geissenklösterle as an open issue.

A corollary of the evidence reviewed above is that Hahn's (1988) organization of the Aurignacian stratigraphy of the Geissenklösterle into two archeological horizons has outlived its usefulness. For the future, grouping the different layers recognized during excavation along the lines of the three phase model suggested here (cf. Fig. 3.15) seems to be a more promising way of making progress in sorting out the different issues of association raised by the site's late Middle and early Upper Paleolithic levels. Provided, of course, that the continuous rather than discrete nature of the distributions and the relative rather than absolute nature of the boundaries between level groupings are duly considered in the process.

Further support to this contention comes from the fact that level I-c should be assigned to the Aurignacian instead of the Gravettian, given Moreau's (2009, pp. 195-210; 2010) convincing arguments to that effect: sedimentological continuity with the very poor Aurignacian level II-n below (cf. Fig. 3.13); raw-material economy, namely the preference for Bohnerzhornstein over radiolarite among retouched tools, as in the site's AH-II Aurignacian horizon and the reverse of the Gravettian pattern; typology, namely the dominance of scrapers over burins and the presence of typical nosed scrapers; technology, namely the fact that bladelet tool blanks were extracted from "burin"-type cores; and refitting, namely of a burin from I-c with two burin spalls from II-b. Except for a microgravette fragment made of radiolarite and deemed to be intrusive from the overlying Gravettian, the kinds of backed microliths present in I-c also exist in the AH-II Aurignacian horizon, where they are found in association with characteristic Dufour bladelets made of the same Bohnerzhornstein. Such a co-occurrence of bladelets trimmed in both Dufour and backing fashion is documented in Evolved and especially Later Aurignacian (Aurignacian III-IV) contexts from elsewhere in Europe (e.g., at the Portuguese site of Pego do Diabo; Zilhão et al. 2010b; see also Pesesse 2008, 2010). This evidence indicates that the affinities of level I-c lie indeed with the Aurignacian, in agreement with the $32,900 \pm 450{ }^{14} \mathrm{C} \mathrm{BP}$ result obtained for this level by Higham et al., which falls fully within the time range of the Aurignacian II.

\subsubsection{Willendorf II}

The other Central European site where a precocious occurrence of the Aurignacian I has been claimed is Willendorf II, in Austria. As most recently argued by Nigst and Haesaerts (2012), assignment of layer 3 of this locality to the Early Aurignacian would be supported by technological analysis of a hitherto undescribed set of hundreds of lithic artifacts from the early twentieth-century excavations. At the same time, two AMS dates in the $\sim 38-39 \mathrm{ka}{ }^{14} \mathrm{C}$ BP range would indicate that the previously available conventional date in the $\sim 34 \mathrm{ka}{ }^{14} \mathrm{C} \mathrm{BP}$ range is an underestimate of the level's true age. Finally, refitting work would support the integrity of the level, i.e., a stratigraphical and functional relationship between the lithics and the dated charcoal, closing the case for the Aurignacian I to be five millennia older in Lower Austria than anywhere else in Europe.

That diagnostic material of clear Aurignacian affinitiesnamely, carinated and nosed scrapers/cores-is present in layer 3 of Willendorf II has also been suggested by others (e.g., Hahn 1977; Teyssandier 2003) and will not be disputed here. There is also no reason to question the accuracy of the new AMS radiocarbon dating results. The leap of faith made by Nigst and Haesaerts (2012) is to infer from this evidence that layer 3 is chronologically homogeneous and that all of the lithics recovered therein relate to the Aurignacian I and to the charcoal pieces dated to $\sim 38-39 \mathrm{ka}{ }^{14} \mathrm{C} \mathrm{BP}$. However, that is not necessarily the case.

The small assemblage of formal retouched tools (35 in total) in layer 3 includes not only five carinated and four nosed scrapers/cores but also two sidescrapers and 12 "laterally retouched blanks" among which, from the illustrations supplied, a number could also correspond to sidescraper fragments. If at all present, sidescrapers, however, are a rare occurrence in Aurignacian I assemblages. For instance, none exist in either the AH-II or AH-III horizons of the Geissenklösterle, and very few in the reference sequence of the Abri Pataud, France (layers 9-14; Table 3.6), where they are absent from most levels and represent, in total, $0.47 \%$ of the formal tools, contra a minimum of $5.71 \%$ in layer 3 of Willendorf II. With present evidence, it is therefore conceivable that at least two different components are present in this layer, one of which is of Mousterian or Upper Paleolithic but pre-Aurignacian (e.g., Szeletian, Altmühlian or Bohunician) affinities, and that the radiocarbon dates are all accurate and reflect this cultural heterogeneity.

This possibility is contradicted neither by the fact that refits could be carried out in the collection from the old excavations, nor by eventual refits to be obtained in the future between material in that collection and material from the new excavations being carried out at the site since 2006 (Nigst et al. 2008). In a classic paper whose key points are all too often overlooked, Bordes (1980) discussed the applicability, and limits, of refitting for the assessment of issues of contemporaneity within potentially heterogeneous assemblages. To illustrate the point, Bordes provided an example from near the Billabong station in Western Australia: "Tools undoubtedly belonging to the base of layer 2 of the local sequence, uncovered by deflation and dating from the beginning of our era, and fragments of motorbikes, cars, etc., are scattered on the same surface. No doubt that, with patience, it would be possible to refit aboriginal flakes between them, and car fragments between them. Yet, 2,000 years separate the two 
Table 3.6 The relative frequency of sidescrapers in the Aurignacian I levels of the AbriPataud (data from Chiotti 1999)

\begin{tabular}{lcll}
\hline Layer & Total tools & Sidescrapers & $\%$ \\
\hline 9 and $9 / 10$ & 27 & - & - \\
\hline 10 & 59 & - & - \\
\hline 11 & 976 & 8 & 0.82 \\
\hline 12 & 387 & 1 & 0.26 \\
\hline 13 & 83 & - & - \\
\hline 14 & 177 & 9 & - \\
\hline TOTAL & 1,923 & & 0.47 \\
\hline
\end{tabular}

series." A similar time span could well be represented in layer 3 of Willendorf II, with the sidescrapers representing displaced material from an earlier period and the blade production refits and carinated cores representing a later one.

Even if the stone tool assemblage is eventually shown to be homogeneous and Aurignacian, the case for the occurrence to be a precocious one would still require demonstration of two additional points: firstly, that the age of all of the associated charcoal is indeed $\sim 38-39 \mathrm{ka}{ }^{14} \mathrm{C} \mathrm{BP}$; secondly, that such charcoal is functionally related to the stone tools instead of representing an inherited component of the deposit. Where this latter point is concerned, I have laid out in a preceding section the case for the presence of a significant inherited component to be the most likely explanation for the very old dates obtained for samples from the Early Ahmarian levels of Kebara. I had previously made a similar case for the Austrian site: "At Willendorf II, Austria, the evidence comes from level 3, which yielded a small assemblage of artifacts in secondary position sitting on an eroded surface that yielded soliflucted charcoal dated to ca. $43 \mathrm{kyr}$ cal BP. However, as recently acknowledged by the site's researchers, 'dating small charcoal fragments dispersed in soliflucted layers must be avoided' because of the 'lateral supply of older charcoal fragments.' Such a supply clearly explains the anomalous results, which simply provide a terminus post quem for the lithics, the affinities of which lie with the Aurignacian I" (Zilhão 2006a, p. 187). Nigst and Haeserts (2012, p. 598) have misunderstood this argument as one for the layer 3 charcoal to represent material displaced from underlying units. The potential problem, however, is one of lateral (not vertical) supply of older material, i.e., a mechanism of progradation whereby, downslope, a level formed subsequent to the occurrence of an erosional truncation will inevitably be a palimpsest mixing new sediment inputs (e.g., windblown loess) with components derived by gravity or solifluction from pre-existing, upslope deposits.

From the published descriptions and illustrations of the geometry of layer 3 of Willendorf II (e.g., Nigst et al. 2008, Fig. 5), there can be little doubt that the archeology therein is not in primary position (as otherwise indicated by the absence of features such as hearths), and that the impact of progradation processes on the association between lithics and charcoal must be duly considered in its interpretation. In such circumstances, the apparent, anomalously early age of the lithics of Early Aurignacian affinities from layer 3 of Willendorf II must be treated as just that: an anomaly for which no definitive explanation exists at present but upon which it would be foolhardy to hang any model of population dispersal or replacement at the time of the Middle-to-Upper Paleolithic transition in Central Europe.

\subsection{Discussion}

The preceding discussion of the key sites and finds can be briefly summarized as follows:

(a) The deposit containing the St.-Césaire partial skeleton also yielded Middle Paleolithic artifacts and its genesis was complex, but direct dating rejects assignment of the skeleton to the Mousterian and stratigraphic context precludes assigning it to the Protoaurignacian. Association of the fossil with the diagnostic Châtelperronian lithics found alongside remains the parsimonious reading of the evidence. At the Grotte du Renne, a Neandertal authorship of the Châtelperronian (including, in this case, abundant, evidently symbolic material culture) is also supported by the associated human fossils, while spatial distributions and radiocarbon dating corroborate the largely intact nature of the stratigraphic sequence.

(b) Given sample size and the documented overlaps in dental anatomy between late Neandertals and early modern humans, the nature of the Kent's Cavern and Cavallo fossils is an open issue, as is their true age, so the Oase 1 mandible and Oase 2 cranium remain Europe's oldest modern humans. Oase 1 is directly dated to $\sim 40 \mathrm{ka}$ cal BP, with the associated uncertainty implying assignment to either the Protoaurignacian or the Aurignacian I. Speculations to the effect that the Uluzzian and the coeval, so-called transitional Upper Paleolithic cultures of Europe, including the Châtelperronian, could have been the work of modern humans, are unsupported.

(c) Boundary fuzziness, post-depositional displacement of finds and palimpsest formation preclude the discretization of the Geissenklösterle sequence into Bayesian phases and command that only anthropically modified samples of game taxa be used as proxies for human 
activity at the site. When this is done, there is no disagreement between the age of the levels that yielded finds diagnostic of the Aurignacian I and the chronology of the latter everywhere else in Europe. A precocious presence of Aurignacian I modern humans in Central Europe is not supported by layer 3 of Willendorf II either, as this layer is in secondary position and potentially heterogeneous in terms of both its stone tool and charcoal components.

(d) The source of Europe's first modern human immigrants is agreed to lie in western Asia and the Early Ahmarian. Claims for an emergence of the latter prior to 46,000 calendar years ago are based on the dating of samples from Kebara that reflect the presence of inherited Middle Paleolithic charcoal in the Early Ahmarian strata. A second population of age measurements from the same stratigraphic units dates the technocomplex to some five millennia later on, at about the same time as the Protoaurignacian and in agreement with regional chronostratigraphic patterns.

(e) As documented by the dates obtained for Les Cottés and Grotte du Renne, the Châtelperronian emerged in central and northern France at least four millennia before the Protoaurignacian is first documented in regions to the south. Given the association with large numbers of ornaments, bone tools and pigments, and this from its very beginnings in level X of the Grotte du Renne, the emergence of the Châtelperronian cannot possibly be the reflection of an immediate cultural influence exerted by (non-existent) early modern human neighbors, and must result instead from the action of cultural processes indigenous to the Neandertal populations of western Europe.

The archeological and radiometric dating evidence accumulated over the last 15 years therefore fails to reject the chronological model put forward by d'Errico et al. (1998) and Zilhão and d'Errico (1999). This new evidence remains entirely consistent with the notion that, in Europe, the onset of the processes of population interaction that led to the eventual assimilation of the Neandertals broadly coincides with the emergence of the Protoaurignacian $\sim 36.5 \mathrm{ka}^{14} \mathrm{C} \mathrm{BP}$ ( $41.5 \mathrm{ka}$ cal BP). Consequently, no reason exists to question the corresponding implication that Neandertals were the makers of the material manifestations of symbolic or artistic behavior seen in the archeological record of the continent prior to that date.

A first corollary of these chronological patterns is that symbolism and "anatomical modernity" cannot be construed as causally related (d'Errico 2003; Zilhão 2006a, 2007; Conard 2008). This was to be expected, given the paleontological and genetics evidence for significant admixture and, therefore, species sameness, between Neandertals and early moderns. It is also something that should have been realized ever since ornaments were uncovered in the Aterian culture of North Africa, which, in this time range ( 100 ka BP), was inhabited by people who, while not Neandertal, were not fully anatomically modern either-as apparent, namely, in the cranial, mandibular and dental anatomy of the Dar-es-Soltan fossils (Klein 1992; Wolpoff 2002; Trinkaus 2005; Bouzouggar et al. 2007; Bouzouggar and Barton 2012; Hublin et al. 2012b).

A second corollary is that, given the limited temporal resolution of stratigraphic sequences and the relatively poor precision of the radiometric techniques that can be applied to the dating of sites and fossils from this time range, the "Who Made What" question for the material culture of the couple of millennia bracketing the $\sim 36.5{ }^{14} \mathrm{C} / 41.5 \mathrm{cal} \mathrm{ka} \mathrm{BP}$ interval, even if relevant, may not be answerable. In fact, that Assimilation occurred implies processes of gene flow and population dispersal (of which the Assimilation process probably represents no more than a step-up in frequency and intensification) that must have been in operation before, even if at a smaller scale. If so, then cultural exchange and diffusion hitch-hiking such biological interaction and operating in both directions must also have been in place well before the crossing of the critical threshold, that is, well before the replacement of the Neandertal by the early modern human phenotype became visibly and unambiguously apparent in the human paleontological record of western Eurasia.

In the context of these chronological patterns, it is useful to elaborate on the potential implications of the cave art dating results recently obtained by Pike et al. (2012) with the U-series method. That Neandertals are likely to be the makers of the red disks from the Panel of Hands at El Castillo (Fig. 3.16) follows from the fact that one such disk is covered by calcite dated to $40.8-42.0 \mathrm{ka}$ (95.4\% probability interval), while the corresponding calendar age interval for the Oase 1 mandible is 38.8-42.0 ka, and Banks et al.'s (2013) modeled calendar range for the earliest conceivable archeological proxy for European early moderns, the Protoaurignacian, is $39.9-41.5 \mathrm{ka}$. These ranges overlap in the 40.8-41.5 ka interval but we must bear in mind that, at El Castillo, the date represents a minimum age for the underlying art, not its real, if imprecise age, as is the case with the dates for Oase 1 and the Protoaurignacian.

This means that the dated El Castillo art could have been made in the 42nd calendar millennium BP and, therefore, conceivably, by Europe's earliest modern human populations, only if the length of time separating its execution from the growth of the overlying calcite was a short one. This is unlikely to be the case, however, because Pike et al. followed a sampling protocol whereby, in order to avoid contamination by detrital thorium from the cave wall or from pigments in the paintings, the first calcite to grow over the art was not collected. Subsequent work at the Panel of Hands, carried out in October 2012, showed that, in fact, sufficient material remained between the red disk and the base of the previously measured calcite, and an additional sample was collected. So, the execution of that symbol and the published calcite date 


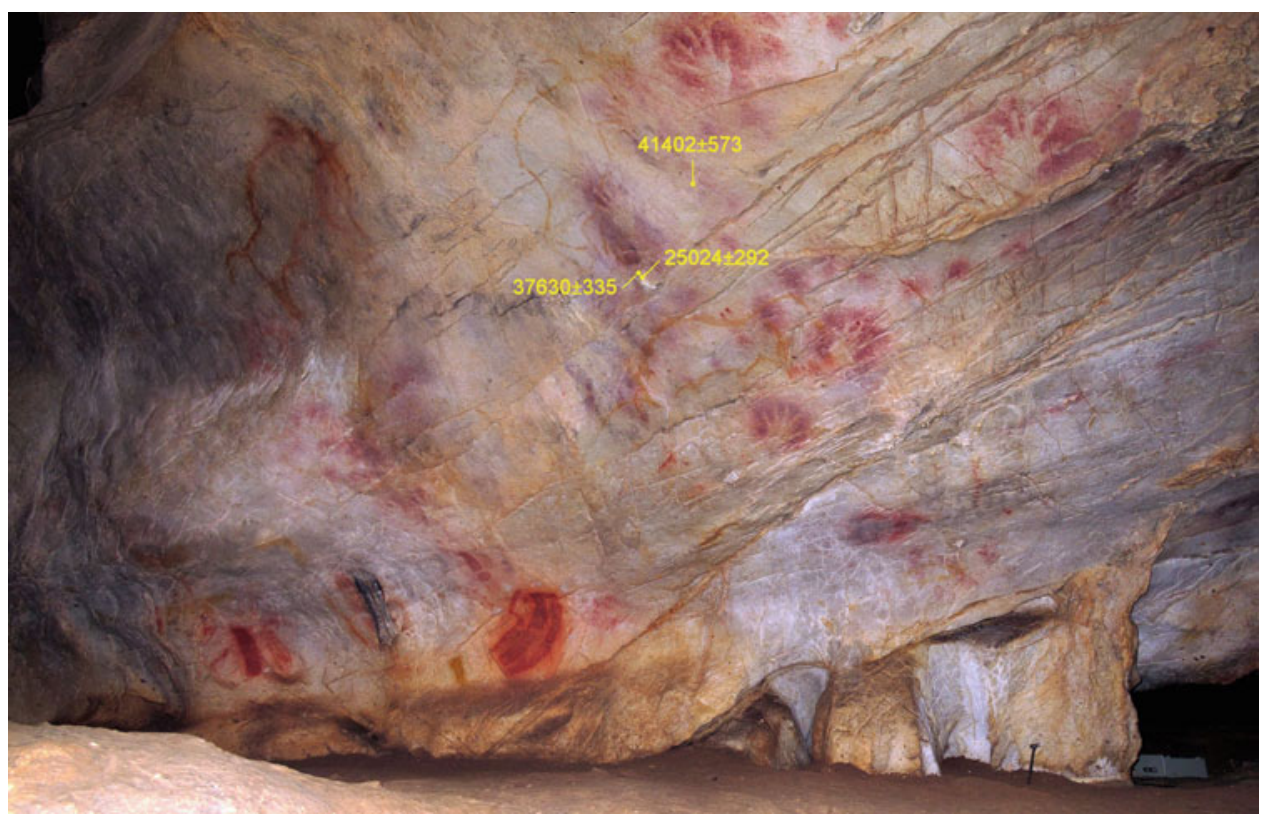

Fig. 3.16 El Castillo. The Panel of Hands, with indication of the location and age (95.4\% probability intervals) of the calcite samples dated by Pike et al. (2012)

are separated by an interval of time of unknown length during which the first calcite formed; the art is therefore older than calcite that is itself more than $\sim 41.4$ thousands of years old.

The wider implication of these observations becomes apparent if we consider that $>50 \%$ of the minimum ages reported by Pike et al. for 11 Paleolithic cave art sites in northern Spain are $\leq 10,000$ years, while, on stylistical grounds (validated by previous radiocarbon dating and the U-series results), the age of the motifs under the dated calcite is in the range of 20,000 years or more. The probability is very high, therefore, that, at El Castillo, the red disk under the dated calcite was executed in the 43rd millennium or before, i.e., at a time when Europe was still a fully Neandertal continent. Moreover, late Neandertal authorship of such geometric signs (and, perhaps, of the associated hand stencils) is consistent with what we know of their symbolic material culture, namely, at the Grotte du Renne, the decoration of bone awls: of the 52 recovered in the site's Châtelperronian levels, more than a third are marked along the edges with non-utilitarian, regularly arranged incisions (d'Errico 2003; Caron et al. 2011).

Beyond their significance for controversies surrounding the cognition and behavior of the Neandertals and their taxonomic status, Pike et al.'s U-series dates also suggest that the earliest forms of art may well have been non-figurative. Traditionally, the birth of art has been equated with the emergence of the naturalistic animal representations that are so emblematic of the Paleolithic. This is understandable, given that, hitherto, the dating of parietal art has relied heavily on stylistical comparison with mobiliary art items recovered in stratified archeological contexts. However, while the conventions used to represent animals can and did change over time, the same does not necessarily apply to such universals as geometric shapes or the human hand. It has been largely assumed that motifs of these kinds are of the same age as the animals found on the same walls and that dating the animals also dates the signs and the other symbols, but Pike et al.'s results show the assumption to be unwarranted.

If, in Europe, the evidence for personal ornaments and heavy use of pigments correlates from the very (Neandertal) beginnings with the presence of rock art alongside, then we should expect the same to be true for Africa and Asia. Thus, the ultimate implication of the El Castillo results may well be that the graphic tradition revealed in the geometric decoration of the ostrich eggshell containers from the 60,000 year-old Howiesons Poort levels of Diepkloof rock-shelter, in South Africa (Texier et al. 2010), is likely to stand for a behavior that encompassed all areas of life, including the rock art domain - much as in coeval Europe but, in the South African case, in a paleontological context that, if nonNeandertal, is not modern human either and is perhaps succinctly best referred to as near-modern (Trinkaus 2005).

Future research will show whether these speculations are supported. For the time being, they serve to illustrate the "Brave New World" that opens to Paleoanthropology if it dares to remove the Human Revolution eye-band that, as also argued by McBrearty and Brooks (2000) for the African record for so long blinded scholars to the evidence concerning the behavioral "modernity" of anatomically "archaic" humans. Hopefully, what the last 15 years of developments in the study of the emergence of the Upper Paleolithic and modern humans will have taught us is that the transformations we see in the archeological and human paleontological 
records of that time have deep roots in the preceding Middle Paleolithic and its non-"modern" populations.

Rather than discussing the reality of the chronology of the Middle-to-Upper Paleolithic and Neandertal to modern human transitions in Europe apparent when respecting the "primacy of stratigraphy" principle (Zilhão et al. 2011), future research should concentrate, at an empirical level, on refining it to the extent possible with current techniques; as the preceding sections illustrate, developing a better understanding of the applicability (and limits) of Bayesian methods to the interpretation of dating results in a stratigraphic context is also badly needed. At a theoretical level, the chronology of those transitions also carries implications for the understanding of how, between 100,000 and 40,000 years ago, convergent developments led toward symbolic material cultures in both Africa and Eurasia; in a scenario where the very phenomenon of anatomical Neandertalness implies a significant level of isolation between these continents (Wolpoff 2009), what kinds of processes explain what nonetheless happened? Where the changes in social structure reflected in the emergence of symbolic material culture are concerned, a complex interplay of numerous factors-natural selection, technological progress, demographic pressure, climate change, response to catastrophic events, etc.,-clearly must be involved. Explanations will therefore have to be based on historical models that try to capture this complexity instead of reducing it to some deus ex machina, whatever its nature (genetical, cognitive, adaptive, etc.).

\subsection{Conclusion}

Elsewhere (Zilhão 2012), I have argued that a persistent, if subconscious influence in academia of Victorian-age ideas of evolution-as-progress and ancient-as-primitive must go a long way into explaining ongoing Neandertal debates. I certainly have no better explanation for the continued attempts at negating the clear and unambiguous, if limited (by comparison with later periods) evidence for Middle Paleolithic and pre-modern human symbolism accumulated over the last 15 years. In other scientific domains, the distortions of method and logic involved in such attempts would hardly go unnoticed, but they remain all-pervasive in Neandertal and modern human origins controversies.

The unwarranted application of Bayesian statistics in the modeling of radiocarbon results for this period is a good example of this problem. As applied by, for instance, Higham et al. (2010, 2011c, d, 2012), that is, coupled with outlier analysis, the approach needs to deal with the following logical issues: (a) if stratigraphic ordering is assumed, the outlier analysis will detect analytical error in the dating; (b) if dating accuracy is assumed, the outlier analysis will detect stratigraphic disorder; (c) if neither stratigraphic ordering nor dating accuracy can be assumed, then the Bayesian approach cannot be applied.
Given this, where Bayesian modeling is potentially of most use is in dealing with issues of chronostratigraphy, as in Banks et al.'s (2013) study of the timing and causes of the change from Protoaurignacian to Aurignacian I in Western Europe. This is because, under the axiomatic principles of Paleolithic archeology, the repetitive pattern of stratigraphic succession whereby the Protoaurignacian always precedes the Aurignacian I carries two important implications: firstly, that any time lags that may have existed in the succession of one by the other across the continuous geographic space where both occur are undetectable and of negligible consequence for the kinds of questions that archaeology can address; secondly, that any overlap in dating results can therefore be treated as reflecting no more than the statistical uncertainty inherent to the dating technique. In this context, case (a) of the preceding paragraph can be safely assumed and any anomalies detected can be treated just as exactly that-anomalies ("outliers").

When dealing with successions that are specific to a single site, however, whether case (a), (b) or (c) applies depends on a different type of external referent, and that referent can only be that site's taphonomic study. If refitting work or the vertical distributions of diagnostic finds yield results that are coherent with the stratigraphic outline underpinning the ascription of samples to Bayesian "phases," then the approach is viable but the implication is that outliers primarily reflect dating error, not stratigraphic disturbance. If the same types of evidence show that the stratigraphic sequence is unreliable, or that the boundaries between stratigraphic units are fuzzy, then the Bayesian approach is not viable; this is either because the samples' time ordering indicated by stratigraphic provenience is apparent, not real, or because the discretization of the sequence into Bayesian "phases" is unwarranted and the sequence has to be treated as a single continuum where the interpretation of individual results is contingent upon contextual, not mathematical arguments. Regrettably, most recent implementations of Bayesian methods to sets of dates related to the Middle-to-Upper Paleolithic transition in Europe have ignored these logical issues.

The widespread application of double standards in the assessment of the evidence is another aspect of the same problem. Take the set of conditions put forward by Higham et al. (2011b) to change their minds on the issue of stratigraphic integrity vs. sample contamination raised by Zilhão et al. (2011) in relation to the results obtained by the ORAU for the Grotte du Renne. Higham et al. contend that it falls upon their critics "to prove conclusively that the [excavator's] stratigraphic interpretation was without fault ... [and] that all of the material is in situ" [my emphasis]. This stand reverses the burden of proof: if inferences about the past cannot be made from a site where, despite minor problems, the vertical and horizontal distribution of the diagnostic finds has the extraordinary coherence that Caron et al. (2011) documented and Higham et al. did not question, then archeology would be an impossible disci- 
pline. Moreover, accepting the behavioral implications of those distributions in no way requires meeting Higham et al.'s conditions. Neandertal symbolism can be inferred from the Grotte du Renne even if only some of the material is in situ, because, obviously, Neandertals would not cease to be symbolic simply because the number of in situ ornaments in level X turned out to be, instead of 29, say, 19 (or 9, or only 4), nor would they become super-symbolic if that number were of, say, 59 (or 590, or 5,900). This is an issue of quality, not quantity.

Interestingly, it is indisputable that the kind of proof requested by Higham et al. has not been provided for any of the sites reviewed here and invoked in support of the notion of a precocious settlement of Europe by modern humansKent's Cavern, Cavallo, Kebara, Geissenklösterle, etc. In fact, no one has even so much as pretended that these sites meet the over-stringent criteria requested from the Grotte du Renne, and the publication of the dating evidence contains explicit remarks concerning observed or potential postdepositional disturbance. Yet, when dealing with those other sites, the dating experts felt their case was strong enough for inferences of major paleoanthropological significance to be made, and these are by and large the same authors who, for the Grotte du Renne, require that the stratigraphy be proven without fault.

It should go without saying that "conclusive proof that all the material is in situ" is something that has never been provided for any archeological site whatsoever. In fact, as in proving that God does not exist and similar philosophical problems, such a demonstration simply cannot be madeand, indeed, requesting a set of impossible conditions as a precondition to retract is a stance that one seldom finds, if at all, in scientific debates ... except, that is, when it comes to Neandertals and modern humans. One can only hope the day will come when that shall be the case no more.

Acknowledgments I thank the organizers of the Tokyo conference on the "Replacement of Neanderthals by Modern Humans: Testing Evolutionary Models of Learning" (November 18-24, 2012) for their invitation to participate in such an instructive event. I am especially grateful to Ofer Bar-Yosef for his assistance in obtaining the material from the Kebara archive reproduced here. Paul Bahn, William Banks, Ofer Bar-Yosef, Francesco d'Errico, Alistair Pike, Nicolas Teyssandier, Erik Trinkaus and an anonymous reviewer read preliminary versions of the manuscript and offered valuable comments and/or critique. As usual, any errors or omissions are my own.

\section{References}

Bailey SE, Hublin JJ (2006) Dental remains from the Grotte du Renne at Arcy-sur-Cure (Yonne). J Hum Evol 50:485-508

Bailey SE, Weaver TD, Hublin JJ (2009) Who made the Aurignacian and other early Upper Paleolithic industries? J Hum Evol 57:11-26

Banks WE, d'Errico F, Zilhão J (2013) Human-climate interaction during the early Upper Paleolithic: testing the hypothesis of an adaptive shift between the Proto-Aurignacian and the Early Aurignacian. J Hum Evol 64:39-55
Bar-Yosef O (2006) Neanderthals and Modern Humans: a different interpretation. In: Conard NJ (ed) When Neanderthals and Modern humans met. Kerns, Tübingen, pp 467-482

Bar-Yosef O, Bordes JG (2010) Who were the makers of the Châtelperronian culture? J Hum Evol 59:586-593

Bar-Yosef O, Meignen L (eds) (2007) Kebara Cave, Mt Carmel, Israel: the Middle and Upper Paleolithic Archaeology, part I. American School of Prehistoric Research/Peabody Museum of Archaeology and Ethnology, Cambridge

Bar-Yosef O, Arnold M, Mercier N, Belfer-Cohen A, Goldberg P, Housley R, Laville H, Meignen L, Vogel JC, Vandermeersch B (1996) The dating of the Upper Paleolithic Layers in Kebara Cave, Mt Carmel. J Archaeol Sci 23:297-306

Bayle P, Macchiarelli R, Trinkaus E, Duarte C, Mazurier A, Zilhão J (2010) Dental maturational sequence and dental tissue proportions in the early Upper Paleolithic child from Abrigo do Lagar Velho, Portugal. Proc Natl Acad Sci U S A 107:1338-1342

Belfer-Cohen A, Goring-Morris AN (2003) Current issues in Levantine Upper Palaeolithic research. In: Goring-Morris AN, Belfer-Cohen A (eds) More than meets the eye: Studies on Upper Palaeolithic diversity in the Near East. Oxbow, Oxford, pp 1-12

Benazzi S, Douka K, Fornai C, Bauer CC, Kullmer O, Svoboda J, Pap I, Mallegni F, Bayle P, Coquerelle M, Condemi S, Ronchitelli A, Harvati K, Weber GW (2011) Early dispersal of modern humans in Europe and implications for Neanderthal behaviour. Nature 479:525-529

Benazzi S, Fornai C, Buti L, Toussaint M, Mallegni F, Ricci S, Gruppioni G, Weber GW, Condemi S, Ronchitelli A (2012) Cervical and crown outline analysis of worn Neanderthal and modern human lower second deciduous molars. Am J Phys Anthropol 149:537-546

Bergman CA, Stringer CB (1989) Fifty years after: Egbert, an early Upper Palaeolithic juvenile from Ksar Akil, Lebanon. Paléorient 15:99-111

Binford L (1983) In Pursuit of the Past. Thames and Hudson, London

Bodu P (1990) L'application de la méthode des remontages à l'étude du matériel lithique des premiers niveaux châtelerroniens d'Arcy-surCure. In: Farizy C (ed) Paléolithique moyen récent et Paléolithique supérieur ancien en Europe. Musée de Préhistoire de l'Ile de France, Nemours, pp 309-312

Bon F (2002) L'Aurignacien entre Mer et Océan. Réflexion sur l'unité des phases anciennes de l'Aurignacien dans le sud de la France. Société Préhistorique Française, Paris

Bon F, Bodu P (2002) Analyse technologique du débitage aurignacien. In: Schmider B (ed) L'Aurignacien de la grotte du Renne. Les fouilles d'André Leroi-Gourhan à Arcy-sur-Cure (Yonne). CNRS, Paris, pp 115-133

Bordes F (1980) Question de contemporanéité : l'illusion des remontages. Bull Soc Préhist Franç 77:132-133

Bordes JG, Teyssandier N (2011) The Upper Paleolithic nature of the Châtelperronian in South-Western France: Archeostratigraphic and lithic evidence. Quat Int 246:382-388

Bouzouggar A, Barton N (2012) The identity and timing of the Aterian in Morocco. In: Hublin JJ, McPherron SP (eds) Modern origins: a North African perspective. Springer, New York, pp 93-105

Bouzouggar A, Barton N, Vanhaeren M, d'Errico F, Collcutt S, Higham T, Hodge E, Parfitt S, Rhodes E, Schwenninger JL, Stringer C, Turner E, Ward S, Moutmir A, Stambouli A (2007) 82,000-Year-old shell beads from North Africa and implications for the origins of modern human behavior. Proc Natl Acad Sci U S A 104:9964-9969

Brock F, Higham T (2009) AMS radiocarbon dating of Paleolithic-aged charcoal from Europe and the Mediterranean rim using ABOX-SC. Radiocarbon 51:839-846

Bronk Ramsey C (2009) Bayesian analysis of radiocarbon dates. Radiocarbon 51:337-360

Camps M, Higham T (2012) Chronology of the Middle to Upper Palaeolithic transition at Abric Romaní, Catalunya. J Hum Evol 62:89-103 
Caron F, d'Errico F, Del Moral P, Santos F, Zilhão J (2011) The reality of Neandertal symbolic behavior at the Grotte du Renne, Arcy-surCure. PLoS One 6:e21545

Chiotti L (1999) Les industries lithiques des niveaux aurignaciens de l'Abri Pataud, Les Eyzies-de-Tayac (Dordogne): étude technologique et typologique. Ph.D. dissertation, Institut de Paléontologie Humaine

Churchill SE, Smith FH (2000) Makers of the Early Aurignacian of Europe. Yearbook Phys Anthropol 43:61-115

Conard NJ (2008) A critical view of the evidence for a southern African origin of behavioural modernity. South African Archaeol Soc Goodwin Ser 10:175-179

Conard NJ, Bolus M (2003) Radiocarbon dating the appearance of modern humans and timing of cultural innovations in Europe: new results and new challenges. J Hum Evol 44:331-371

Conard NJ, Grootes PM, Smith FH (2004) Unexpectedly recent dates for human remains from Vogelherd. Nature 430:198-201

Conard NJ, Bolus M, Goldberg P, Munzel SC (2006) The last Neanderthals and first modern humans in the Swabian Jura. In Conard NJ (ed) When Neanderthals and Modern Humans met. Kerns, Tübingen, pp 305-341

d'Errico F (2003) The invisible frontier. A multiple species model for the origin of behavioral modernity. Evol Anthropol 12:188-202

d'Errico F, Zilhão J, Baffier D, Julien M, Pelegrin J (1998) Neanderthal acculturation in western Europe? A critical review of the evidence and its interpretation. Curr Anthropol 39:S1S44

d'Errico F, Borgia V, Ronchitelli A (2012) Uluzzian bone technology and its implications for the origin of behavioural modernity. Quat Int 259:59-71

David F, Connet N, Girard M, Lhomme V, Miskovsky JC, Roblin-Jouve A (2001) Le Châtelperronien de la grotte du Renne à Arcy-sur-Cure (Yonne). Données sédimentologiques et chronostratigraphiques. Bull Soc Préhist Franç 98:207-230

De Vivo B, Rolandi G, Gans B, Calvert A, Bohrson WA, Spera FJ, Belkin HE (2001) New constraints on the pyroclastic eruptive history of the Campanian volcanic Plain (Italy). Mineral Petrol 73:47-65

Douka K (2011) An Upper Palaeolithic shell scraper from Ksar Akil (Lebanon). J Archaeol Sci 38:429-437

Douka K, Grimaldi S, Boschian G, Del Lucchese A, Higham TFG (2012) A new chronostratigraphic framework for the Upper Palaeolithic of Riparo Mochi (Italy). J Hum Evol 62:286-299

Duarte C, Maurício J, Pettitt PB, Souto P, Trinkaus E, van der Plicht H, Zilhão J (1999) The early Upper Paleolithic human skeleton from the Abrigo do Lagar Velho (Portugal) and modern human emergence in Iberia. Proc Natl Acad Sci U S A 96:7604-7609

Finlayson C, Brown K, Blasco R, Rosell J, Negro JJ, Bortolotti GR, Finlayson G, Sánchez Marco A, Giles Pacheco F, Rodríguez Vidal J, Carrión JS, Fa DA, Rodríguez Llanes JM (2012) Birds of a feather: Neanderthal exploitation of raptors and corvids. PLoS One 7:e45927

Flas D (2011) The Middle to Upper Paleolithic transition in Northern Europe: the Lincombian-Ranisian-Jerzmanowician and the issue of acculturation of the last Neanderthals. World Archaeol 43:605-627

Gambassini P, Mallegni F, Ricci S (2005) Reperti Dentari dagli Strati Uluzziani di Grotta del Cavallo (Lecce): Stato dell'Arte su Stratigrafia e Aspetti Biologici. In: Guerci A, Consigliere S, Castagno S (eds) Atti del XVI Congresso degli Antropologi Italiani. Il processo di umanizzazione. Genova

Green RE, Krause J, Briggs AW, Maricic T, Stenzel U, Kircher M, Patterson N, Li H, Zhai W, Fritz MHY, Hansen NF, Durand EY, Malaspinas AS, Jensen J, Marques-Bonet T, Alkan C, Prüfer K, Meyer M, Burbano HA, Good JM, Schultz R, Aximu-Petri A, Butthof A, Höber B, Höffner B, Siegemund M, Weihmann A, Nusbaum C, Lander ES, Russ C, Novod N, Affourtit J, Egholm M, Verna C, Rudan P, Brajkovic D, Kucan Ž, Gušic I, Doronichev VB, Golovanova LV, Lalueza-Fox C, de la Rasilla M, Fortea J, Rosas A,
Schmitz RW, Johnson LF, Eichler EE, Falush D, Birney E, Mullikin JC, Slatkin M, Nielsen R, Kelso J, Lachmann M, Reich D, Pääbo S (2010) A draft sequence of the Neandertal genome. Science 328:710-722

Gioia P (1990) An aspect of the transition between Middle and Upper Palaeolithic in Italy: the Uluzzian. In: Farizy C (ed) Paléolithique moyen récent et Paléolithique supérieur ancien en Europe. Musée de Préhistoire de l'Ile de France, Nemours, pp 241-250

Goldberg P, Laville H, Meignen L, Bar-Yosef O (2007) Stratigraphy and geoarchaeological history of Kebara Cave, Mount Carmel. In: Bar-Yosef O, Meignen L (eds) Kebara cave, Mt Carmel, Israel: the Middle and Upper Paleolithic Archaeology, part I. American School of Prehistoric Research/Peabody Museum of Archaeology and Ethnology, Cambridge, pp 49-89

Gravina B, Mellars P, Bronk Ramsey C (2005) Radiocarbon dating of interstratified Neanderthal and early modern human occupations at the Chatelperronian type-site. Nature 438:51-56

Hahn J (1977) Aurignacien, das ältere Jungpaläolithikum in Mittel- und Osteuropa. Böhlau, Köln/Wien

Hahn J (1988) Das Geissenklösterle I. Konrad Theiss, Stuttgart

Hawks J (2012) Dynamics of genetic and morphological variability within Neandertals. J Archaeol Sci 90:1-17

Higham T (2011) European Middle and Upper Palaeolithic radiocarbon dates are often older than they look: problems with previous dates and some remedies. Antiquity 85:235-249

Higham TFG, Brock F, Peresani M, Broglio A, Wood R, Douka K (2009) Problems with radiocarbon dating the Middle to Upper Palaeolithic transition in Italy. Quat Sci Rev 28:1257-1267

Higham TFG, Jacobi RM, Julien M, David F, Basell L, Wood R, Davies W, Bronk Ramsey C (2010) Chronology of the Grotte du Renne (France) and implications for the context of ornaments and human remains within the Châtelperronian. Proc Natl Acad Sci U S A 107:20234-20239

Higham TFG, Brock F, Bronk Ramsey C, Davies W, Wood R, Basell L (2011a) Chronology of the site of Grotte du Renne, Arcy-sur-Cure, France: implications for Neanderthal symbolic behaviour. Before Farm 2011(2):1-9, article 1

Higham TFG, Brock F, Bronk Ramsey C, Davies W, Wood R, Basell L (2011b) Chronology of the Grotte du Renne, Arcy-sur-Cure, France: a response to Zilhão et al (this issue). Before Farm 2011(3):1-5, article 4

Higham T, Compton T, Stringer C, Jacobi R, Shapiro B, Trinkaus E, Chandler B, Gröning F, Collins C, Hillson S, O'Higgins P, Fitzgerald C, Fagan M (2011c) The earliest evidence for anatomically modern humans in northwestern Europe. Nature 479:521-524

Higham T, Jacobi R, Basell L, Bronk Ramsey C, Chiotti L, Nespoulet R (2011d) Precision dating of the Palaeolithic: a new radiocarbon chronology for the Abri Pataud (France), a key Aurignacian sequence. J Hum Evol 61:549-563

Higham T, Basell L, Jacobi RM, Wood R, Bronk Ramsey C, Conard NJ (2012) Testing models for the beginnings of the Aurignacian and the advent of figurative art and music: the radiocarbon chronology of Geißenklösterle. J Hum Evol 62:664-676

Hoffmann D, Pike AWG, Wainer K, Zilhão J (2013) New U-series results for the speleogenesis and the Palaeolithic archaeology of the Almonda karstic system (Torres Novas, Portugal). Quat Int 294:168-182

Holliday TW (2006) Neanderthals and modern humans: an example of a mammalian syngameon? In: Harvati $\mathrm{K}$, Harrison $\mathrm{T}$ (eds) Neanderthals revisited: new approaches and perspectives. Springer, New York, pp 289-306

Hublin JJ (2000) Modern-nonmodern hominid interactions: a Mediterranean perspective. In: Bar-Yosef O, Pilbeam D (eds) The geography of Neandertals and modern humans in Europe and the Greater Mediterranean. Peabody Museum, Cambridge, pp $157-182$ 
Hublin JJ, Spoor F, Braun M, Zonneveld F, Condemi S (1996) A late Neanderthal associated with Upper Palaeolithic artefacts. Nature 381:224-226

Hublin JJ, Talamo S, Julien M, David F, Connet N, Bodu P, Vandermeersch B, Richards MP (2012a) Radiocarbon dates from the Grotte du Renne and Saint-Césaire support a Neandertal origin for the Châtelperronian. Proc Natl Acad Sci U S A 109:18743-18748

Hublin JJ, Verna C, Bailey SE, Smith T, Olejniczak A, Sbihi-Alaoui FZ, Zouak M (2012b) Dental evidence from the Aterian human populations of Morocco. In: Hublin JJ, McPherron SP (eds) Modern origins: a North African perspective vertebrate. Springer, New York, pp 189-204

Jacobi RM, Higham TFG (2011) The British earlier Upper Palaeolithic: settlement and chronology. In: Ashton N, Lewis S, Stringer C (eds) The ancient human occupation of Britain. Elsevier, Amsterdam, pp $181-222$

Jones M, Marks AE, Kaufman D (1983) Boker. The artifacts. In: Marks AE (ed) Prehistory and paleoenvironments in the central Negev, Israel. The Avdat/Aqev Area, Part 3, vol III. Southern Methodist University, Dallas, pp 283-329

Julien M, Baffier D, Liolios D (2002) L'industrie osseuse. In: Schmider B (ed) L'Aurignacien de la grotte du Renne. Les fouilles d'André Leroi-Gourhan à Arcy-sur-Cure (Yonne). CNRS, Paris, pp 217-250

Klein RG (1992) The archaeology of modern human origins. Evol Anthropol 1:5-14

Koumouzelis M, Ginter B, Kozłowski JK, Pawlikowski M, Bar-Yosef O, Albert RM, Litynska-Zajac M, Stworzewicz E, Wojtal P, Lipecki G, Tomek T, Bochenski ZM, Pazdur A (2001a) The Early Upper Palaeolithic in Greece: the excavations in Klisoura cave. J Archaeol Sci 28:515-539

Koumouzelis M, Kozłowski JK, Escutenaire C, Sitlivy V, Sobczyk K, Valladas H, Tisnerat-Laborde N, Wojtal P, Ginter B (2001b) La fin du Paléolithique moyen et le début du Paléolithique supérieur en Grèce : la séquence de la Grotte 1 de Klissoura. L'anthropol 105:469-504

Kuhn SL (2002) Paleolithic archeology in Turkey. Evol Anthropol 11:198-210

Kuhn SL (2003) In what sense is the Levantine Initial Upper Paleolithic a "transitional" industry? In: Zilhão J, d'Errico F (eds) The chronology of the Aurignacian and of the transitional technocomplexes. Dating, stratigraphies, cultural implications. Instituto Português de Arqueologia, Lisboa, pp 61-69

Kuhn SL, Stiner MC, Reese DS, Güleç E (2001) Ornaments of the earliest Upper Paleolithic: new insights from the Levant. Proc Natl Acad Sci U S A 98(13):7641-7646

Kuhn SL, Stiner MC, Güleç E, Özer I, Yilmaz H, Baykara I, Açikkol A, Goldberg P, Martínez Molina K, Ünay E, Suata-Alpaslan F (2009) The early Upper Paleolithic occupations at Üçağızlı Cave (Hatay, Turkey). J Hum Evol 56:87-113

Le Cabec A, Gunz P, Kupczik K, Braga J, Hublin JJ (2013) Anterior tooth root morphology and size in Neanderthals: taxonomic and functional implications. J Hum Evol 64:169-193

Leroi-Gourhan A (1958) Etude des restes humains fossiles provenant des Grottes d'Arcy-sur-Cure. Annal Paléontol 44:87-148

Lévêque F, Vandermeersch B (1980) Découverte de restes humains dans un niveau castelperronien à Saint-Césaire (Charente-Maritime). Comptes Rendus de l'Académie des Sciences de Paris 291D:187-189

Marks AE (1983) The sites of Boker and Boker Tachtit: a brief introduction In: Marks AE (ed) Prehistory and paleoenvironments in the central Negev, Israel. Vol. III. The Avdat/Aqev Area, Part 3. Southern Methodist University, Dallas, pp 15-37

McBrearty S, Brooks A (2000) The revolution that wasn't: a new interpretation of the origin of modern human behavior. J Hum Evol 39:453-563

Mellars PA (1999) The Neanderthal problem continued. Curr Anthropol 40(3):341350
Mellars PA (2004) Neanderthals and the modern human colonization of Europe. Nature 432:461-465

Mellars PA (2010) Neanderthal symbolism and ornament manufacture: the bursting of a bubble? Proc Natl Acad Sci U S A 107:20147-20148

Mellars PA, Gravina B (2008) Châtelperron: theoretical agendas, archaeological facts, and diversionary smoke-screens. PaleoAnthropol 2008:43-64

Mellars PA, Stringer CB (eds) (1989) The Human Revolution. University Press, Edinburgh

Mellars PA, Gravina B, Bronk Ramsey C (2007) Confirmation of Neanderthal/modern human interstratification at the Chatelperronian type-site. Proc Natl Acad Sci U S A 104:3657-3662

Monigal K (2003) Technology, economy and mobility at the beginning of the Levantine Upper Palaeolithic. In: Goring-Morris AN, BelferCohen A (eds) More than meets the eye. Studies on Upper Palaeolithic diversity in the Near East. Oxbow, Oxford, pp 118-133

Moreau L (2009) Geißenklösterle. Das Gravettien der Schwäbischen Alb im europäischen Kontext. Kerns Verlag, Tübingen

Moreau L (2010) Geisenklösterle. The Swabian Gravettian in its European context. Quartär 57:79-93

Moreau L (2012) Le Gravettien ancien d'Europe centrale revisité: mise au point et perspectives. L'anthropol 116:609-638

Morin E, Laroulandie V (2012) Presumed symbolic use of diurnal raptors by Neanderthals. PLoS One 7:e32856

Morin E, Tsanova T, Sirakov N, Rendu W, Mallye JB, Lévêque F (2005) Bone refits in stratified deposits: testing the chronological grain at Saint-Césaire. J Archaeol Sci 32:1083-1098

Moroni A, Boscato P, Ronchitelli A (2012) What roots for the Uluzzian? Modern behaviour in Central-Southern Italy and hypotheses on AMH dispersal routes. Quat Int. doi:10.1016/j. quaint.2012.10.051

Münzel SC, Conard NJ (2004) Change and continuity in subsistence during the Middle and Upper Palaeolithic in the Ach Valley of Swabia (South-west Germany). Intl J Osteoarchaeol 14:225-243

Nigst R, Haesaerts P (2012) L'Aurignacien en Basse Autriche : résultats préliminaires de l'analyse technologique de la couche culturelle 3 de Willendorf II et ses implications pour la chronologie du Paléolithique supérieur ancien en Europe centrale. L'anthropol 116:575-608

Nigst R, Bence Viola TH, Haesaerts P, Blockley S, Damblon F, Frank C, Fuchs M, Götzinger M, Hambach U, Mallol C, Moreau L, Niven L, Richards M, Richter D, Zöller L, Trnka G, Hublin JJ (2008) New research on the Aurignacian of Central Europe: a first note on the 2006 fieldwork at Willendorf II. Quartär 55:9-15

Peresani M, Fiore I, Gala M, Romandini M, Tagliacozzo A (2011) Late Neandertals and the intentional removal of feathers as evidenced from bird bone taphonomy at Fumane Cave 44 ky B.P., Italy. Proc Natl Acad Sci U S A 108:3888-3893

Pesesse D (2008) Les premières sociétés gravettiennes. Analyse comparée des systèmes lithiques de la fin de l'Aurignacien aux débuts du Gravettien. Ph.D. dissertation, University of Provence

Pesesse D (2010) Quelques repères pour mieux comprendre l'émergence du Gravettien en France. Bull Soc Préhist Franç 107:465-487

Pike AWG, Hoffmann DL, García-Diez M, Pettitt PB, Alcolea J, de Balbin R, González-Sainz C, de las HC, Lasheras JA, Montes R, Zilhão J (2012) U-series dating of Paleolithic art in 11 caves in Spain. Science 336:1409-1413

Pinhasi R, Higham TFG, Golovanova LV, Doronichev VB (2011) Revised age of late Neanderthal occupation and the end of the Middle Paleolithic in the northern Caucasus. Proc Natl Acad Sci U S A 108:8611-8616

Rebollo NR, Weiner S, Brock F, Meignen L, Goldberg P, Belfer-Cohen A, Bar-Yosef O, Boaretto E (2011) New radiocarbon dating of the transition from the Middle to the Upper Paleolithic in Kebara Cave, Israel. J Archaeol Sci 38:2424-2433 
Reimer PJ, Baillie MGL, Bard E, Bayliss A, Beck JW, Bertrand C, Blackwell PG, Buck CE, Burr G, Cutler KB, Damon PE, Edwards RL, Fairbanks RG, Friedrich M, Guilderson TP, Hughen KA, Kromer B, McCormac FG, Manning S, Bronk Ramsey C, Reimer RW, Remmele S, Southon JR, Stuiver M, Talamo S, Taylor FW, van der Plicht J, Weyhenmeyer CE (2009) Intcal09 and Marine09 radiocarbon age calibration curves, $0-50,000$ years Cal BP. Radiocarbon 51:1111-1150

Riel-Salvatore J (2009) What is a 'transitional' industry? The Uluzzian of southern Italy as a case study. In: Camps M, Chauhan PR (eds) A sourcebook of Paleolithic transitions. Springer, New York, pp 377-396

Semal P, Rougier H, Crevecoeur I, Jungels C, Flas D, Hauzeur A, Maureille B, Germonpré M, Bocherens H, Pirson S, Cammaert L, de Clerck N, Hambucken A, Higham T, Toussaint M, van der Plicht J (2009) New data on the late Neandertals: direct dating of the Belgian Spy fossils. Am J Phys Anthropol 138:421-428

Soressi M (2011) Révision taphonomique et techno-typologique des deux ensembles attribués au Châtelperronien de la Roche-à-Pierrot à Saint-Césaire. L'anthropol 115:569-584

Soressi M, d'Errico F (2007) Pigments, gravures, parures: les comportements symboliques controversés des Néandertaliens. In: Vandermeersch B, Maureille B (eds) Les Néandertaliens. Biologie et cultures. Éditions du CTHS, Paris, pp 297-309

Stuiver M, Reimer PJ (1993) Extended ${ }^{14} \mathrm{C}$ data base and revised CALIB 3.0 ${ }^{14} \mathrm{C}$ Age calibration program. Radiocarbon 35:215230

Taborin Y (1998) Comment to d'Errico F, Zilhão J, Julien M, Baffier D, Pelegrin J, Neandertal acculturation in western Europe? A critical review of the evidence and its interpretation. Curr Anthropol 39:28-29

Taborin Y (2002) Les objets de parure et les curiosa. In: Schmider B (ed) L'Aurignacien de la grotte du Renne: les fouilles d'André Leroi-Gourhan à Arcy-sur-Cure (Yonne). CNRS, Paris, pp 251-256

Talamo S, Soressi M, Roussel M, Richards M, Hublin JJ (2012) A radiocarbon chronology for the complete Middle to Upper Palaeolithic transitional sequence of Les Cottés (France). J Archaeol Sci 39:175-183

Texier PJ, Porraz G, Parkington J, Rigaud JP, Poggenpoel C, Miller C, Tribolo C, Cartwright C, Coudenneau A, Klein R, Steele T, Verna C (2010) A Howiesons Poort tradition of engraving ostrich eggshell containers dated to 60,000 years ago at Diepkloof Rock Shelter, South Africa. Proc Natl Acad Sci U S A 107:6180-6185

Teyssandier N (2003) Les débuts de l'Aurignacien en Europe. Discussion à partir des sites de Geissenklösterle, Willendorf II, Krems-Hundssteig et Bacho Kiro. Ph. D. dissertation, University of Paris X

Teyssandier N (2008) Revolution or evolution: the emergence of the Upper Paleolithic in Europe. World Archaeol 40:493-519

Teyssandier N, Liolios D (2003) Defining the earliest Aurignacian in the Swabian Alb: the relevance of the Geißenklösterle (BadenWürttemberg, Germany) lithic and organic productions. In: Zilhão J, d'Errico F (eds) The chronology of the Aurignacian and of the transitional technocomplexes. Dating, stratigraphies, cultural implications. Instituto Português de Arqueologia, Lisboa, pp 179-196

Trinkaus E (2005) Early modern humans. Annu Rev Anthropol $34: 207-230$

Trinkaus E (2007) European early modern humans and the fate of the Neandertals. Proc Natl Acad Sci U S A 104:7367-7372

Trinkaus E, Zilhão J (2013) Paleoanthropological implications of the Peştera cu Oase and its contents. In: Trinkaus E, Constantin S, Zilhão J (eds) Life and death at the Peştera cu Oase: a setting for modern human emergence in Europe. Oxford University Press, New York, pp 389-400

Trinkaus E, Churchill SE, Ruff CB, Vandermeersch B (1999) Long bone shaft robusticity and body proportions of the Saint-Césaire 1 Châtelperronian Neanderthal. J Archaeol Sci 26:753-773
Trinkaus E, Constantin S, Zilhão J (eds) (2013) Life and death at the Peştera cu Oase: a setting for modern human emergence in Europe. Oxford University Press, New York

Valladas H, Joron JL, Valladas G, Arensburg B, Bar-Yosef O, BelferCohen A, Goldberg P, Laville H, Meignen L, Rak Y, Tchernov E, Tillier AM, Vandermeersch B (1987) Thermoluminescence dates for the Neanderthal burial site at Kebara in Israel. Nature 330:159-160

Vallois H (1949) The Fontéchevade fossil man. Am J Phys Anthropol 7:339-362

Vandermeersch B (1993) Was the Saint-Césaire discovery a burial? In: Lévêque F, Backer AM, Guilbaud M (eds) Context of a Late Neandertal. Prehistory, Madison, pp 129-131

Vaquero M, Carbonell E (2012) Some clarifications on the MiddleUpper Paleolithic transition in Abric Romaní: Reply to Camps and Higham (2012). J Hum Evol 63:711-717

Ward GK, Wilson SR (1978) Procedures for comparing and combining radiocarbon age determinations: a critique. Archaeometry 20:19-31

White M, Pettitt P (2012) Ancient digs and modern myths: the age and context of the Kent's Cavern 4 maxilla and the earliest Homo sapiens specimens in Europe. Eur J Archaeol 15:1-30

White R (2001) Personal ornaments from the Grotte du Renne at Arcysur-Cure. Athena Rev 2:41-46

White R (2002) Observations technologiques sur les objets de parure. In: Schmider B (ed) Les fouilles d'André Leroi-Gourhan à Arcysur-Cure (Yonne). CNRS, Paris, pp 257-266

White R, Mensan R, Bourrillon R, Cretin C, Higham TFG, Clarke AE, Sisk ML, Tartar E, Gardère P, Goldberg P, Pelegrin J, Valladas H, Tisnérat-Laborde N, de Sanoit J, Chambellan D, Chiotti L (2012) Context and dating of Aurignacian vulvar representations from Abri Castanet, France. Proc Natl Acad Sci U S A 109:8450-8455

Wood R, Barroso-Ruíz C, Caparrós M, Jordá Pardo JF, Galván Santos B, Higham TFG (2013) Radiocarbon dating casts doubt on the late chronology of the Middle to Upper Palaeolithic transition in southern Iberia. Proc Natl Acad Sci U S A 110:2781-2786

Wolpoff M (2002) Human paleontology. University of Michigan, Ann Arbor

Wolpoff M (2009) How Neandertals inform human variation. Am J Phys Anthropol 139:91-102

Wolpoff M, Smith FH, Malez M, Radovčić J, Rukavina D (1981) Upper Pleistocene human remains from Vindija Cave, Croatia, Yugoslavia. Am J Phys Anthropol 54:499-545

Zilhão J (2006a) Neandertals and moderns mixed, and it matters. Evol Anthropol 15:183-195

Zilhão J (2006b) Aurignacian, behavior, modern: Issues of definition in the emergence of the European Upper Paleolithic. In: Bar-Yosef O, Zilhão J (eds) Towards a definition of the Aurignacian. American School of Prehistoric Research/Instituto Português de Arqueologia, Lisboa, pp 53-69

Zilhão J (2007) The emergence of ornaments and art: an archaeological perspective on the origins of behavioural "modernity". J Archaeol Res 15:1-54

Zilhão J (2011) Aliens from outer time? Why the "Human Revolution" is wrong, and where do we go from here? In: Condemi S, Weniger G-C (eds) Continuity and discontinuity in the peopling of Europe: one hundred fifty years of Neanderthal Study. Springer, New York, pp 331-366

Zilhão J (2012) Personal ornaments and symbolism among the Neanderthals. In: Elias S (ed) Origins of human innovation and creativity. Elsevier, London, pp 35-49

Zilhão J, d'Errico F (1999) The chronology and taphonomy of the earliest Aurignacian and its implications for the understanding of Neanderthal extinction. J World Prehist 13:1-68

Zilhão J, d'Errico F (2003) An Aurignacian "Garden of Eden" in southern Germany? An alternative interpretation of the Geissenklösterle and a critique of the Kulturpumpe model. Paléo 15:69-86 
Zilhão J, Angelucci D, Badal-García E, d'Errico F, Daniel F, Dayet L, Douka K, Higham TFG, Martínez-Sánchez MJ, Montes-Bernárdez R, Murcia-Mascarós S, Pérez-Sirvent C, Roldán-García C, Vanhaeren M, Villaverde V, Wood R, Zapata J (2010a) Symbolic use of marine shells and mineral pigments by Iberian Neandertals. Proc Natl Acad Sci U S A 107:1023-1028

Zilhão J, Davis SJM, Duarte C, Soares AMM, Steier P, Wild E (2010b) Pego do Diabo (Loures, Portugal): Dating the emergence of anatomical modernity in westernmost Eurasia. PLoS One 5:e8880

Zilhão J, d'Errico F, Bordes JG, Lenoble A, Texier JP, Rigaud JP (2006) Analysis of Aurignacian interstratification at the Châtelperronian- type site and implications for the behavioral modernity of Neandertals. Proc Natl Acad Sci U S A 103:12643-12648

Zilhão J, d'Errico F, Bordes JG, Lenoble A, Texier JP, Rigaud JP (2008a) Grotte des Fées (Châtelperron): History of research, stratigraphy, dating, and archaeology of the Châtelperronian type-site. Paleoanthropol 2008:1-42

Zilhão J, d'Errico F, Bordes JG, Lenoble A, Texier JP, Rigaud JP (2008b) Like Hobbes' chimney birds. Paleoanthropology 2008:65-67

Zilhão J, d'Errico F, Julien M, David F (2011) Chronology of the site of Grotte du Renne, Arcy-sur-Cure, France: implications for radiocarbon dating. Before Farm 2011(3):1-14, article 3 